\title{
SPATIAL AND TEMPORAL DISTRIBUTION OF BENTHIC MACROINVERTEBRATES AND SEDIMENTS COLLECTED IN THE VICINITY OF THE J.H. CAMPBELL PLANT, EASTERN LAKE MICHIGAN, 1979
}

\author{
By \\ Michael H. Winnell \\ and \\ David J. Jude
}
Spec. Rep. No. 77 of the Great Lakes Research Division
The University of Michigan
Ann Arbor, Michigan

November 1980 



\section{ACKNOWLEDGMENTS}

This study was funded by a grant from Consumers Power Company, Jackson, Michigan, through their Environmental Services Department. We are indebted to Dr. Ibrahim Zeitoun and John Gulvas for their congenial treatment and help through all phases of this project. Nelson Navarre from the Great Lakes and Marine Waters Center was also very helpful with the administrative aspects of the study. We would like to express our gratitude to Great Lakes Research Division benthos personnel whose invaluable assistance helped produce this report. Special thanks are due Polly Fairchild who sorted and identified the majority of the animals collected. We are thankful to Thomas Zdeba who identified the pisidia, Dr. David White for confirmation of trichopteran identifications, and Jarl Hiltunen who aided with distinguishing the naidids. In addition, Polly Fairchild, Roger LaDronka, Cathy Zawacki, Tom Zdeba, Dave McPherson, Fredric Leutheuser, Zeny Catalan, and Mary Jo Caterall aided in collection of animals and sediments during field surveys and are thanked for their assistance. We are grateful to the crew of the $R / V$ Mysis (Captain Ed Dunster and Ear1 Wilson) and to George Heufelder and Cliff Tetzloff for scheduling, logistics, and patience.

Appreciation for sediment analysis is extended to Dr. Ronald Rossmann. Special thanks are given to $\mathrm{Dr}$. William Chang for editing and untiring help with the statistical problems associated with this project, Dr. David White for encouragement and editing, Polly Fairchild for the tedious job of inking all figures, Linda Gardner and Polly Fairchild for their careful typing all the tables, and Steve Schneider for assistance in the production of this report. We thank Frank Tesar for his thorough review and many helpful comments regarding this report. Sherry Stapleton, Judy Farris, and Jan Farris are thanked for handling requisitions, time cards, and travel requests. 

CONTENTS

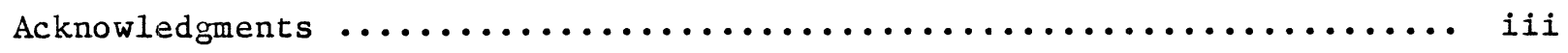

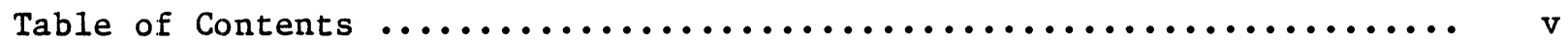

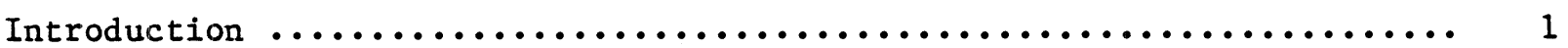

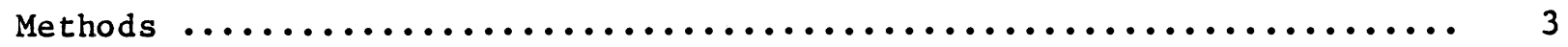

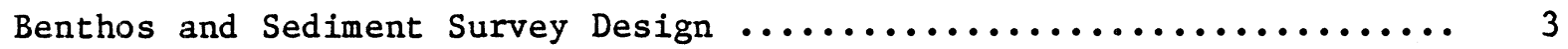

Benthos and Sediment Sample Collection and Processing ............. . . . . .

Statistical Analysis of 1978-1979 Preoperational Data ............. 7

Statistical Analysis of Preoperational and Operational Data

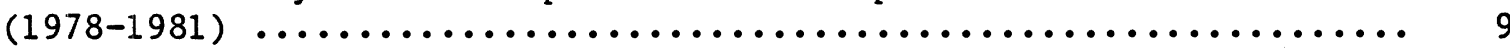

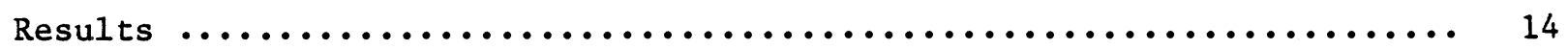

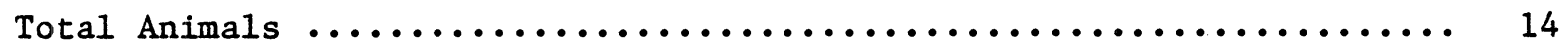

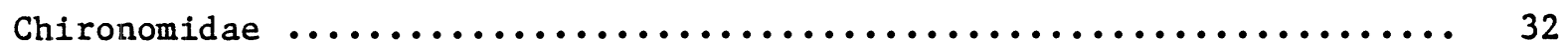

Naididae .............................................. 42

Tubificidae ........................................... 52

Turbellaria .......................................... 55

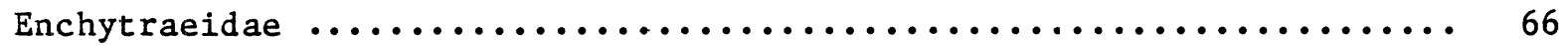

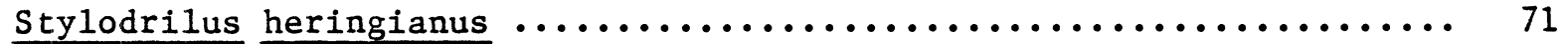

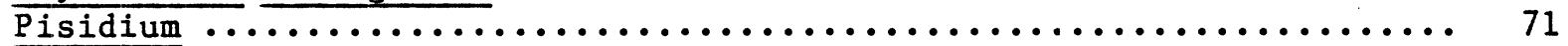

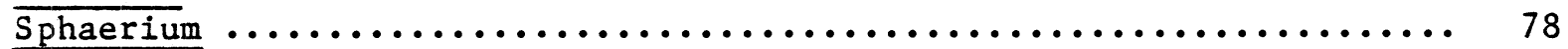

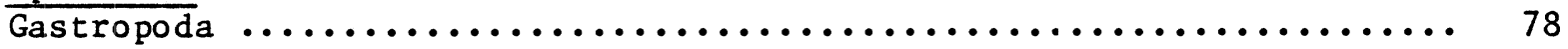

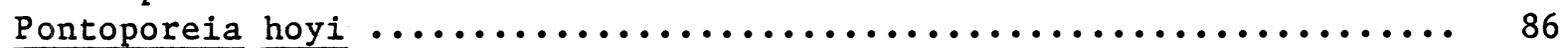

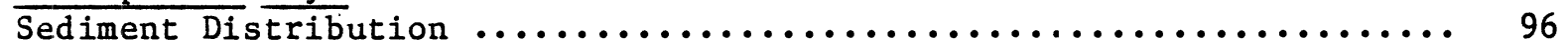

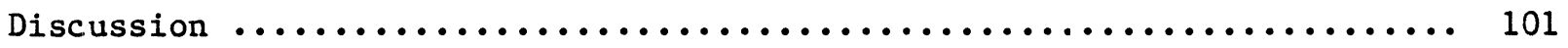

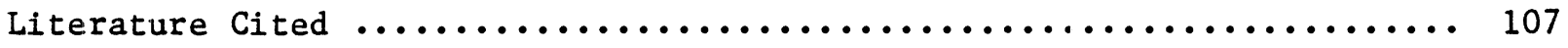

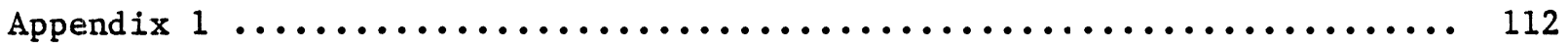

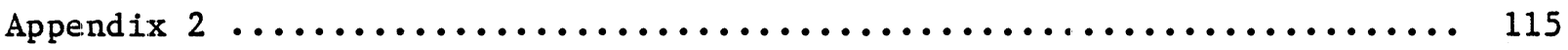

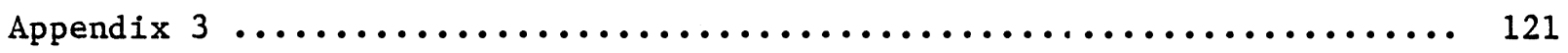

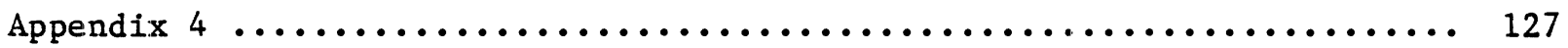




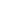


The J. H. Campbell Plant is comprised of three coal-fired operational units. While Units 1 and 2 have used and will continue to utilize Lake Michigan water drawn through Pigeon Lake for cooling purposes, Unit 3 draws cooling water from an intake structure located in approximately $11 \mathrm{~m}(1.1 \mathrm{~km}$ offshore) of water in Lake Michigan. Heated water from Units 1, 2, and 3 are discharged through the offshore discharge structure. While Unit 3 was not operational during 1979, in September 1980 all three units began discharging heated effluents at approximately $6 \mathrm{~m}(0.3 \mathrm{~km}$ offshore), thereby ending the preoperational period. Data have been collected for preoperational years 1978 and 1979.

This is the third in a series of benthos reports that began in 1977 concurrent with reports on larval, juvenile, and adult fish (Jude et al. 1978, 1979, and 1980). The first benthos report (Jude et al. 1978) was a pilot study ascertaining the approximate density and variety of benthic macroinvertebrates near the Campbell Plant during June 1977. In addition, variance and sample replicability were addressed. The second report, based on 1978 data (Winnell and Jude 1979), presented quantitative and qualitative differences between a treatment and two reference areas near the plant for benthic taxa and sediments. The purpose of this report is to present and analyze all preoperational data collected during 1978 and 1979. Analysis will be oriented toward determining monthly, depth, and regional distribution similarities for benthic and sediment parameters between control and treatment regions in 1979 and between the years 1978 and 1979. The overall purpose of this study is to determine whether density and species composition of benthos collected from 1978 and 1979 differ significantly from estimates covering the operational 
period. Analyses will be conducted after collection of 1981 samples in accordance with the statistical analysis technique (Johnston 1973, 1974) utilized at the D.C. Cook Nuclear Power Plant, southeastern Lake Michigan [see METHODS - STATISTICAL ANALYSIS OF PREOPERATIONAL AND OPERATIONAL DATA, $(1978-1981)]$.

The general distribution of benthos in southeastern and eastern Lake Michigan has been studied by Powers and Robertson (1965), Robertson and Alley (1966), Hiltunen (1967), Alley (1968), Mozley and Garcia (1972), Mozley and Winnell (1975), and Alley and Mozley (1975). However, the most comparable benthic studies were conducted in the immediate vicinity of the Campbell Plant by Truchan (1970) and Beak Inc. (Consumers Power Company 1975) to determine the effect of the shoreline thermal discharge on benthic macroinvertebrate distribution. While Truchan (1970) did find evidence of greater diversity near the discharge canal when compared with reference areas, he found no adverse impact on local benthos populations in the treatment area. In addition, studies completed by Beak Inc. from 1968 to 1974 indicated that, although some differences in benthic numbers were evident between treatment and reference areas, there appeared to be no "appreciable harm to the benthic community" due to shoreline thermal discharge (Consumers Power Company 1975). Based on information from the June 1977 pilot study, Jude et al. (1978) concurred with earlier conclusions made by Beak Inc. In the more extensive 1978 survey (Winnell and Jude 1979) we found that, although depth and time had the greatest impact on benthic macroinvertebrate density, region (i.e., treatment and reference areas) was an important consideration in several instances. Completion of benthos sampling in the second and final preoperational year (1979) ensured a sound data base, verified depth, time, and regional trends from 1978 to 1979, and noted regional differences and similarities within 1979 
they relate to benthos and sediments collected near the Campbell Plant. Significant differences between years or regions have been noted and tentative causes for these differences suggested. However, evaluation of any thermal effects due to plant operation must await collection and analysis of 1981 benthic samples.

METHODS

\section{BENTHOS AND SEDIMENT SURVEY DESIGN}

The survey was composed of 10 stations located along two transects perpendicular to the shoreline (Fig. 1). Along each transect, stations were located at 3-, 6-, 9-, 12- and 15-m depths. The first transect represented the treatment area (inner region) near the present thermal discharge. The second transect represented the reference area (outer region) located $5.0 \mathrm{~km}$ north of the discharge canal. During both April and July 1979, the inner transect was located $0.16 \mathrm{~km}$ north of the present thernal discharge canal. Due to construction activities during October 1979, it was necessary to move the inner transect $0.32 \mathrm{~km}$ north of the discharge canal.

The 1978 survey design was modified in 1979 by eliminating the intermediate region and including only inner and outer regions. In addition, during 1978, benthic and sediment parameters for each region were estimated from three replicates at each of two stations located equidistant north and south of the discharge canal at each depth. In 1979, the same parameters were estimated by one station sampled six times at each depth within a region. Since estimates of the benthos and sediments from 1978 were made by combining the two sets of three replicates collected at a selected depth and region, replication from 1978 to 1979 remained constant at six within a given region and depth. 


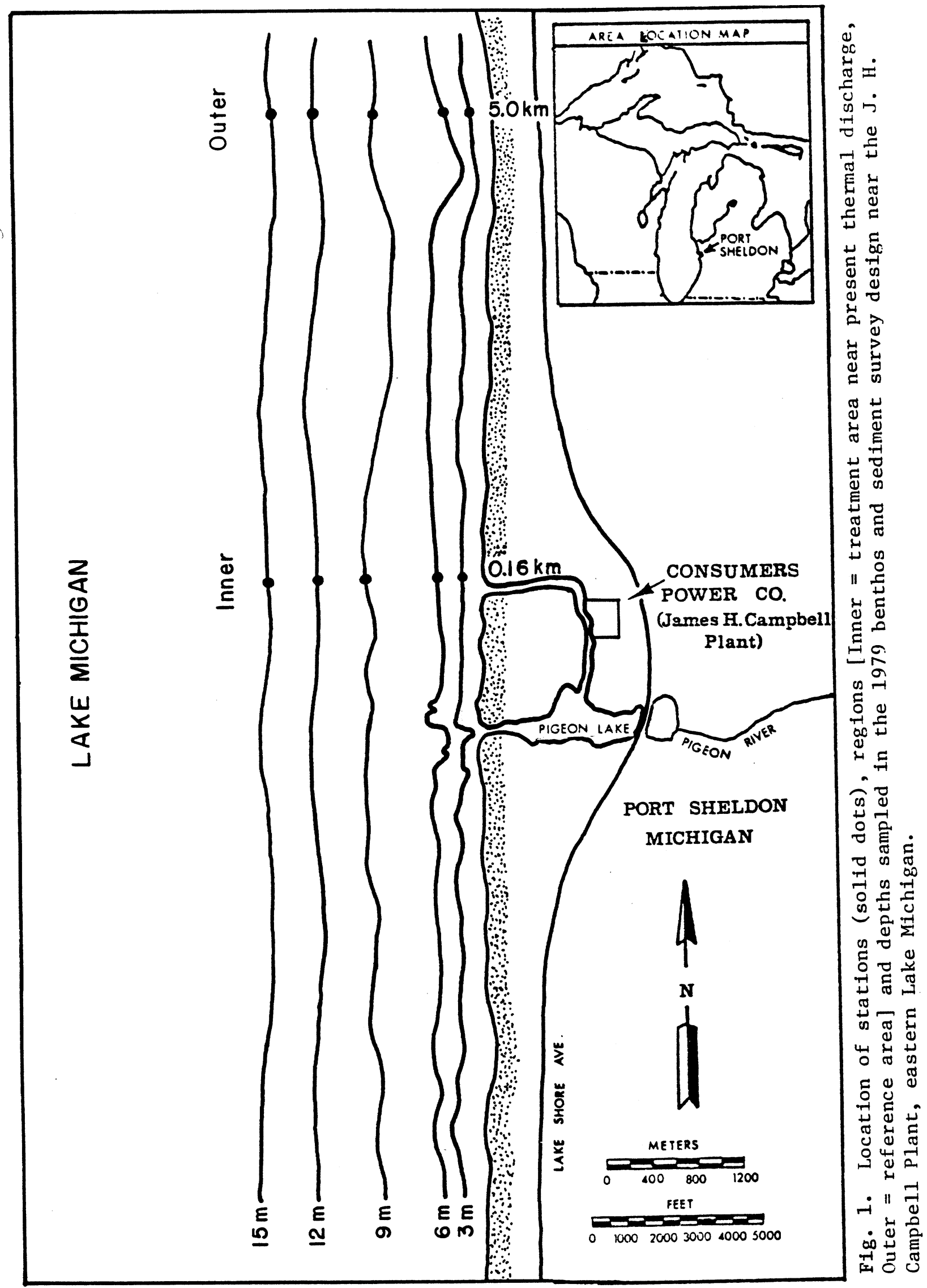


BENTHOS AND SEDIMENT SAMPLE COLLECTION AND PROCESSING

Benthic macroinvertebrate and sediment samples were collected on 19 April, $20 \mathrm{July}$, and 16 October 1979 in the vicinity of the J.H. Campbell Power Plant, eastern Lake Michigan. Sixty samples were collected for benthos and sediments during each sampling month from the University of Michigan's R/V Mysis. During 1979, 180 samples were collected for each parameter. No samples were lost due to breakage or spillage.

Benthos and sediment samples were collected using a triplex (threechambered) Ponar grab sampler (Mozley and Chapelsky 1.973). Each chamber of the Ponar grab samples $0.0165 \mathrm{~m}^{2}$. A conversion factor of 60.6 was used to convert numbers of animals present in each grab to numbers per square meter. One side chamber of the Ponar grab was used to estimate numbers of benthic macroinvertebrates occurring in a square meter. Contents from the remaining two chambers of the Ponar were emptied into a tub and mixed, and approximately $30 \mathrm{~g}$ of sediment removed for sediment analysis. Six replicates (A-F) were collected to estimate benthic populations and sediments at any particular depth and region during each month sampled.

The portion of the Ponar grab used to estimate benthic macroinvertebrates was placed in a "funnel-shaped hopper" (see Mozley 1975 for details) aboard the $\mathrm{R} / \mathrm{V}$ Mysis. Benthic samples were washed through a $0.2-$ mm mesh net to concentrate animals and remove excess sediment and debris. The mesh size of the net used to sieve organisms from sediments was reported as $0.35 \mathrm{~mm}$ in Jude et al. (1978) and Winnell and Jude (1979). However, the material supplied to us as $0.35-\mathrm{mm}$ mesh and from which our nets were constructed was in fact $0.2 \mathrm{~mm}$. Concentrated samples were stored in externally and internally labelled 1-pint Mason jars and preserved with carbonate-buffered, 4\% formaldehyde solution. 
Samples were returned to the Great Lakes Research Division benthos laboratory for sorting and identification.

Sorting and initial identification of organisms were performed using dissecting microscopes $(3-30 \mathrm{x})$. Specimens unidentified at the genus/species level (Chironomidae, Naididae, and Tubificidae) were mounted on slides with Amman's lactophenol clearing medium and identified using compound microscopes $(40-1000 x)$.

Initial generic identification of chironomids was determined using an unpublished trial key to the chironomids (A.L. Hamilton and O.A. Saether, personal communication, Freshwater Institute, Winnipeg, Manitoba, Canada and Zoological Museum and Department of Morphology, Systematics and Animal Ecology, University of Bergen, Bergen, Norway). In cases where species were determined for chironomid genera, "cf." refers to uncertain larval identification at the species level. Most species designations concur with reared specimens from the D.C. Cook Plant, southeastern Lake Michigan, which are maintained in the Great Lakes Research Division benthos laboratory's permanent collection. Larval, pupal, and adult chironomid associations at the D.C. Cook Plant have been reviewed by Mozley (1975). However, since none of the chironomid larvae from the J.H. Campbell Plant have been reared, identifications at the species level have been assigned the uncertainty designator "cf." The designator "gr.," which refers to a "group" of species undeterminable from larvae, was associated with the genera Polypedilum, Chironomus, and Paracladopelma. Morphology and taxonomy of other chironomid genera and species were determined from the following references: Lenz (1954), Roback (1957), Curry (1958), Beck and Beck (1969), Saether (1969, 1971, 1973, 1975, 1976, and 1977), Hirvenoja (1973), Jackson (1977), and Soponis (1977).

Naidids and tubificids were identified using an unpublished key to aquatic 
oligochaetes of the Great Lakes (J.K. Hil.tunen, personal communication, Great Lakes Fishery Laboratory, U.S. Fish and Wildlife Service, Ann Arbor, Michigan). Gastropods and pelecypods were identified using a key to molluscs of the Great Lakes being prepared at the Great Lakes Research Division (G. Mackie, D. White, and T. Zdeba, personal communication, University of Michigan, Ann Arbor, Michigan).

While aboard the $\mathrm{R} / \mathrm{V}$ Mysis, sediments were stored in sealed plastic bags bearing external labels. Standard mechanical sieving of sediment samples was performed at the Great Lakes Research Division sediment laboratory. Folk, Inman, and moment measure statistics were computed for each sample collected. Data were expressed in terms of phi units following Krumbein (1938). Upchurch (1969), Coakley and Beal (1972), and Seibel et al. (1974) indicated that moment measure statistics were the "preferred method for deriving sediment textural parameters." Two moment measure statistics, mean grain size and standard deviation of the mean grain size, were used in this report. Standard deviation has been used as a measure of sorting, following Seibel et al. (1974). In addition to moment measure statistics, percentage of sediments occurring within any given sediment grain size based on units of phi has been included in this report. Description of sediment grain sizes followed that of Seibel et al. (1974), who adapted theirs from the standard Wentworth scale.

\section{STATISTICAL ANALYSIS OF 1978-1979 PREOPERATIONAL DATA}

The preoperational data set (1978-1979) was analysed for annual and regional differences, either within 1979 (inner vs. outer region comparisons) or differences between years (inner 1978 vs. inner 1979 and outer 1978 vs. outer 1979). To determine the presence of preoperational differences, Student's $t$ tests were performed using the Michigan Interactive Data Analysis 
System (MIDAS) on the AMDAHL $470 \mathrm{~V} / 7$ computer at the University of Michigan. MIDAS computes Student's $t$ tests according to the following equation given by Dixon and Massey (1969):

$$
t=\frac{\bar{x}_{1}-\bar{x}_{2}}{s_{p} \sqrt{\frac{1}{N_{1}}+\frac{1}{N_{2}}}}
$$

$t=$ calculated Student's $t$ statistic

$\mathrm{x}_{1}$ and $\mathrm{x}_{2}=$ mean from populations 1 and 2 , respectively

$\mathrm{N}_{1}$ and $\mathrm{N}_{2}=$ number of observations from populations 1 and 2 , respectively $\mathrm{S}_{\mathrm{p}}{ }^{2}=$ pooled variance

where; $\alpha=0.05$

such that, NS = no significance

$$
\begin{aligned}
*= & 0.01<\mathrm{P} \leq 0.05 \\
* *= & 0.001<\mathrm{P} \leq 0.01 \\
* * *= & \mathrm{P} \leq 0.001 \\
-= & \text { no test performed due to no variance or mean estimate } \\
& \text { available for one or both populations tested }
\end{aligned}
$$

All analyses were performed on $\log (x+1)$ transformed values. Elliott (1971) considered the log transformation the most effective transformation when dealing with benthic data that are contagiously distributed, i.e., characterized by a variance to mean ratio significantly greater than one $\left(x^{2}\right.$ - test $)$. Transformation of raw numbers to $\log (x+1)$ transformed values is generally used to condense the range of values observed in the raw data in order to more fully meet assumptions of normality and homogeneously distributed variances upon which validity of the derived significance level for the $t$ test is based. Because no transformation of raw data can guarantee that the transformed data set or subsets thereof meet the assumptions above, we prefer to consider inferences made in the $0.05-0.01$ probability range as marginal. 
Differences between populations based on probability for values of $p \geq 0.01$ are considered as significant in this study. It is thought that the differences observed at $\mathrm{p} \geq 0.01$ were considered disparate enough in this system that improvement upon the assumptions by transformations would not alter the conclusion (Chang and Winnell 1980).

STATISTICAL ANALYSIS OF PREOPERATIONAL AND OPERATIONAL DATA (1978-1981)

In a previous report (Winnell and Jude 1979), we stated that data on benthic macroinvertebrates collected near the J.H. Campbell Plant from 1978 to 1981 would be analyzed statistically following Johnston (1974). With completion of the preoperational survey (1978-1979) and prior to presentation of operational survey data (1980-1981), examination of Johnston's model for the analysis of thermal discharge effects on benthic populations and its application to the Campbell survey area is appropriate. Although this subsection of the METHODS section will not be utilized in this report, it is presented in order to clarify the direction of the 4-yr benthic study design and the statistical methodology undergirding the study prior to the collection of operational data in 1980 and 1981.

Johnston's model has two major objectives. The first objective is to determine thermal effects using an F-ratio comparison derived from a mixed-model, nested analysis of variance (ANOVA). Completion of the analysis for the first objective provides the error mean square estimate used to calculate subsequent parameters used in second objective calculations. The second objective is to determine the sensitivity of the 4-yr survey design regarding the degree of change necessary to detect a thermal effect within treatment area benthic populations when compared with reference area benthic populations. Quantification of the sensitivity is determined by first 
calculating Sokal and Rohlf's (1969) least detectable true difference $(\delta)$ from the equation:

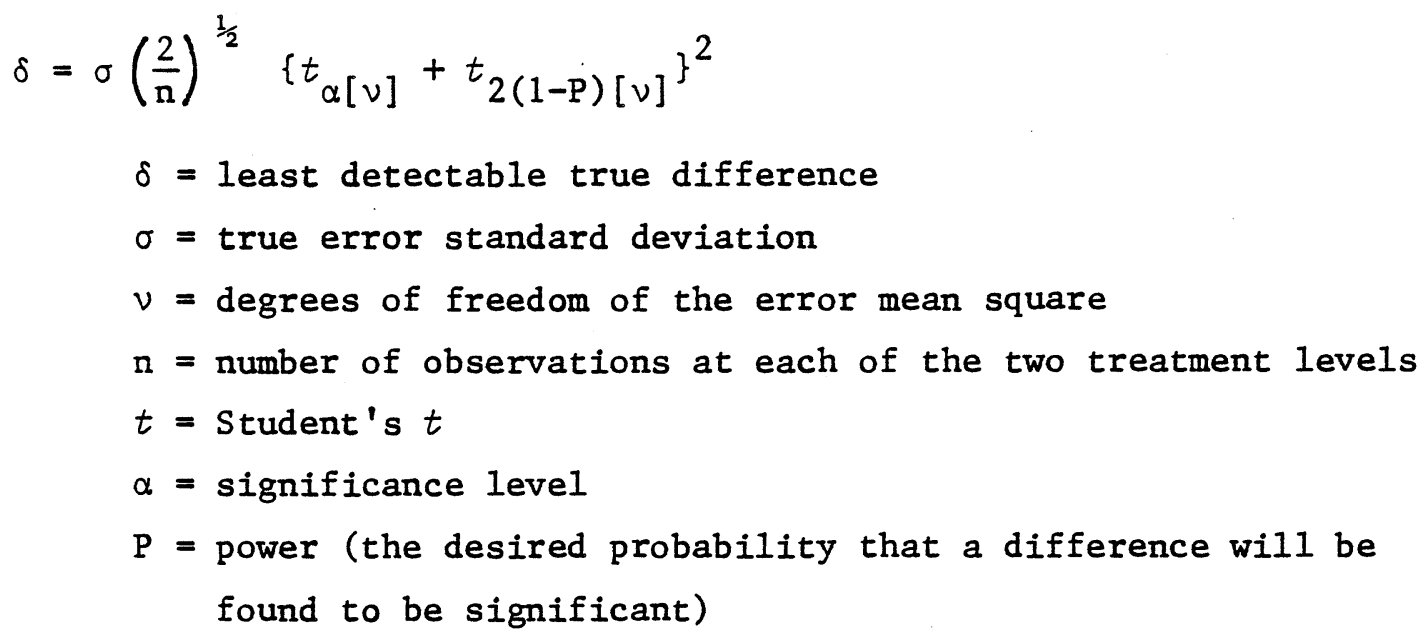

and secondly by determining $R$ from Johnston's derivation of Cohen's (1969) equations to:

$$
\begin{aligned}
& \mathrm{R} \geq 10^{\sqrt{2_{\delta}}} \text { or } \mathrm{R} \leq 10^{-\sqrt{2_{\delta}}} \\
& \mathrm{R}=\text { least detectable true ratio } \\
& \delta=\text { least detectable true difference }
\end{aligned}
$$

Johnston's mixed-model, nested ANOVA has five essential factors: construction time, year, month, depth, and region (treatment and control areas) (Table 1). The model assumes that the effect of month and depth are additive, thereby eliminating the difficulty of "assigning ecological interpretation" to higher-order interactions. Furthermore, Johnston uses Kirk's (1968) justification that once the investigator has selected the components expected to be major contributors to the total variance based on the investigator's knowledge of the system, all other components become part of the experimental error.

Of the model's five main effect factors, all are fixed-effect factors 
TABLE 1. Major factors considered in the mixed-model, nested ANOVA to be applied to benthic populations surveyed from 1978-1981 near the J. H. Campbell Plant, eastern Lake Michigan (After Johnston 1974).

\begin{tabular}{llll}
\hline $\begin{array}{l}\text { Name of } \\
\text { factor }\end{array}$ & $\begin{array}{c}\text { Factor } \\
\text { abbreviation }\end{array}$ & \multicolumn{1}{c}{$\begin{array}{c}\text { Number of } \\
\text { levels }\end{array}$} & \multicolumn{1}{c}{$\begin{array}{c}\text { Type of } \\
\text { factor }\end{array}$} \\
\hline Construction time (Before, After) & $\mathrm{C}$ & 2 (Before, After) & $\begin{array}{l}\text { Fixed } \\
\text { Random (nested within C) }\end{array}$ \\
Year $(1978-1982)$ & $\mathrm{Y}$ & $2(1978-1982)$ & Fixed \\
Region & $\mathrm{R}$ & 2 (Inner, Outer) & Fixed \\
Month & $\mathrm{M}$ & 3 (April, July, October) & Fixed \\
Depth & $\mathrm{D}$ & $5(3,6,9,12,15 \mathrm{~m})$ & - \\
Error & $\mathrm{E}$ & 6 (Number of replicates) & \\
& & & \\
Total number of observations $=2 \times 2 \times 2 \times 3 \times 5 \times 6=720$ & & \\
Total degrees of freedom $=719$ & & &
\end{tabular}

except year which is random and nested within construction time. In all, 32 interaction components are possible, but Johnston considered only nine essential for determination of heat effects (Table 2). The term used to determine thermal effects is the interaction ( $C \times R$ ) of construction time (C) and region $(R)$. The null hypothesis assumes that ${ }^{C} \mathrm{CR}=0$, i.e., the beginning of discharging heated water through the offshore discharge diffusers has had "no effect on the difference between the mean transformed benthic density" in the inner region (area of thermal discharge) and in the outer region (reference area). The F-ratio of the estimated mean squares (MS) for CR (Construction time $x$ Region) and YR (Year $x$ Region) interactions:

$$
F=\frac{{ }_{\mathrm{CS}}}{\mathrm{MS}_{\mathrm{YR}}}=\frac{\sigma_{\varepsilon}{ }^{2}+180 \sigma^{2} \mathrm{CR}+90 \sigma^{2} \mathrm{YR}}{\sigma_{\varepsilon}{ }^{2}+90 \sigma^{2} \mathrm{YR}}
$$

can be used to test the null hypothesis that $\theta_{C R}=0$. Terms in the F-ratio measure sampling error variance or variability among replicates $\left(\sigma_{\varepsilon}^{2}\right)$ and the annual variability of the "difference between inner and outer populations, averaged over. all months and depths $"\left(\sigma^{2} \mathrm{YR}\right)$. Since the null hypothesis assumes $\sigma_{C R}=0$, then the F-ratio becomes $\left(\sigma_{\varepsilon}^{2}+90 \sigma^{2} \mathrm{YR}\right) /\left(\sigma_{\varepsilon}^{2}+90 \sigma^{2} \mathrm{YR}\right)$ distributed as 
TABLE 2. Important sources of variation, their respective degrees of freedom and expected mean squares derived from the mixed-model ANOVA to be applied to benthic populations surveyed from 1978-1981 near the J. H. Campbell Plant, eastern Lake Michigan. Derivation of expected square coefficients assumes the depth factor (D) has five levels. See Table 1 for key for abbreviated source of variation factors (After Johnston 1974).

\begin{tabular}{ccc}
\hline $\begin{array}{c}\text { Source of } \\
\text { variation }\end{array}$ & $\begin{array}{c}\text { Degrees of } \\
\text { freedom }\end{array}$ & \multicolumn{1}{c}{$\begin{array}{c}\text { Expected } \\
\text { mean square }\end{array}$} \\
\hline $\mathrm{C}$ & 1 & $\sigma_{\mathrm{E}}{ }^{2}+360 \sigma_{\mathrm{C}}{ }^{2}+180 \sigma_{\mathrm{Y}}{ }^{2}$ \\
$\mathrm{Y}$ & 2 & $\sigma_{\mathrm{E}}{ }^{2}+180 \sigma_{\mathrm{Y}}{ }^{2}$ \\
$\mathrm{M}$ & 1 & $\sigma_{\mathrm{E}}{ }^{2}+360 \sigma_{\mathrm{R}}{ }^{2}+90 \sigma_{\mathrm{YR}}{ }^{2}$ \\
$\mathrm{D}$ & 2 & $\sigma_{\mathrm{E}}{ }^{2}+240 \sigma_{\mathrm{M}}{ }^{2}$ \\
$\mathrm{CR}$ & 4 & $\sigma_{\mathrm{E}}{ }^{2}+144 \sigma_{\mathrm{D}}{ }^{2}$ \\
$\mathrm{YR}$ & 1 & $\sigma_{\mathrm{E}}{ }^{2}+180 \sigma_{\mathrm{CR}}{ }^{2}+90 \sigma_{\mathrm{YR}}{ }^{2}$ \\
$\mathrm{E}$ & 2 & $\sigma_{\mathrm{E}}{ }^{2}+90 \sigma_{\mathrm{YR}}{ }^{2}$ \\
\hline Total & 719 & $\sigma_{\mathrm{E}}{ }^{2}$
\end{tabular}


an $F(1,2)$. Johnston uses $\sigma_{\varepsilon}^{2}+90 \sigma^{2} Y R$ in the denominator in the F-ratio, making the quantity $\left(\sigma_{\varepsilon}^{2}+90 \sigma^{2} \mathrm{YR}\right)^{1 / 2}$ the appropriate error standard deviation $(\sigma)$ for use in the power equation.

Calculation of the least detectable true change $(\delta)$ using the error standard deviation from the 4-yr design assumes a $5 \%$ significance level and $95 \%$ power, i.e., "is the minimum amount by which the true treatment means must differ if there is to be a $95 \%$ probability that the means of two samples of size $\mathrm{n}$ will be found significantly different at the $5 \%$ level." When $\delta$ (least detectable true change) is applied to $\mathrm{R}$ (least detectable true ratio), which is derived from Cohen (1969), resulting values of $R$ will estimate the relative increase or decrease of the inner region benthic populations when compared with outer region benthic populations necessary to detect a heat effect using the 4-yr survey design.

Benthic populations and respective depths to be considered in the above analyses include: Chironomidae (3-15 m), Turbellaria (3-15 m), Naididae $(3-15 \mathrm{~m})$, total animals $(3-15 \mathrm{~m})$, Tubificidae $(9-15 \mathrm{~m})$, Pisidium $(9-15 \mathrm{~m})$, Pontoporeia hoyi (9-15 m), Gastropoda (12-15 m), Enchytraeidae (12-15 m), and Stylodrilus heringianus $(15 \mathrm{~m})$. Depths not included in the analyses of benthic groups for either 1978-1979 or 1978-1981 data have been excluded due to low density and frequency of occurrence under the assumption that it is more advisable to test for effects on the main body of a population than on the fringe of the population. Consequently, coefficients for the expected mean square term will differ for those populations where the number of depth factors included in the analysis are less than five. While the coefficients presented earlier were based on five depths, fewer depths tested will not change the F-ratio relationship $\left(\mathrm{MS}_{\mathrm{CR}} / \mathrm{MS}_{\mathrm{YR}}\right)$ but will only alter the magnitude of the coefficients for the expected mean square term. The exception is $\underline{s}$. 
heringianus which has only one level $(15 \mathrm{~m})$ for depth. In this case, there will be no depth factor in the ANOVA.

RESULTS

\section{TOTAL ANIMALS}

The number of identified benthic macroinvertebrate taxa collected from samples taken near the Campbell Plant in 1979 (82) was slightly greater than the revised number of taxa collected during 1978 (76). Based on all samples collected from 1977 through 1979 (660), 105 benthic macroinvertebrate taxa have been collected and identified (Table 3). Representation of the 105 benthic taxa among major taxonomic groups was as follows: Chironomidae (37), Naididae (19), Pisidium (16), Tubificidae (13), Gastropoda (5), Sphaerium (3), and miscellaneous others (12). During 1979, 73 benthic forms were collected in each of the inner and outer regions (Table 4). Combining 1978 and 1979 surveys, the inner region was represented by 82 taxa and the outer region by 81 taxa. Comparing the number of taxa collected in the inner and outer region during 1979, the greatest difference was observed at $3 \mathrm{~m}$. At $3 \mathrm{~m}$, there were twice as many taxa present in the inner region (22) when compared with the outer region (11), which was mainly the result of regional chironomid and naidid taxa differences. Detail regarding these differences will be presented in the chironomid and naidid sections to follow.

Percent occurrence of major taxonomic groups (i.e., Chironomidae, Naididae, Tubificidae, Enchytraeidae, Stylodrilus heringianus, Pisidium, Sphaerium, Gastropoda, Pontoporeia hoyi, and Turbellaria) among months, depths, and regions sampled during 1979 near the Campbell Plant are summarized in Table 5. Chironomids, naidids, and turbellarians were the predominant forms at 3-6 $\mathrm{m}$. A change in the dominant taxon observed at $9 \mathrm{~m}$ was primarily due to an 
TABLE 3. Benthic macroinvertebrates identified from samples collected from 1977 through 1979 at 3 to 25 m near the J. H. Campbell Plant, eastern Lake Michigan.

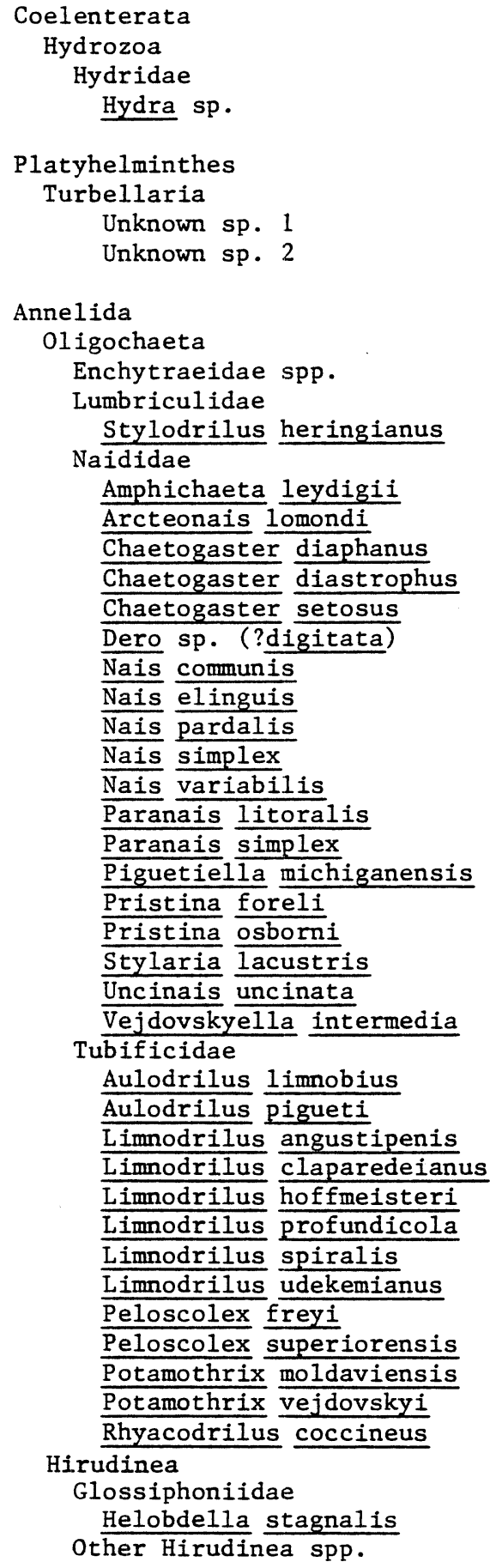

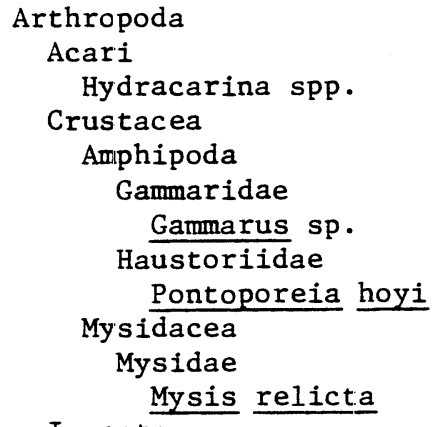


TABLE 3. Continued.

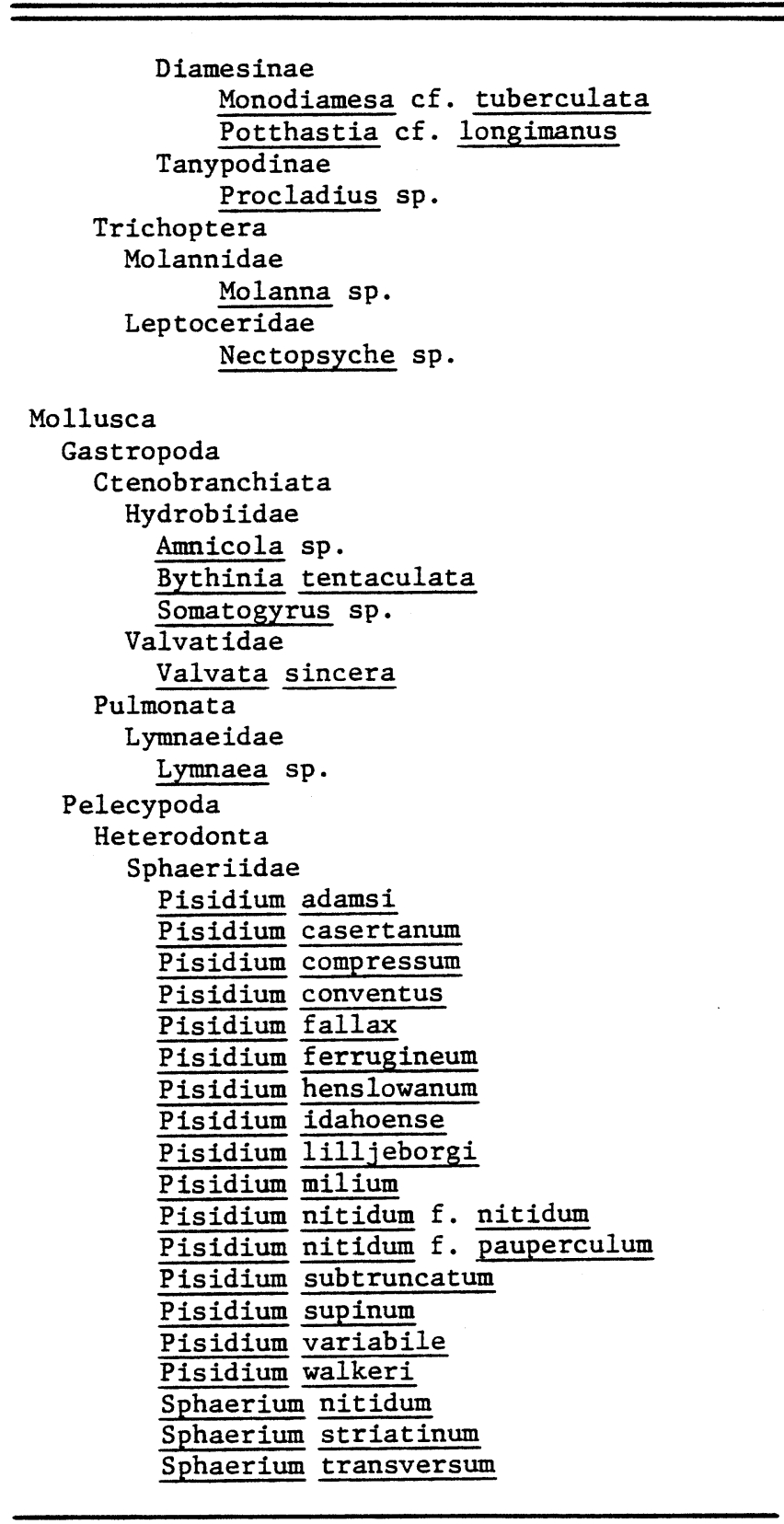




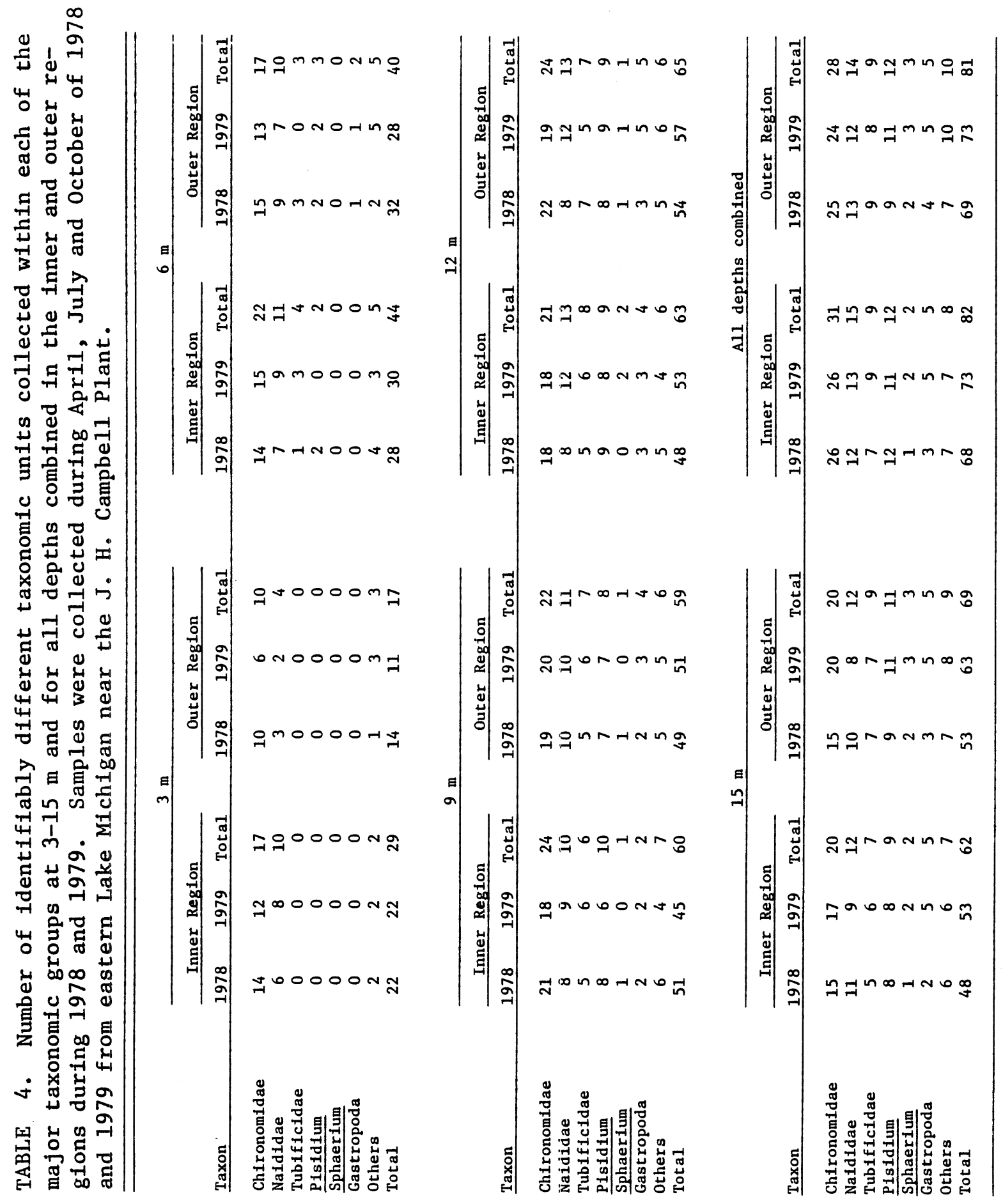


TABLE 5. Percent occurence of major taxonomic groups collected in 1979 at $3-15 \mathrm{~m}$ among inner (treatment area near present thermal discharge) and outer (reference area) regions in the vicinity of the $\mathrm{J}$. H. Campbell Plant, eastern Lake Michigan. Percentages expressed in terms of total animals.

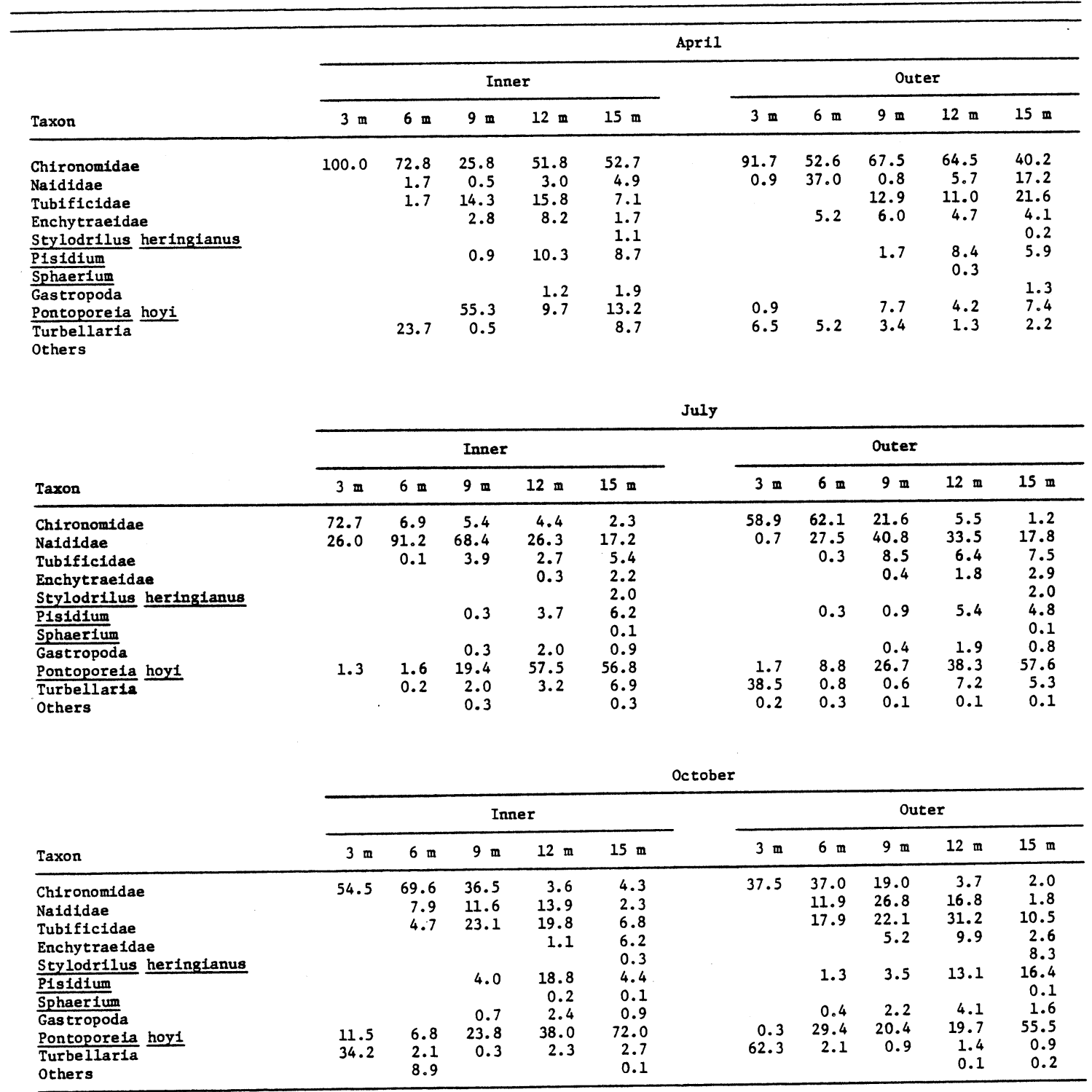


increase in percent occurrence of $\underline{P}$. hoyi, which tended to be the dominant organism from 9 to $15 \mathrm{~m}$. Other benthic forms, such as tubificids, naidids, Pisidium, and chironomids contributed to the benthos at 9-15-m depths, but not to the extent of $\underline{\mathrm{P}}$. hoyi. As in 1978, $\underline{\mathrm{s}}$. $\underline{\text { heringianus was numerous and occurred }}$ regularly at $15 \mathrm{~m}$ only. Within 9-15-m depths, greatest deviation from expected relative abundances of major taxonomic groups occurred at 12-15 m in April 1978 and 1979. Chironomids comprised a high percentage of the benthic population at 12-15 m which differed greatly from that observed during other months. Other than this difference, which also was observed during 1.978, relative densities of the benthos were observed along the depth gradient in a manner similar to that of 1978 .

The 1979 average density of total animals, i.e. the sum total of all benthic macroinvertebrates collected, generally was similar to 1978 estimates with respect to depth and month (Figs. 2 and 3, Appendix 1). However, mean densities at 3-9 m were lower than 1978 estimates, while at 12-15 m the average number of animals was greater. Total numbers of animals collected were significantly lower at $9 \mathrm{~m}$ and significantly higher at: $15 \mathrm{~m}$ than observed during 1978. No significant differences were evident for monthly total animal mean density when comparing similar months across years. Overall, there was no significant difference in the yearly mean density of total macrobenthos collected between $1978\left(6522 \mathrm{~m}^{-2}\right)$ and $1979\left(7940 \mathrm{~m}^{-2}\right)$ (Table 6).

Examination of inner/outer regional benthos data indicated there were significant differences both within and between inner and outer regional means (Tables 7 and 8). In April, July, and October 1979 at 3 and $15 \mathrm{~m}$ there were significantly more benthic macroinvertebrates collected in the outer than in the inner region (Tables 9 and 10). In addition, at 6-12-m during July inner region mean density increased while the 6-12-m outer regional mean density decreased from 1978 estimates of total aninals (Fig. 4). 


\section{Total Animals}

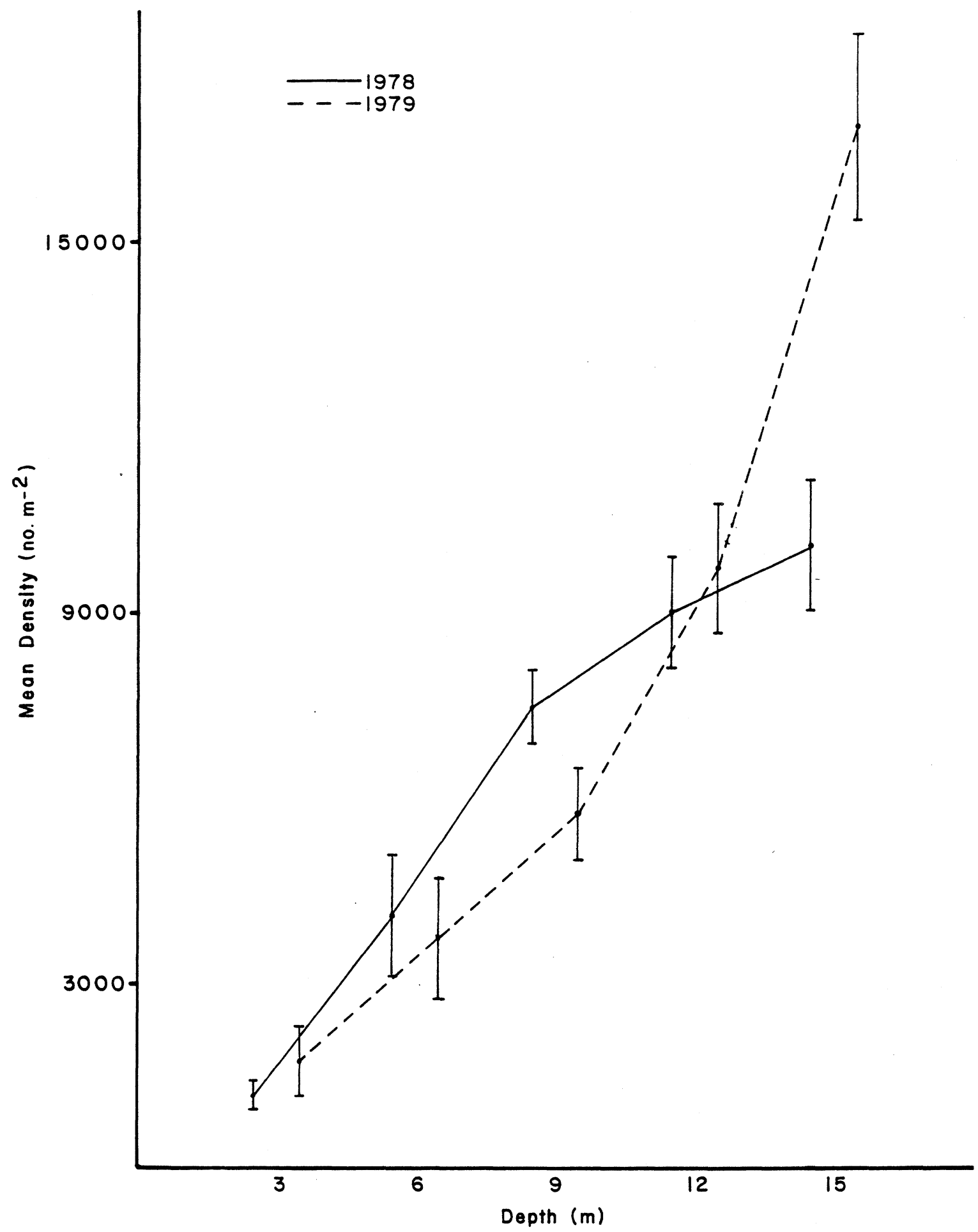

Fig. 2. Mean density (number $\mathrm{m}^{-2}$ ) of total animals collected at 3$15 \mathrm{~m}$ during 1978 and 1979 in eastern Lake Michigan near the J. H. Campbell Plant. Density estimates at each depth were computed by averaging over all months within each year $(n=36)$. Standard error denoted by vertical bar. 


\section{Total Animals}

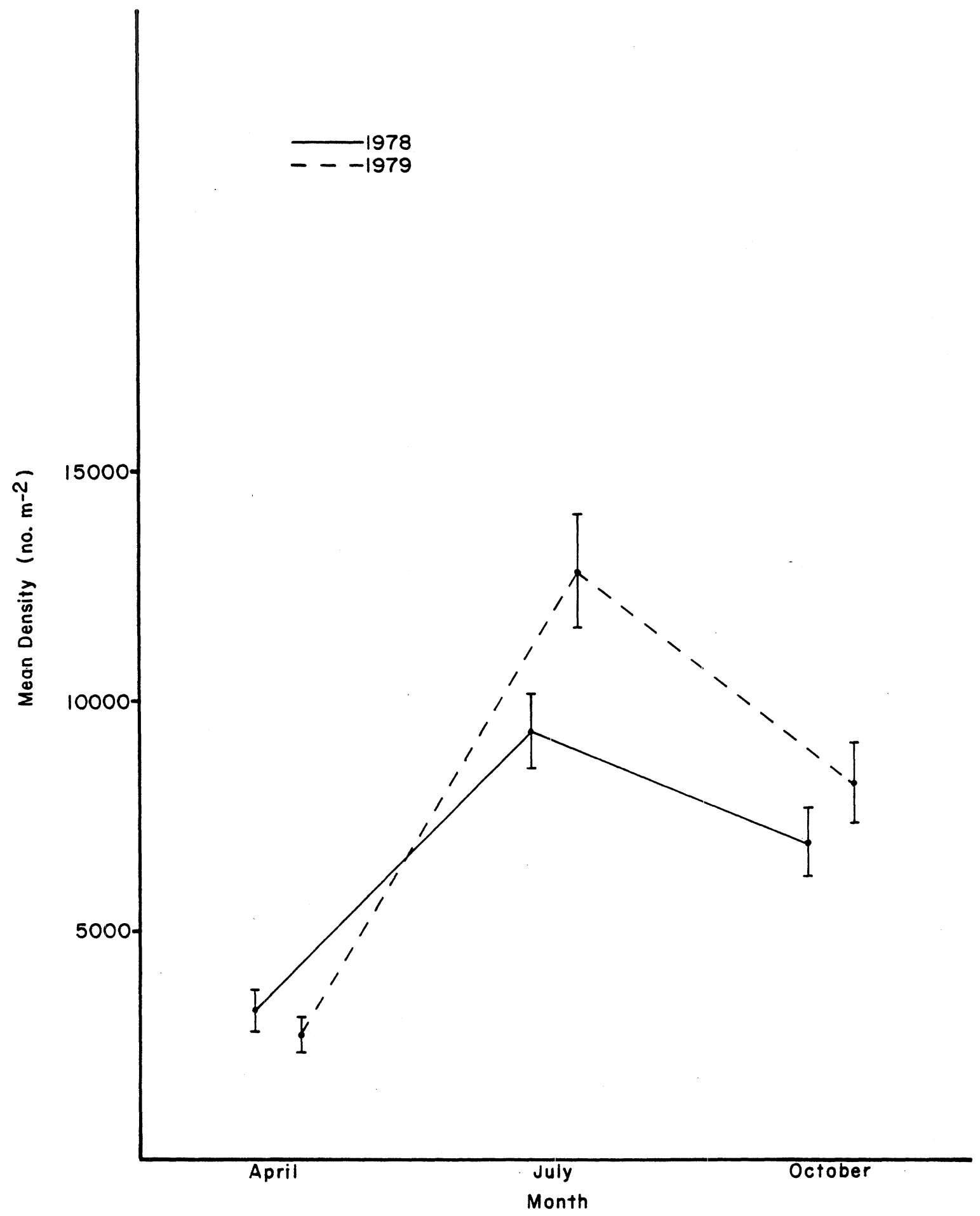

Fig. 3. Mean density (number $\mathrm{m}^{-2}$ ) of total animals collected during April, July and October 1978 and 1979 in eastern Lake Michigan near the J. H. Campbell Plant. Density estimates for each month were computed by averaging over all depths within each year $(n=60)$. Standard error denoted by vertical bar. 


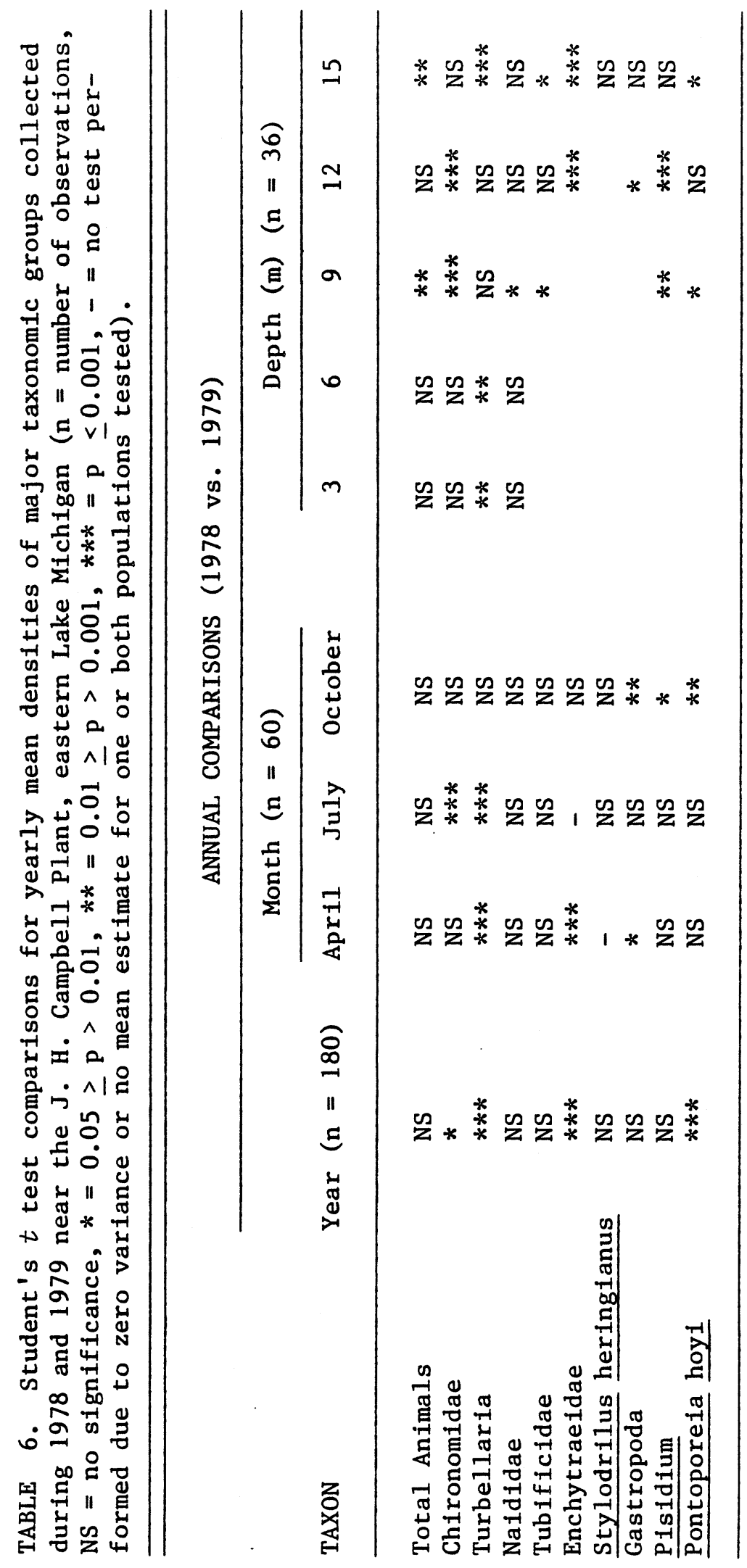




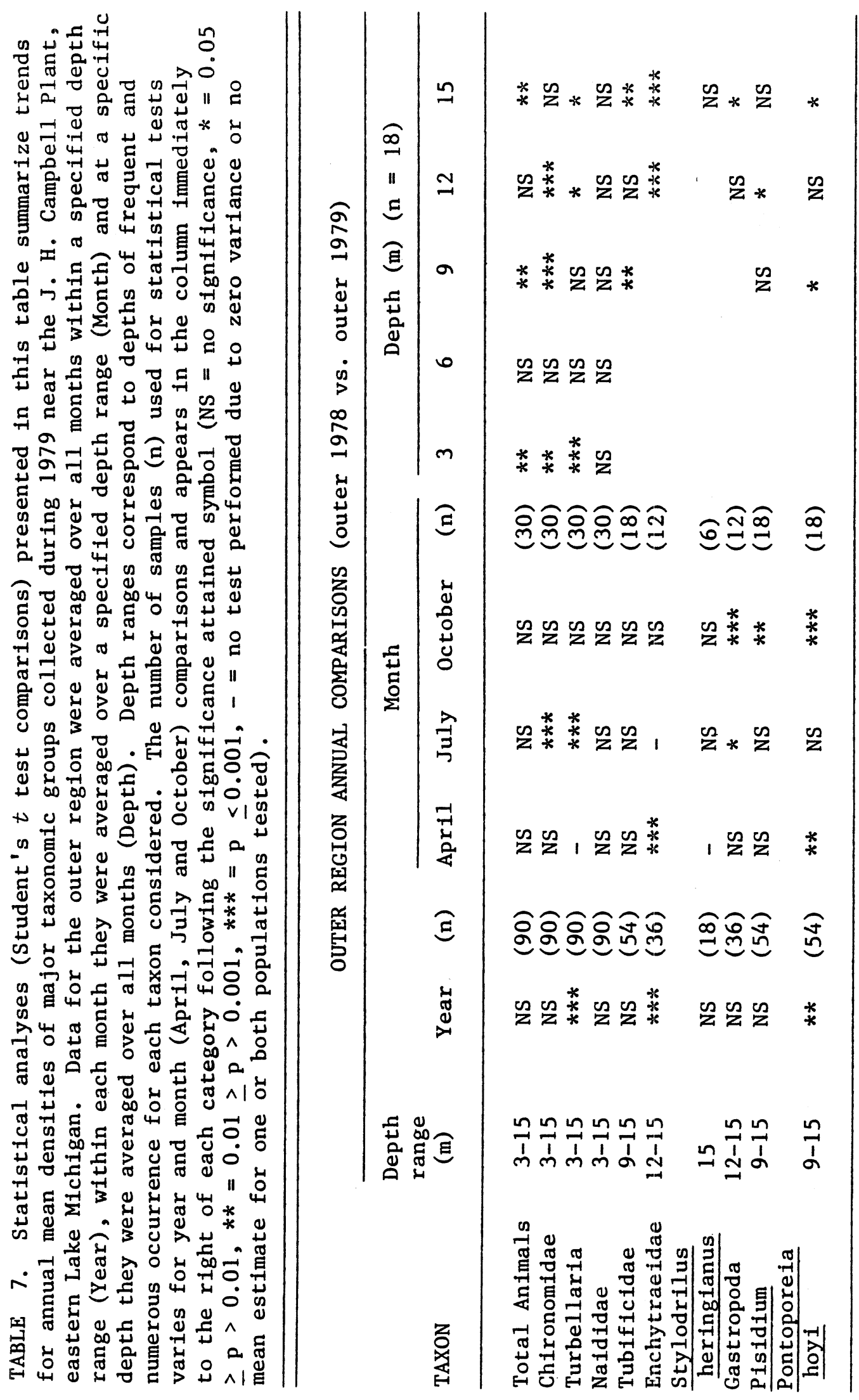




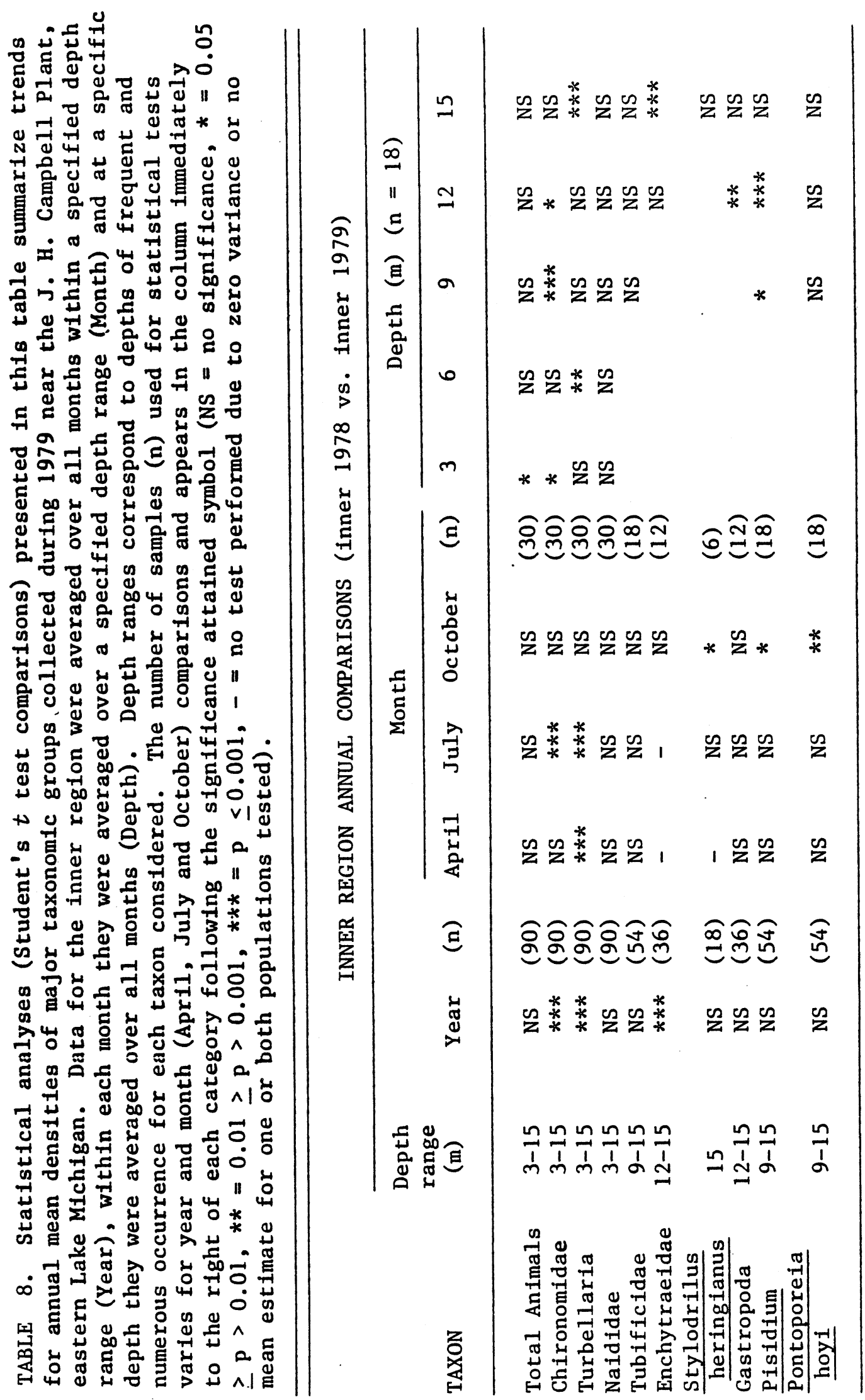




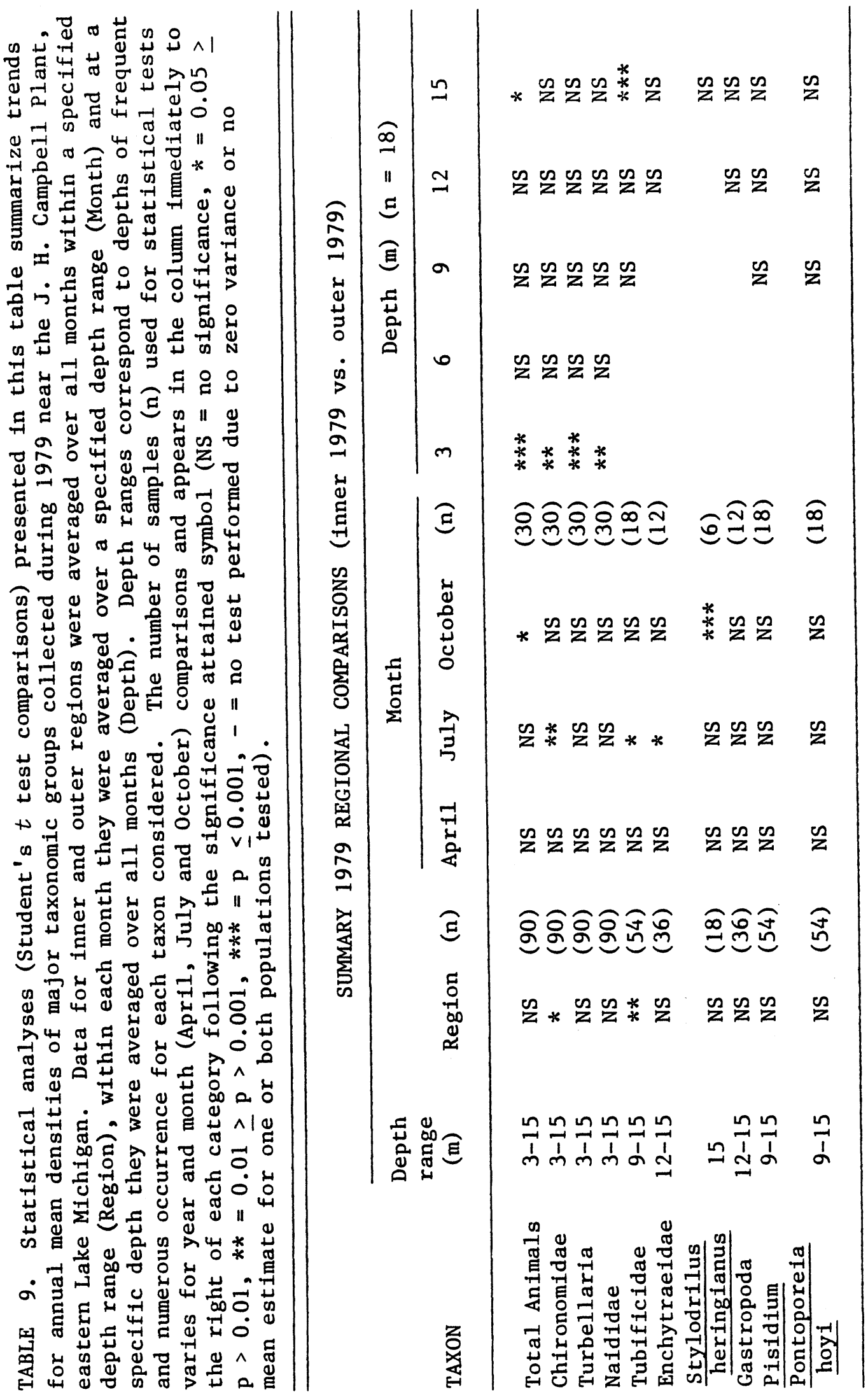




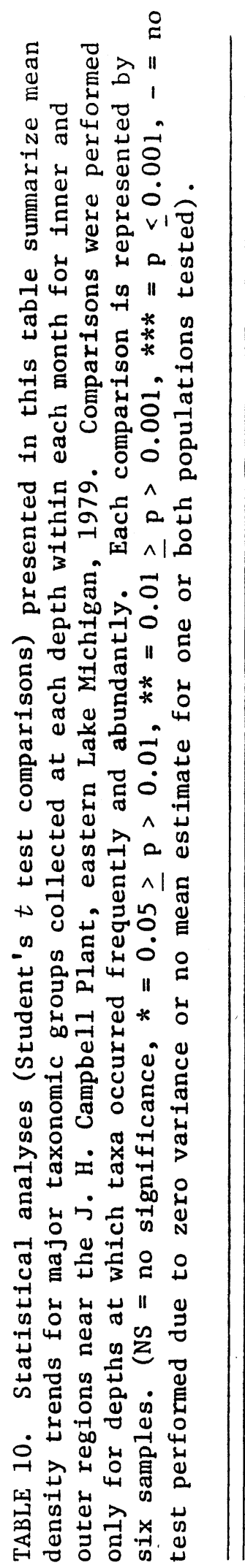

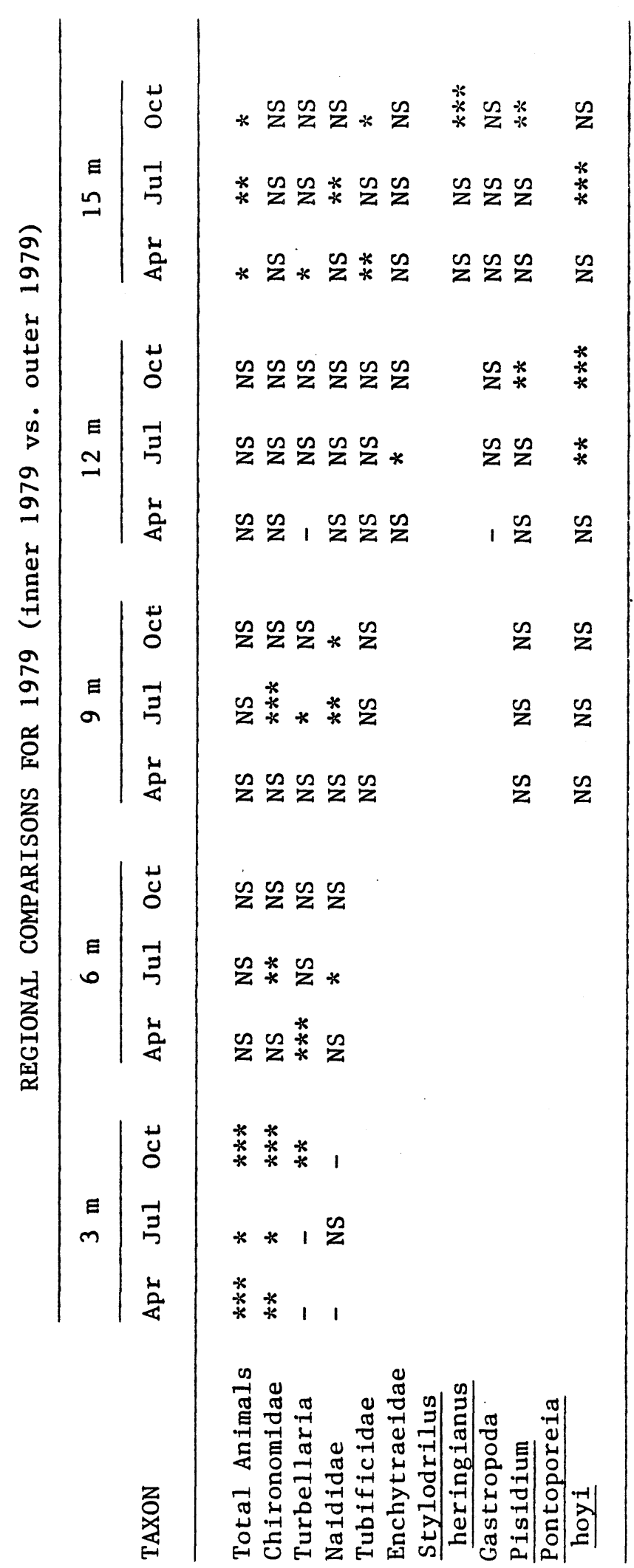




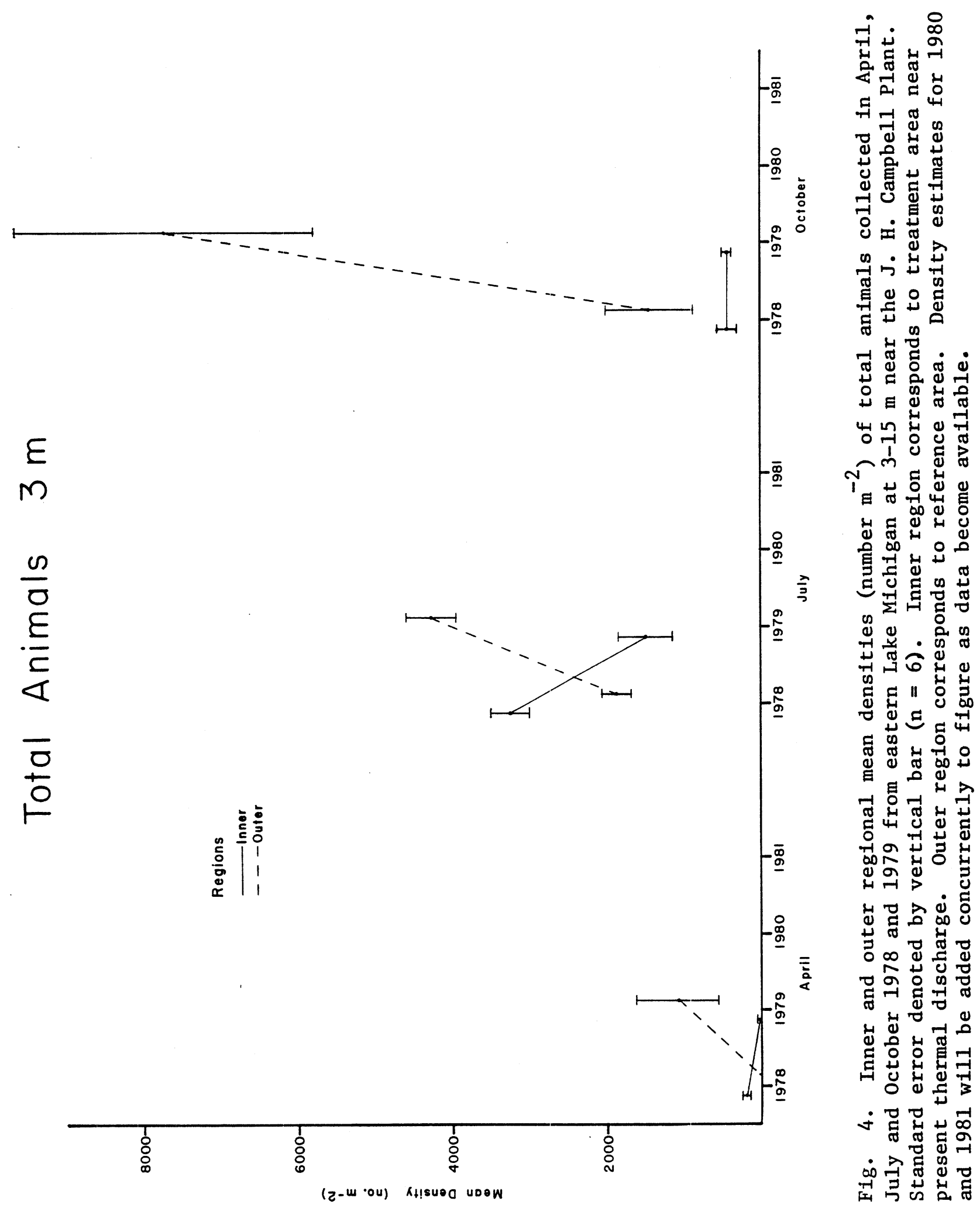




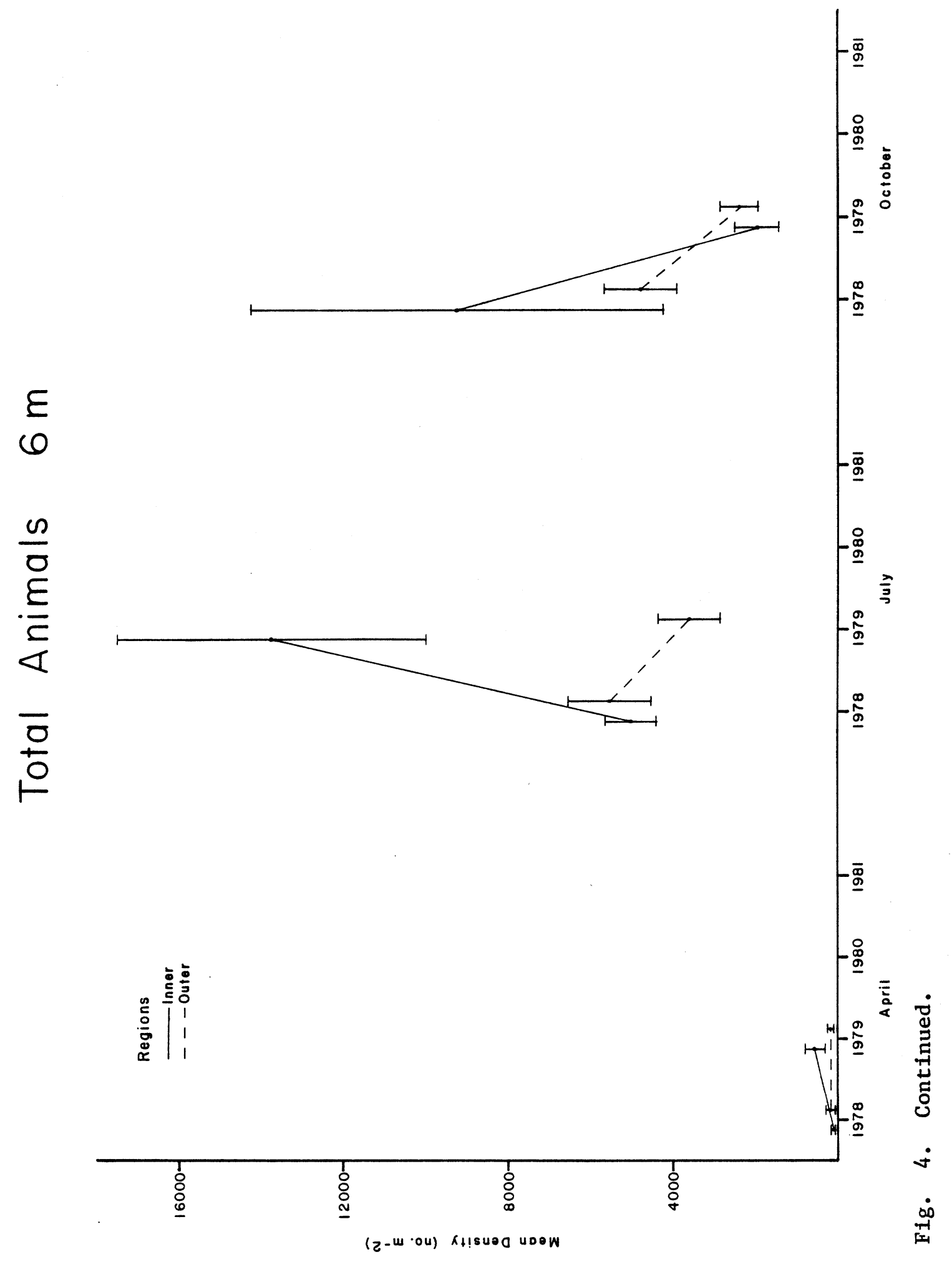



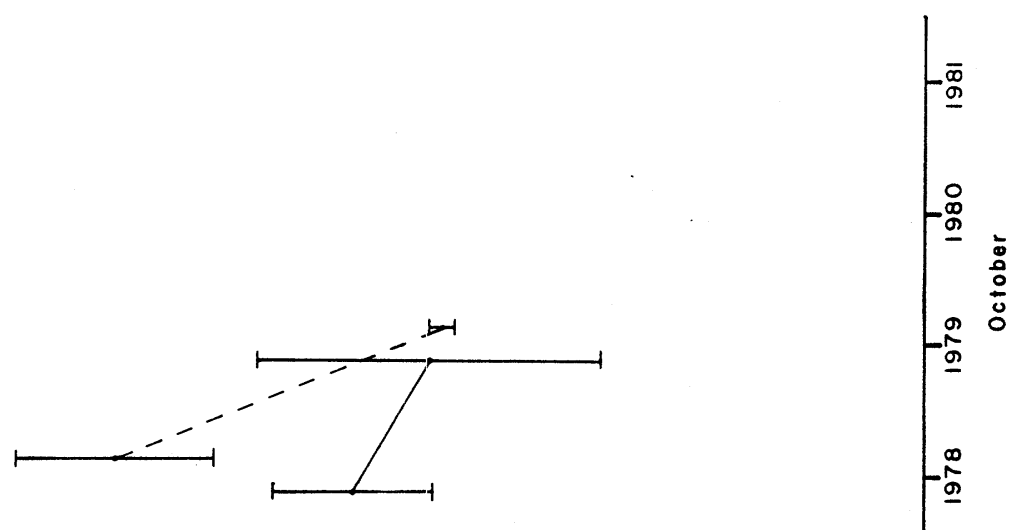

$E$
0
$\frac{0}{0}$
$\frac{5}{5}$
$\frac{1}{1}$
$\frac{0}{0}$
1
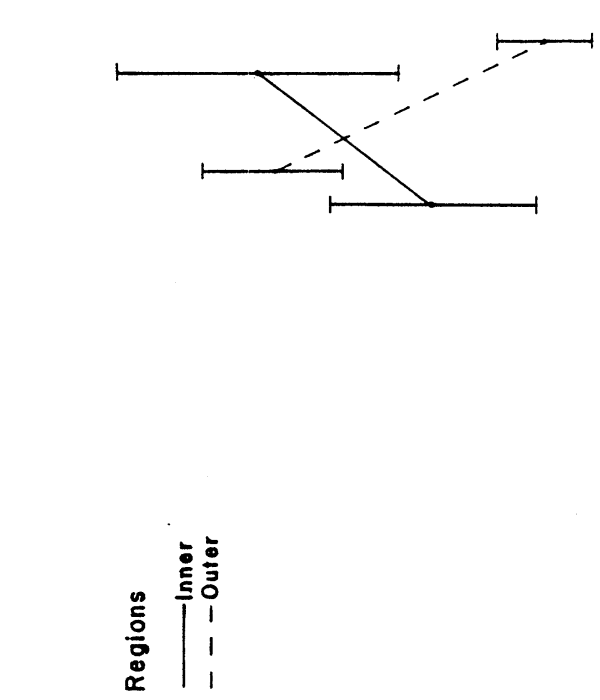


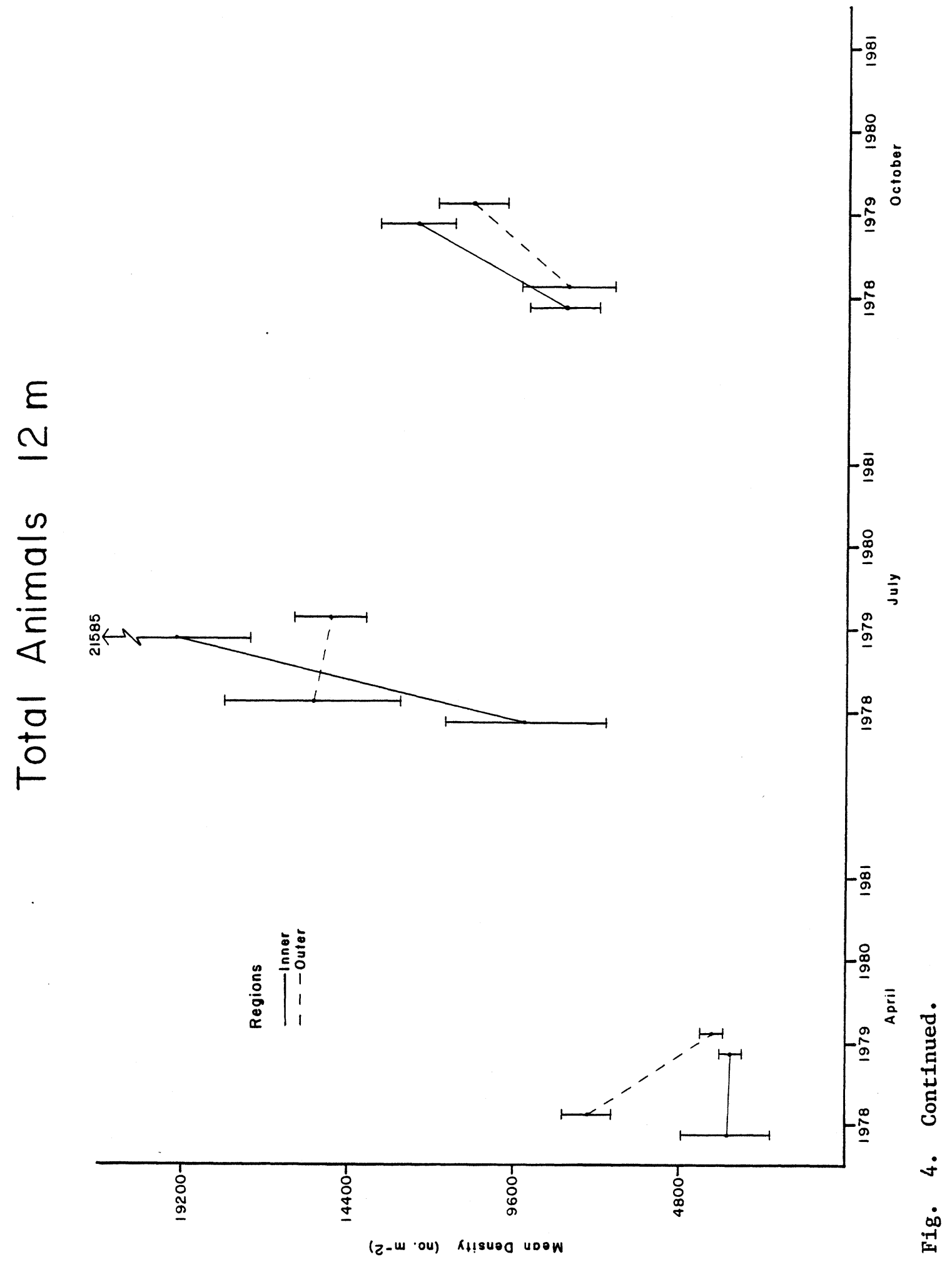




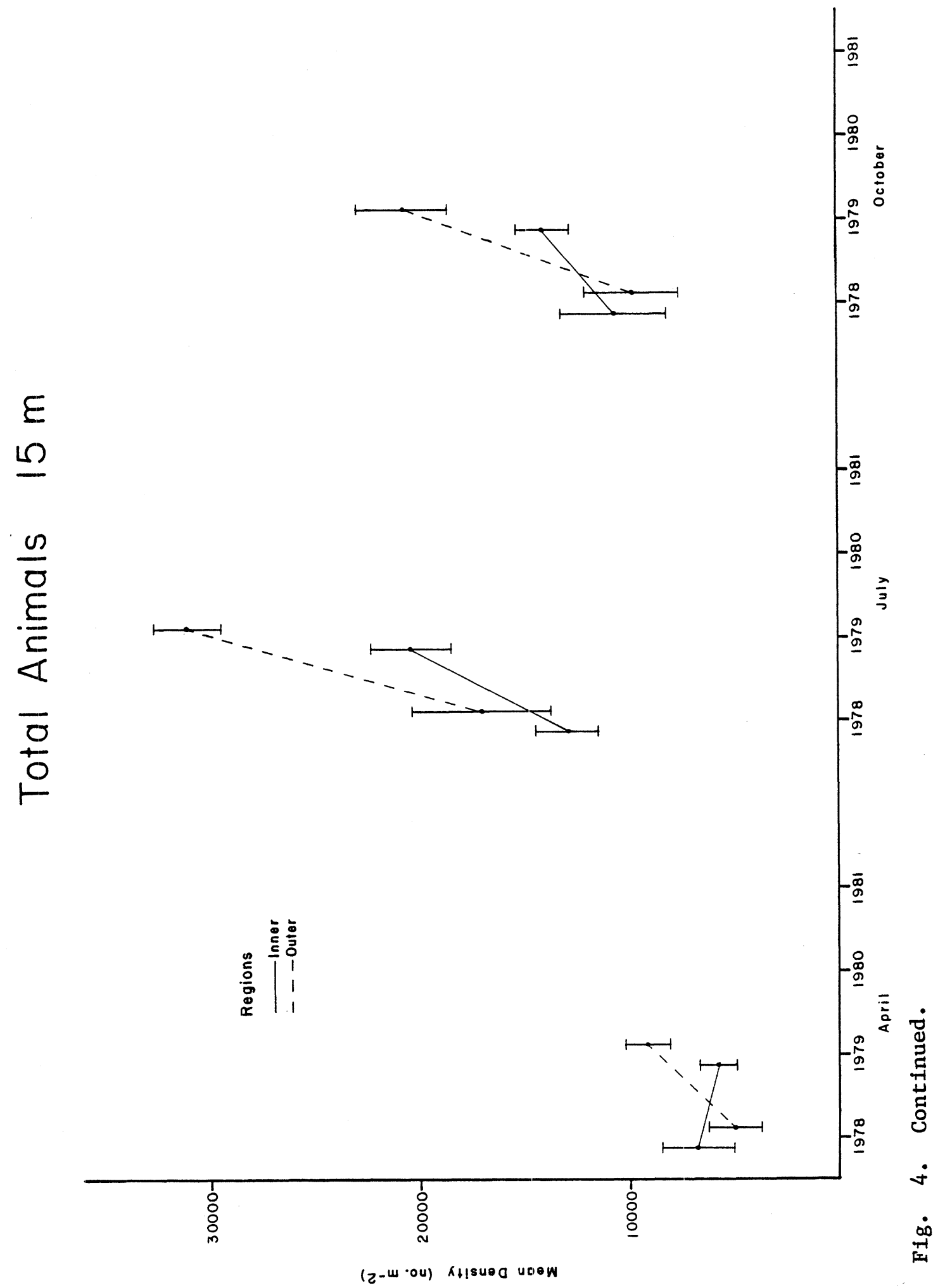


CHIRONOMIDAE

Chironomids were represented in $95 \%$ and $94 \%$ of the samples collected during 1978 and 1979, respectively (Table 11). While chironomids comprised 34\% of the 1978 annual benthic mean density, the relative abundance of chironomids decreased to $15 \%$ of the 1979 annual benthic mean density.

TABLE 11. Frequency of occurrence of major taxonomic groups among benthic samples $(n=180)$ collected during 1979 in eastern Lake Michigan near the J. H. Campbell Plant.

\begin{tabular}{|c|c|c|c|}
\hline Taxon & $\%$ & Taxon & $\%$ \\
\hline Chironomidae & 94.4 & Gastropoda & 37.8 \\
\hline Oligochaeta & 79.4 & S. heringianus & 13.9 \\
\hline P. hoyi & 78.9 & Sphaerium & 5.6 \\
\hline Naididae & 71.1 & Hydracarina & 4.4 \\
\hline Tubificidae & 64.4 & Hydra & 2.8 \\
\hline Turbellaria & 64.4 & Hirudinea & 1.7 \\
\hline Pisidium & 52.2 & M. relicta & 0.6 \\
\hline Enchytraeidae & 42.8 & Samples with Animals & 96.7 \\
\hline
\end{tabular}

The chironomid genera/species list has been revised and updated from 1978 (Table 3). The primary revisions have been to condense Parakiefferiella sp. and Orthacladius (…) sp. 1 and sp. 2 into Cricotopus/Orthocladius (…) sp. 1. Previously, there had been some confusion in that early and late instars differed morphologically. Having seen instar and depth association patterns over $2 \mathrm{yr}$ has helped coalesce some differences observed previously. In addition, what had been thought to be an early instar orthocladiini (sp. 2 ) has subsequently been noted to be a last instar individual as yet unidentified (only one specimen has been collected). 
A total of 37 chironomid taxa have been identified from 1977 to 1979 (Table 3). Generally, the number of chironomid taxa collected was similar between years for a given depth and regional comparison (Table 4). The largest difference occurred at $3 \mathrm{~m}$ where the inner region had 17 taxa present and the outer region had only 10 taxa present over both years. Examination of these regional differences did not appear to indicate any significant differences between regions based on kinds of chironomids observed.

Twenty-six chironomid taxa were found in the inner region over all depths and months in 1978 and 1979. In the outer region 25 chironomid taxa were observed in 1978 and 24 during 1979. Overa11, in the inner region chironomids have been represented by 31 taxa, while 28 chironomid taxa have been identified in the outer region.

Based on annual chironomid mean density, Chironomus fluviatilis-gr., Cryptochironomus sp. 2, Paracladopelma camptolabis-gr., Polypedilum cf. scalaenum, Robackia cf. demeijerei, and Saetheria cf. tylus were the most numerous chironomids collected in each year. Relative importance of these taxa differed between years with $\underline{S}$. cf. tylus $(24 \%), \underline{P}$. camptolabis-gr. $(18 \%)$, $\underline{\text { C. }}$ fluviatilis-gr. (12\%), and $\underline{P}$. cf. scalaenum (12\%) most abundant in 1978.

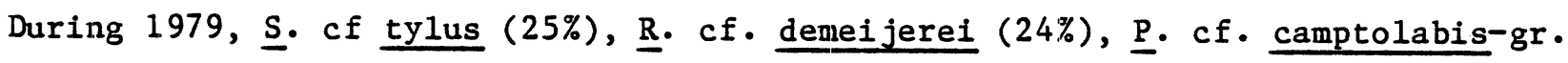
(10\%), and Cryptochironomus sp. 2 (10\%) were the most numerous chironomid taxa (Appendix 2). The greatest change observed was a decrease in relative abundance of $\underline{C}$. fluviatilis-gr. and an increase for $\underline{R}$. cf . demeijerei. Distribution of chironomids with respect to depth and month during 1979 differed from the pattern observed in 1978 (Figs. 5 and 6 ). While the largest mean chironomid densities were observed at 6-12 m during 1978, all depths had a similar average abundance of chironomids in 1979. In particular, the 1979 9and $12-m$ mean density estimates were significantly lower when compared with 


\section{Chironomidae}

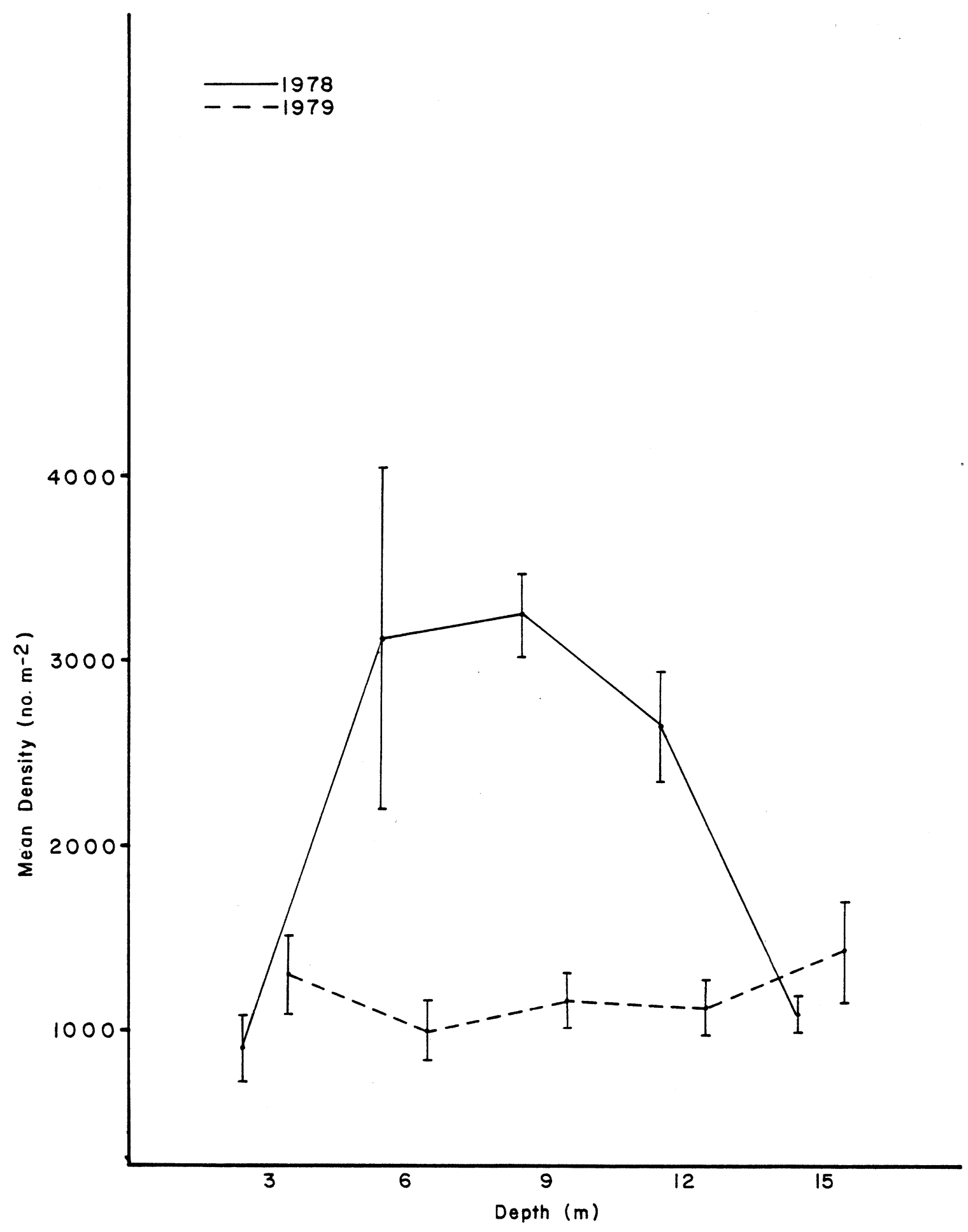

Fig. 5. Mean density (number $\mathrm{m}^{-2}$ ) of chironomids collected at 3-15 $\mathrm{m}$ during 1978 and 1979 in eastern Lake Michigan near the J. H. Campbell Plant. Density estimates at each depth were computed by averaging over all months within each year $(n=36)$. Standard error denoted by vertical bar. 


\section{Chironomidae}

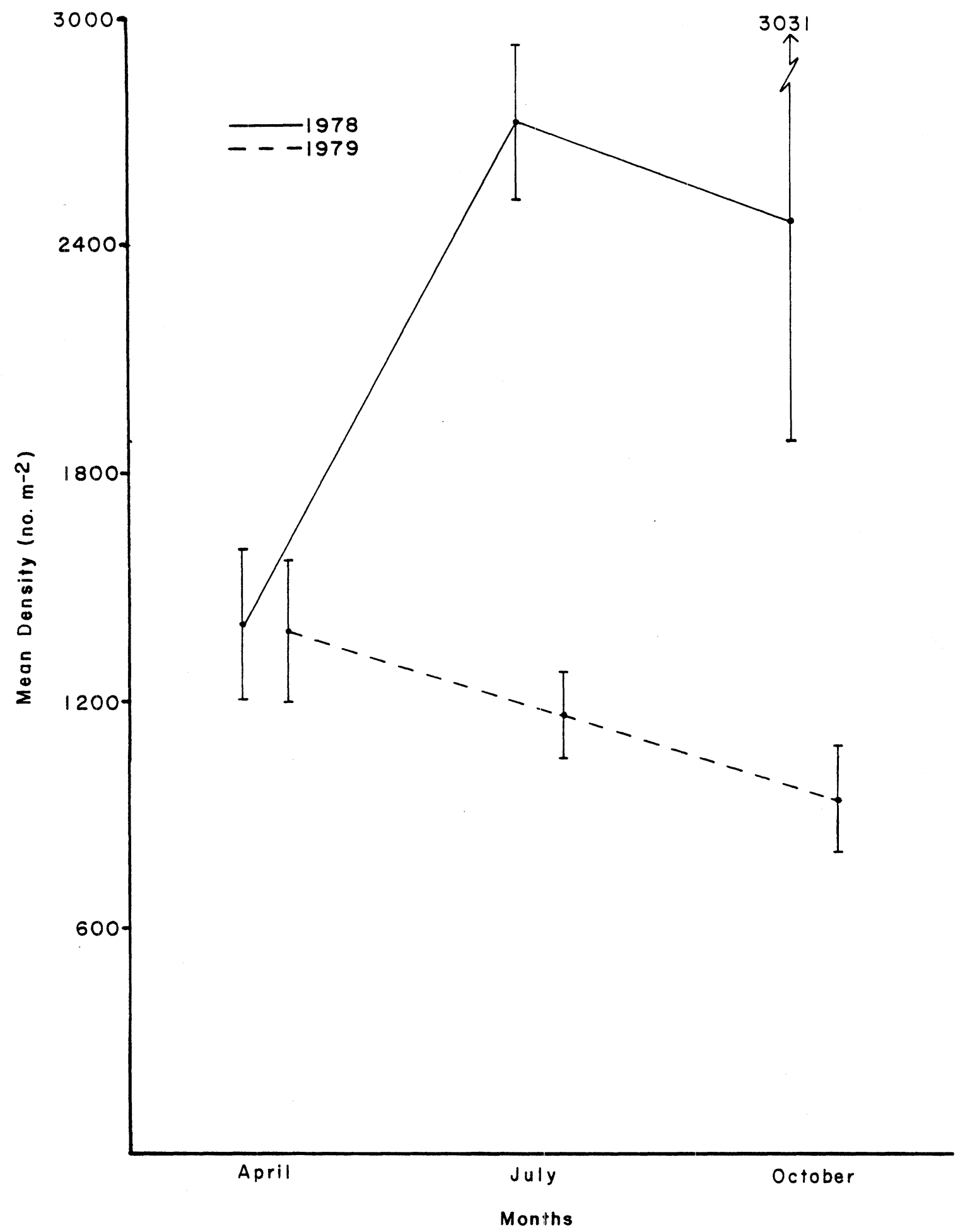

Fig. 6. Mean density (number $\mathrm{m}^{-2}$ ) of chironomids collected during April, July and October 1978 and 1979 in eastern Lake Michigan near the J. H. Campbell Plant. Density estimates for each month were computed by averaging over all depths within each year $(n=60)$. Standard error denoted by vertical bar. 
1978 values (Table 6). The 6-m average chironomid density was not significantly different between years, although densities were much lower in 1979 than 1978, due to the large variation associated with the 1978 6-m estimate. Overall, the 1979 annual mean chironomid density (1203 $\left.\mathrm{m}^{-2}\right)$ was significantly less than that observed during 1978 (2198 $\left.\mathrm{m}^{-2}\right)$.

Monthly mean density of chironomids was significantly lower in July 1979 when compared with July 1978. The October 1979, 6-m mean chironomid abundance was not different from the October 1978 estimate due to the large variation associated with the latter (Table 6).

Comparing inner and outer regional mean densities over all depths and months sampled during 1979, the outer region had a significantly greater number of chironomids than did the inner region. This difference was most evident during July (summed over all depths) and at $3 \mathrm{~m}$ (summed over all months) (Table 9). Analysis of July inner/outer regional mean chironomid densities indicated that during 1979, 3- and 6-m chironomid abundances were significantly greater in the outer when compared with inner region values (Table 10). No significant differences were found among remaining depths for July 1978/1979 comparisons. With respect to observed $3-m$ mean density differences for chironomids, however, the trend observed during July was also evident during April and October. Inner/outer comparisons for chironomids at $3 \mathrm{~m}$ indicated a consistent monthly trend of a decreasing inner region mean density and an increasing outer region mean density from 1978 to 1979. Chironomid abundances at remaining depths tended to increase or decrease in a similar manner from 1978 to 1979 (Fig. 7). Variation in percent occurrence of chironomid species within a given month between inner and outer regions was most extreme during July. The chironomid, Robackia cf. demeijerei, displayed the most consistent inner/outer difference of all chironomid species. The outer region had a consistently greater percent 


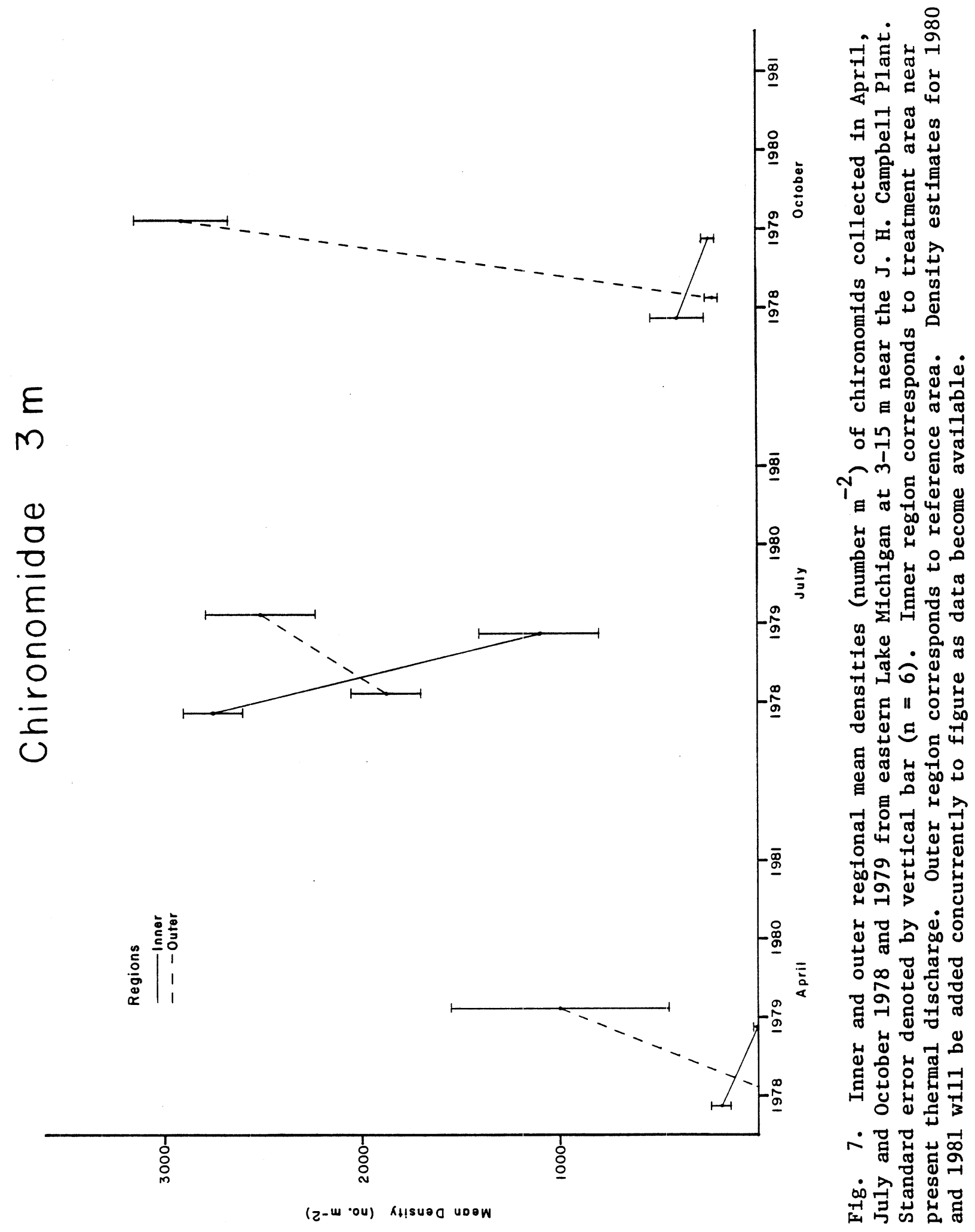



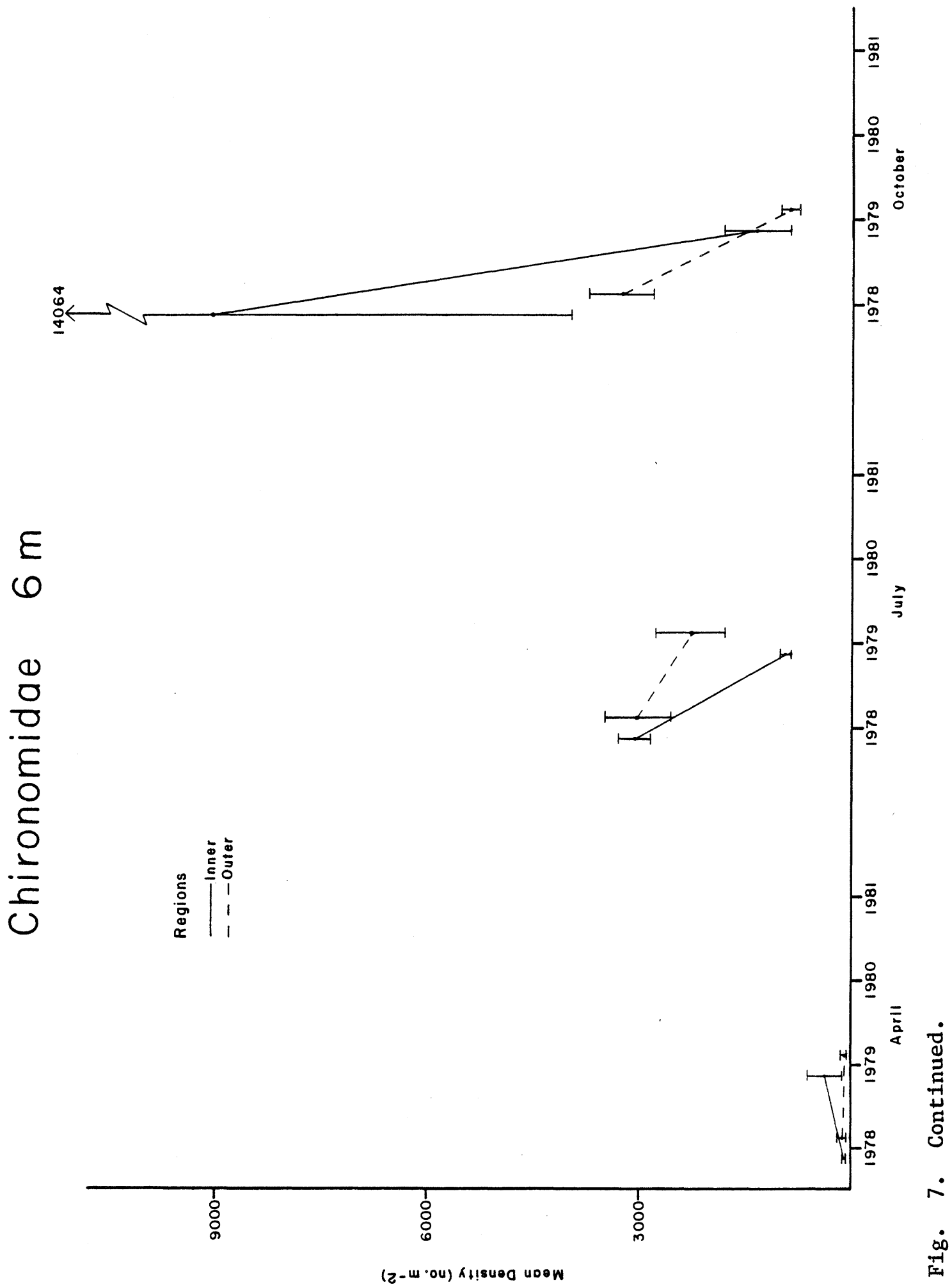


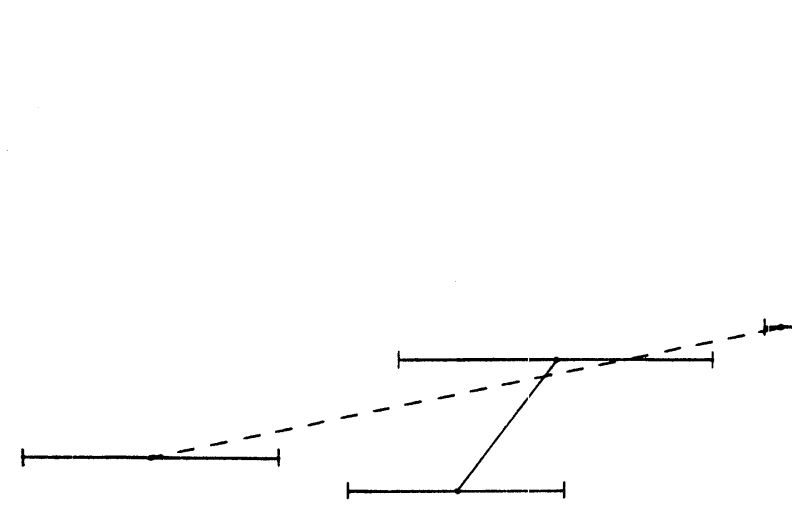

$\varepsilon$

(1)

0

$\frac{E}{0}$
$\frac{E}{0}$
$\frac{1}{\sigma}$
$\frac{1}{0}$

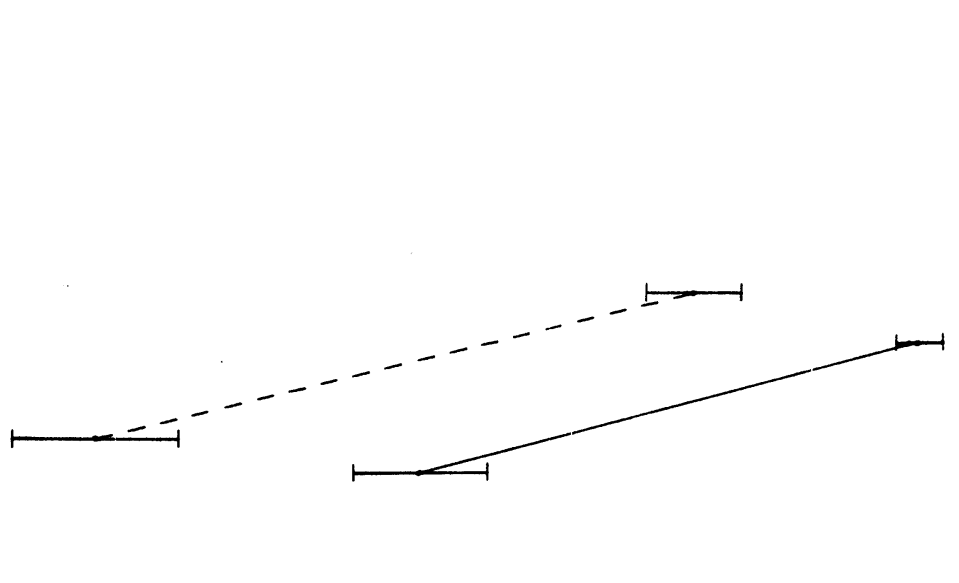

-

วิ

- 商

$-\stackrel{\infty}{2}$

是

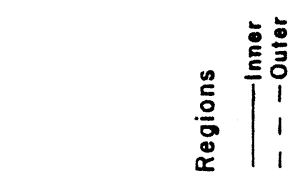




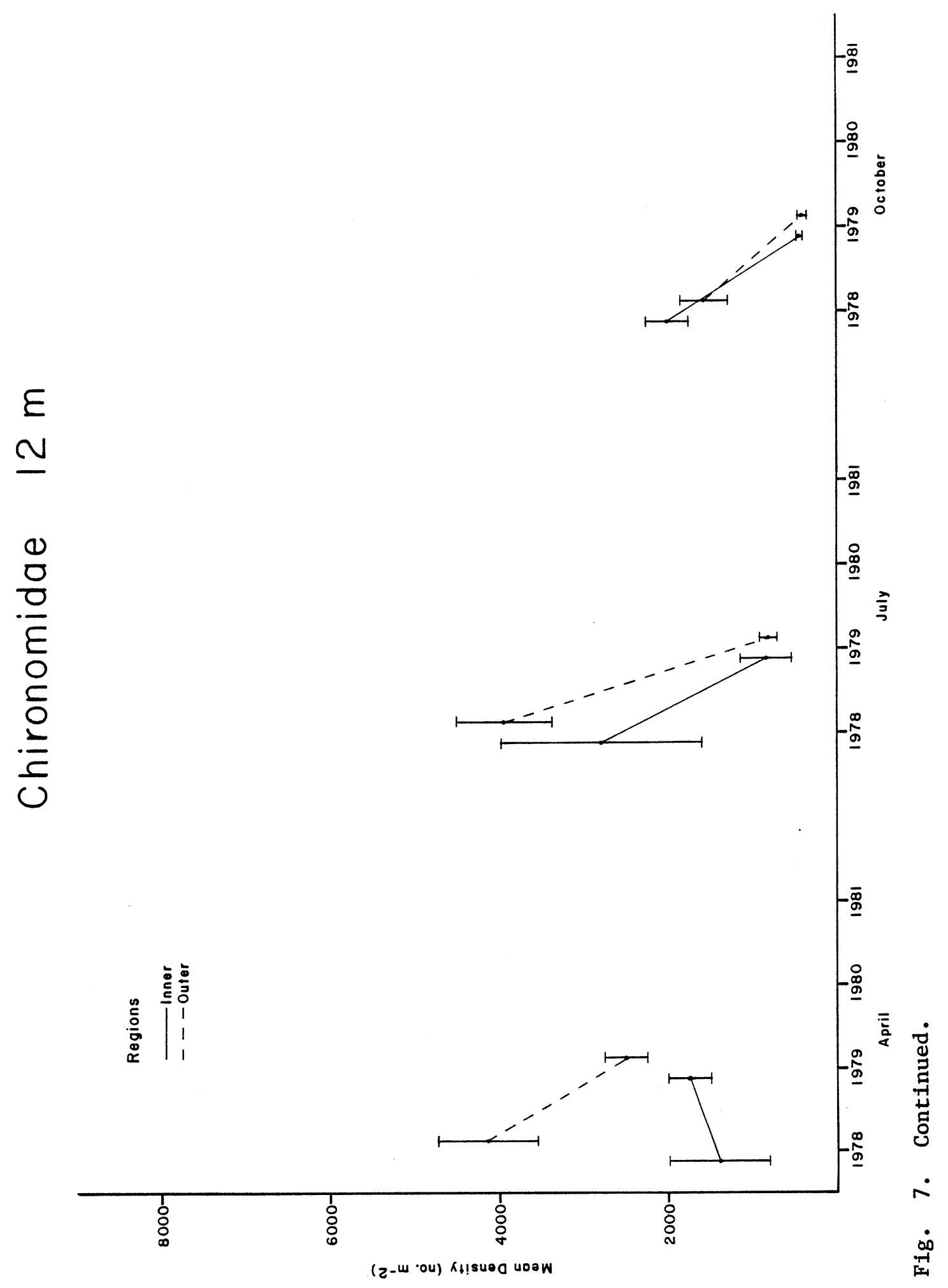




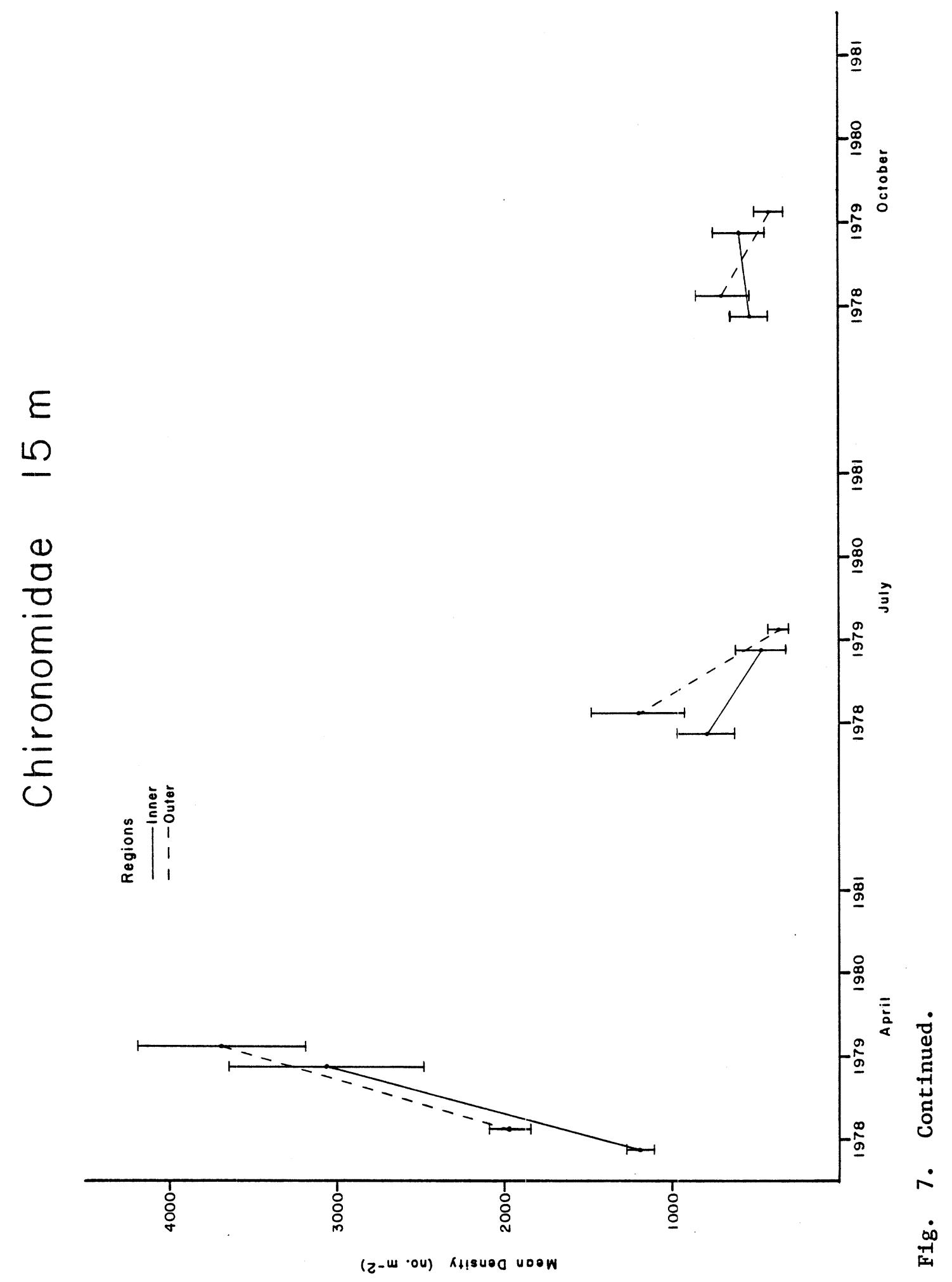


occurrence of $\underline{R}$. cf. demeijerei than the inner with this difference becoming more extreme with each month sampled. The absolute difference in this chironomid's density between regions was $10 \%$ in April, $32 \%$ in July, and $42 \%$ in October. Another chironomid species, Cryptochironomus sp. 1, that occurs with R. cf. demeijerei and comprised $3-7 \%$ of the overall chironomid density during July and October, also was notably absent from the inner region. With the exception of $\underline{R}$. cf. demeijerei, there were no obvious differences regarding percent occurrence among regions for chironomid species during April (Appendix 2).

In addition to regional differences observed for $\underline{R}$. cf. demeijerei and Cryptochironomus sp. 1, the inner region at 3-9 m during July had a disproportionate increase in percent occurrence of chironomid taxa normally found at finer sand depths ( $9-15 \mathrm{~m}$ ) when compared with the outer region ( $39 \%$ and $11 \%$, respectively). Chironomid species showing increases in the inner region at 3-9 m during July were Cyptochironomus sp. 2, Heterotrissocladius cf. changi, Hydrobaenus sp., Micropsectra sp., Monodiamesa cf. tuberculata, Polypedilum cf. scalaenum, Potthastia cf. longimanus, and Procladius sp. These same differences were observed in October but were reduced in intensity.

\section{NAIDIDAE}

Naidids comprised 22\% of the 1979 annual benthic density and occurred in $71 \%$ of the samples collected during 1979 (Table 11). Of 19 species of naidids collected from 1977 to 1979, 15 species were identified from the inner region and 14 species from the outer region during 1979 (Tables 3 and 4).

Compared with 1978, there was a change in naidid species composition in the survey area. Whereas in 1978 Piguetiella michiganensis (49\%), Chaetogaster diaphanus ( $17 \%)$, Stylaria lacustris (15\%), and Uncinais uncinata (12\%) were the most abundant naidid species, samples collected in 1979 were dominated by 
Vejdovskyella intermedia (52\%) and $\underline{P}$. michiganensis (23\%) (Appendix 3 ). All other naidid species comprised less than $10 \%$ of the annual naidid mean density. It also appeared that at $3 \mathrm{~m}$, in 1978 and 1979 combined, the inner region consistently supported a greater number of naidid species (10) than the outer region (4). While the first three of the four 3-m outer region naidid species

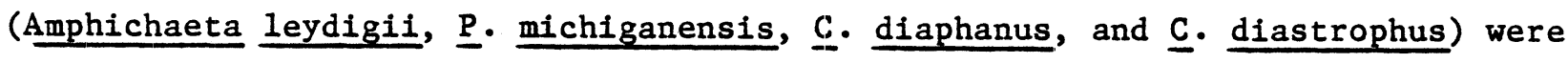
also found in the inner region, Nais elinguis, Nais pardalis, Nais simplex,

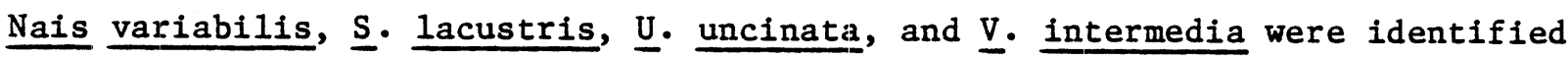
only from the inner region at $3 \mathrm{~m}$. However, all of the above naidid species, with the exception of $\mathrm{N}$. simplex, occurred at one or more other depths in both regions. Although all remaining depths had similar numbers of naidid species, there were additional qualitative reglonal differences which will be discussed after an analysis of quantitative annual and regional depth and monthly differences .

Mean annual density of naidids observed during $1979\left(1782 \mathrm{~m}^{-2}\right)$ was somewhat greater but not significantly different from 1978 average density (1134 $\mathrm{m}^{-2}$ ) (Table 6 ). The depth distributional pattern for naidids collected during both years followed the same pattern although there was a significant difference noted at $9 \mathrm{~m}$ (Fig. 8). Monthly naidid mean abundances were similar and followed the same trend during both years (Table 6, Fig. 9).

Annual within-region comparisons for year, month, or depth indicated that neither the 1979 inner nor outer naidid densities were significantly different from naidid densities in corresponding regions in 1978. Within 1979, although there were no regional naidid density differences for year, month, or at the 6-, 9-, 12-, and 15-m depths, there were significantly more naidids in the inner compared with the outer region at $3 \mathrm{~m}$ (Tables 7-9). Further analysis of regional naidid density differences at each depth sampled in each month 


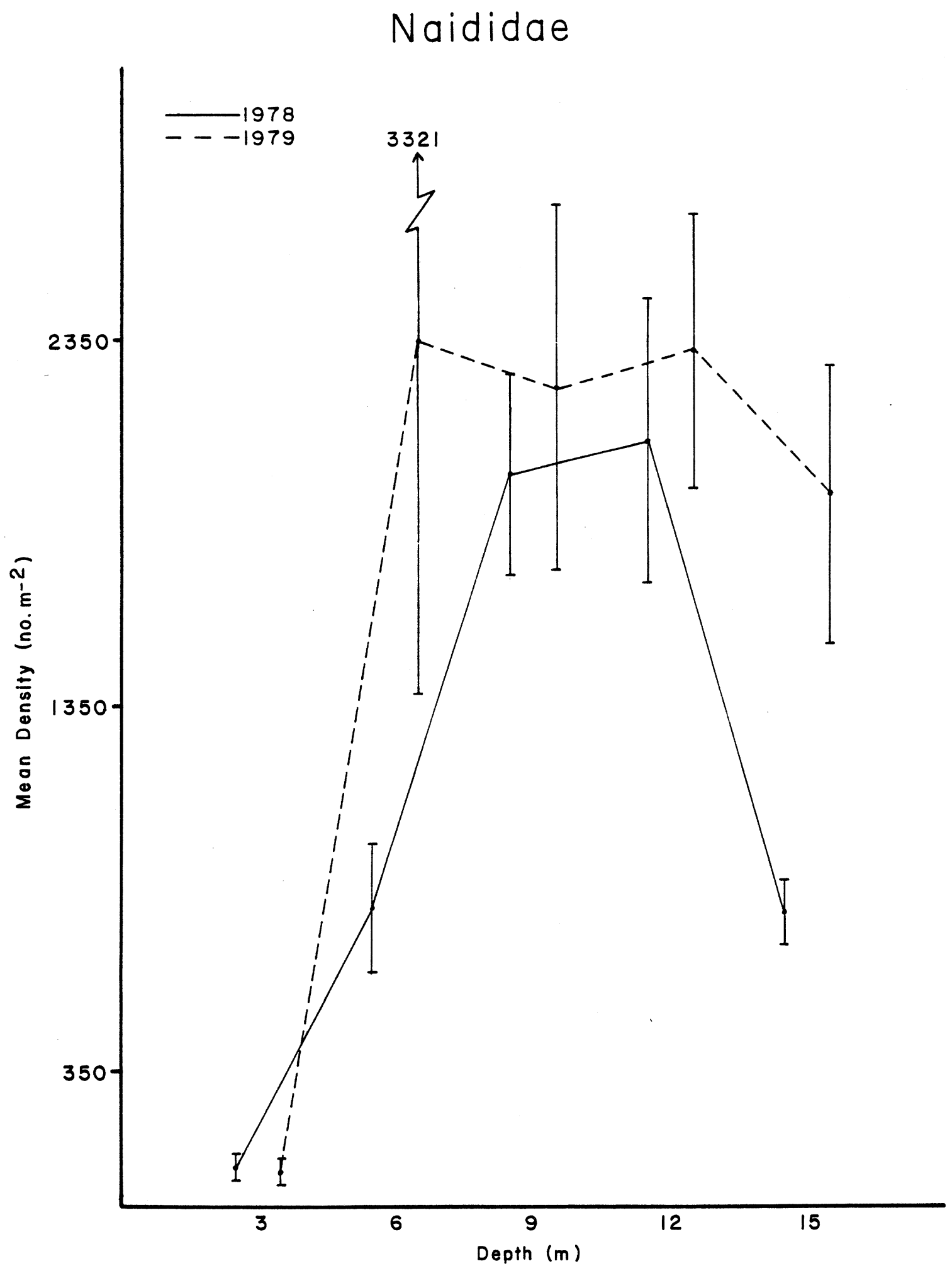

Fig. 8. Mean density (number $\mathrm{m}^{-2}$ ) of naidids collected at 3-15 m during 1978 and 1979 in eastern Lake Michigan near the J. H. Campbell Plant. Density estimates at each depth were computed by averaging over all months within each year $(n=36)$. Standard error denoted by vertical bar. 


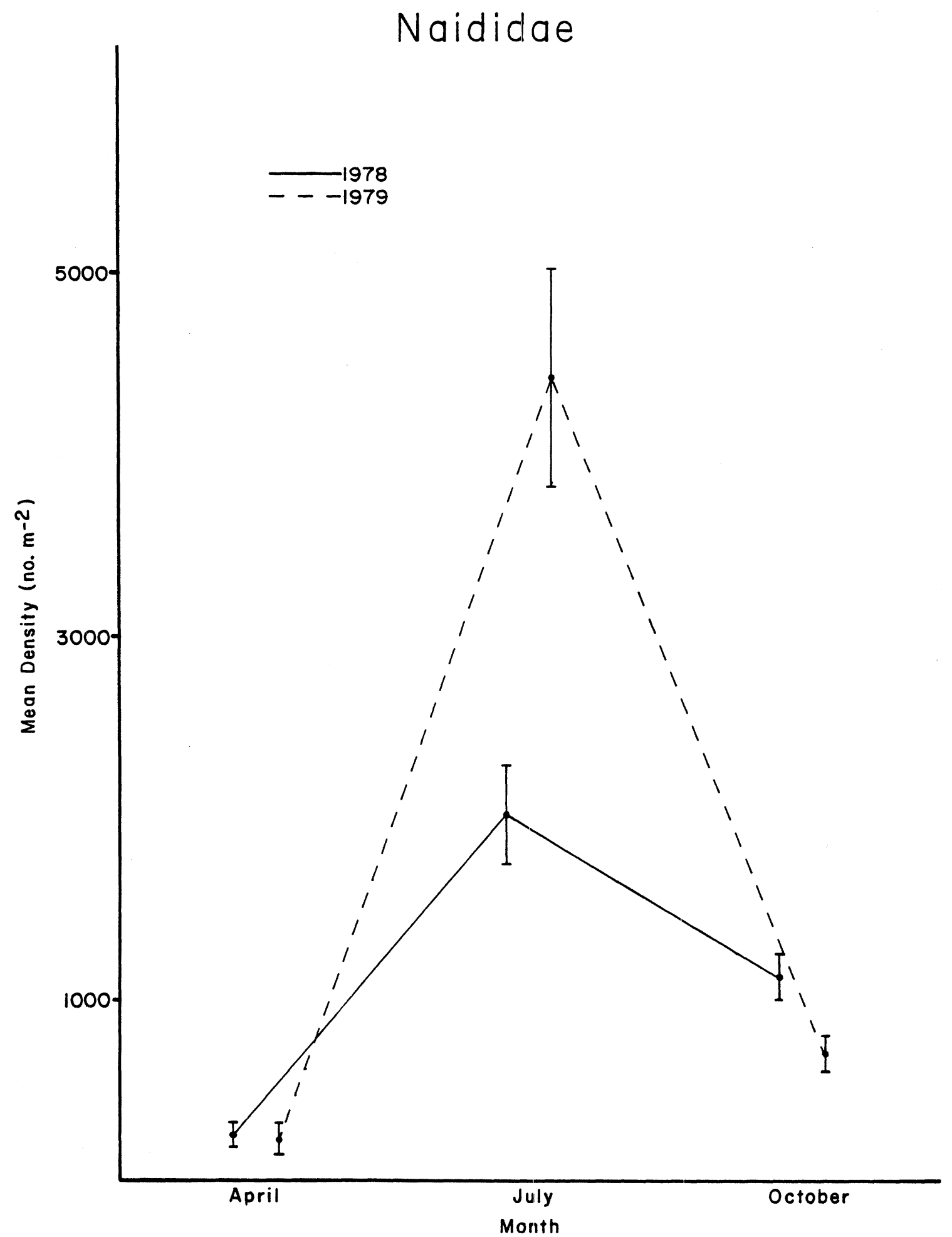

Fig. 9. Mean density (number $\mathrm{m}^{-2}$ ) of naidids collected during April, July and October 1978 and 1979 in eastern Lake Michigan near the J. H. Campbell Plant. Density estimates for each month were computed by averaging over all depths within each year $(n=60)$. Standard error denoted by vertical bar. 
indicated the pattern observed at $3 \mathrm{~m}$ during July 1978 was maintained in July 1979 (Table 10). Naidid densities at $3 \mathrm{~m}$ in July were consistently greater in the inner region compared with the outer region in both years (Fig. 10). However, during July 1978 at $3 \mathrm{~m}$ the naidid species, Uncinais uncinata, was the dominant naidid taxon (70\%); whereas, during 1979, Vejdovskyella intermedia (39\%) and Amphichaeta leydigii (33\%) were dominant. Dominance of U. uncinata at 3-9 $\mathrm{m}$ in 1978 was replaced by $\underline{\mathrm{V}}$. intermedia in 1979, particularly during July when $\underline{U}$. uncinata was most abundant. Comparing inner and outer regions and combining the 3-9-m depths during July 1979 indicated that $\underline{\mathrm{V}}$. intermedia was also an abundant species in the outer region ( $32 \%)$, but not to the extent it was in the inner region (77\%). In the inner region, $\underline{\mathrm{V}}$. intermedia and $\underline{A}$. leydigii comprised $89 \%$ of the July naidid mean density at $3-9 \mathrm{~m}$. In the outer region, the same two species comprised only $33 \%$ Other naidid species such as C. diaphanus $(35 \%)$, $\underline{U}$. uncinata $(10 \%), \underline{P}$. michiganensis $(9 \%)$, and $\underline{S}$. lacustris ( $9 \%)$ comprised significant portions of the naidid abundance when considered separately or as a whole at 3-9 $\mathrm{m}$ in the outer region during July 1979 . These four naidid species comprised $94 \%$ of the inner naidid density and $98 \%$ of the outer naidid density at 3-9 m combined during July 1978, while $\underline{\mathrm{V}}$ intermedia and $\underline{A}$. leydigii comprised $3 \%$ and $1 \%$ of the inner and outer naidid densities, respectively, at the same depth and time period. The 1979 percentage of naidid density for these species at 3-9 $\mathrm{m}$ in the outer region (63\%) more closely approximated 1978 outer region estimates (98\%) than did 1978 (94\%) and 1979 (8\%) inner region percentage comparisons. Significant inner/outer regional naidid mean density differences observed at 3-9 m during July 1979 were due to larger increases of $\mathrm{V}$. intermedia in the inner compared with the outer region. Additional significant differences in mean abundance of naidids observed between inner/outer regions at $15 \mathrm{~m}$ in July and $9 \mathrm{~m}$ in October were due to the 

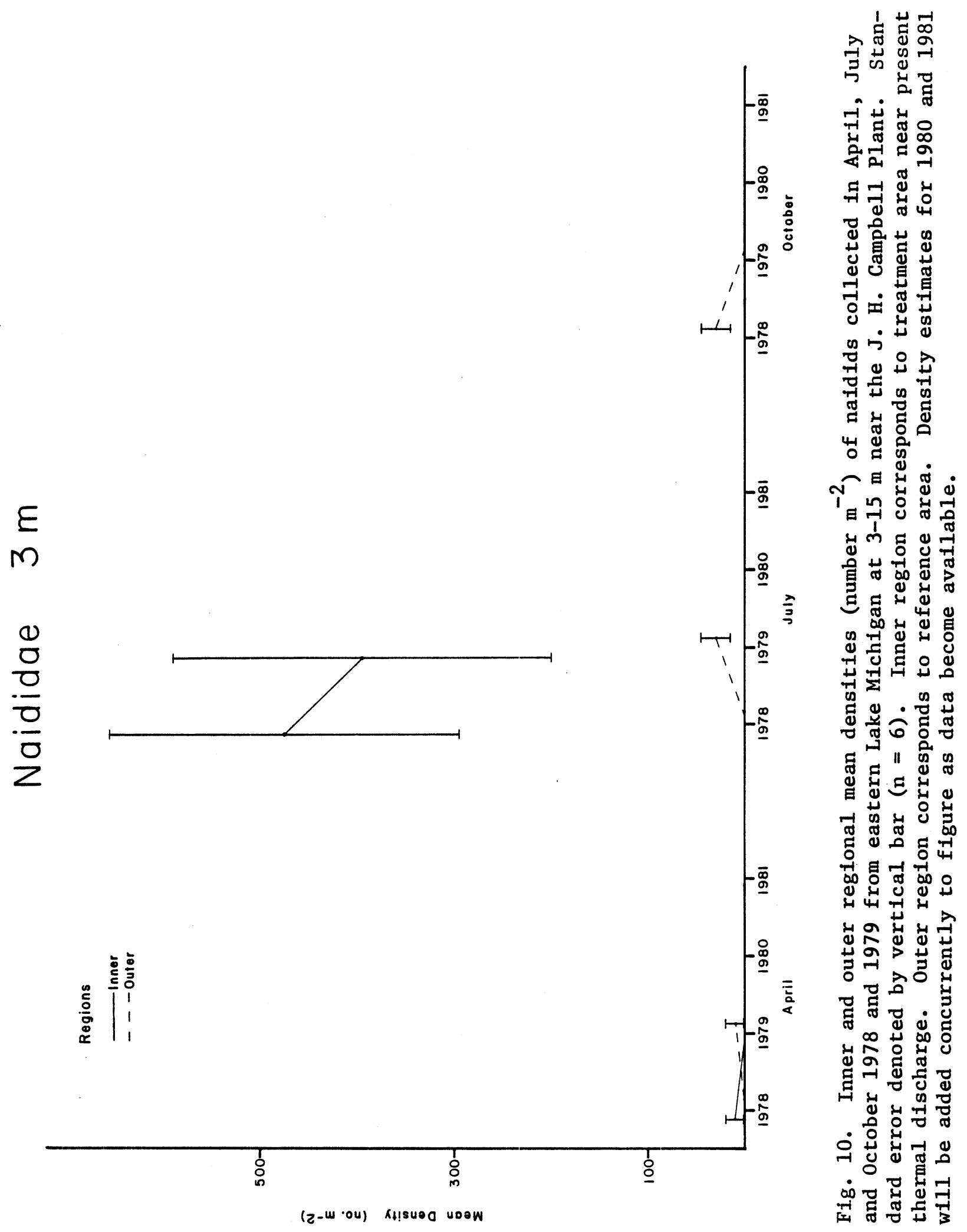


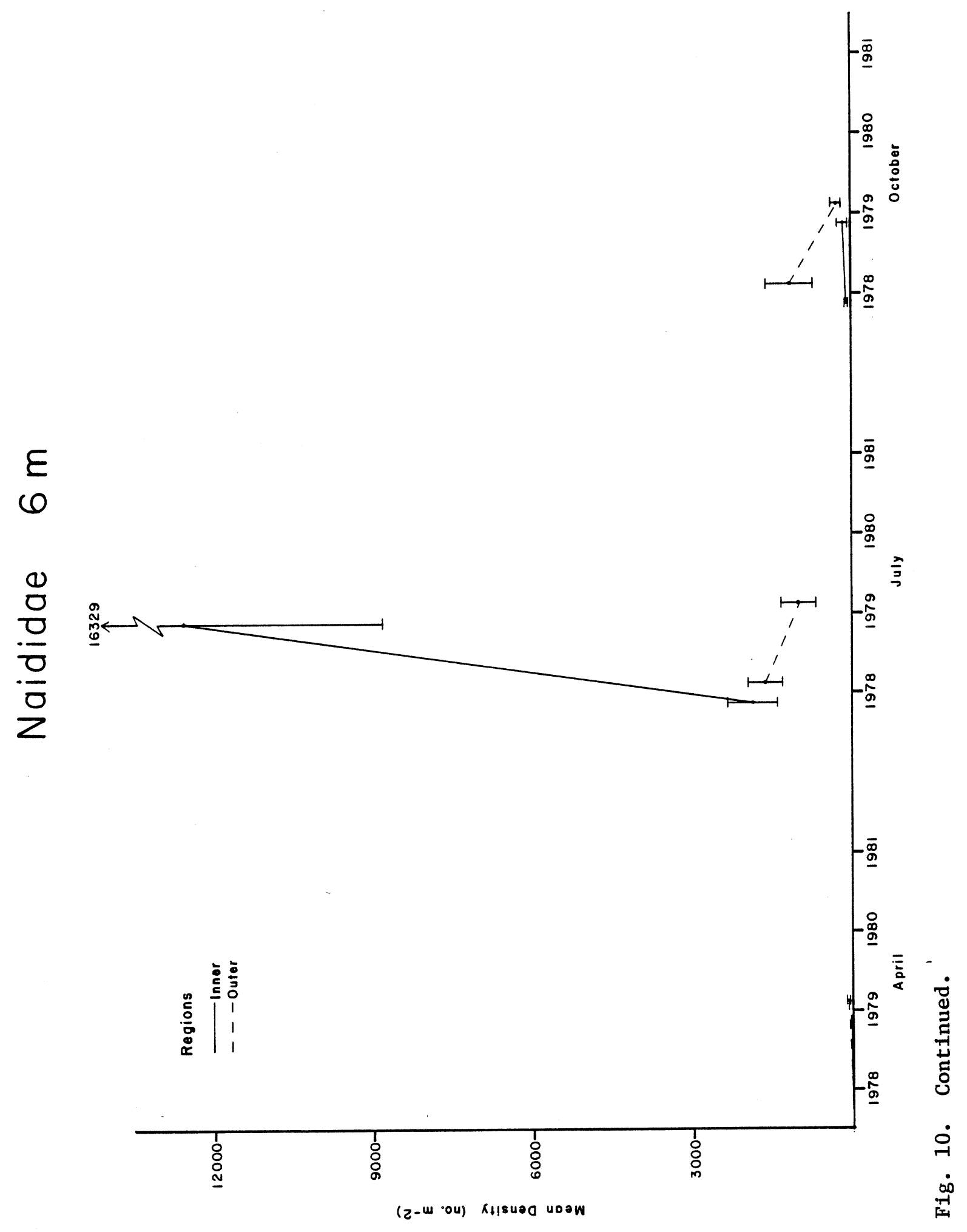




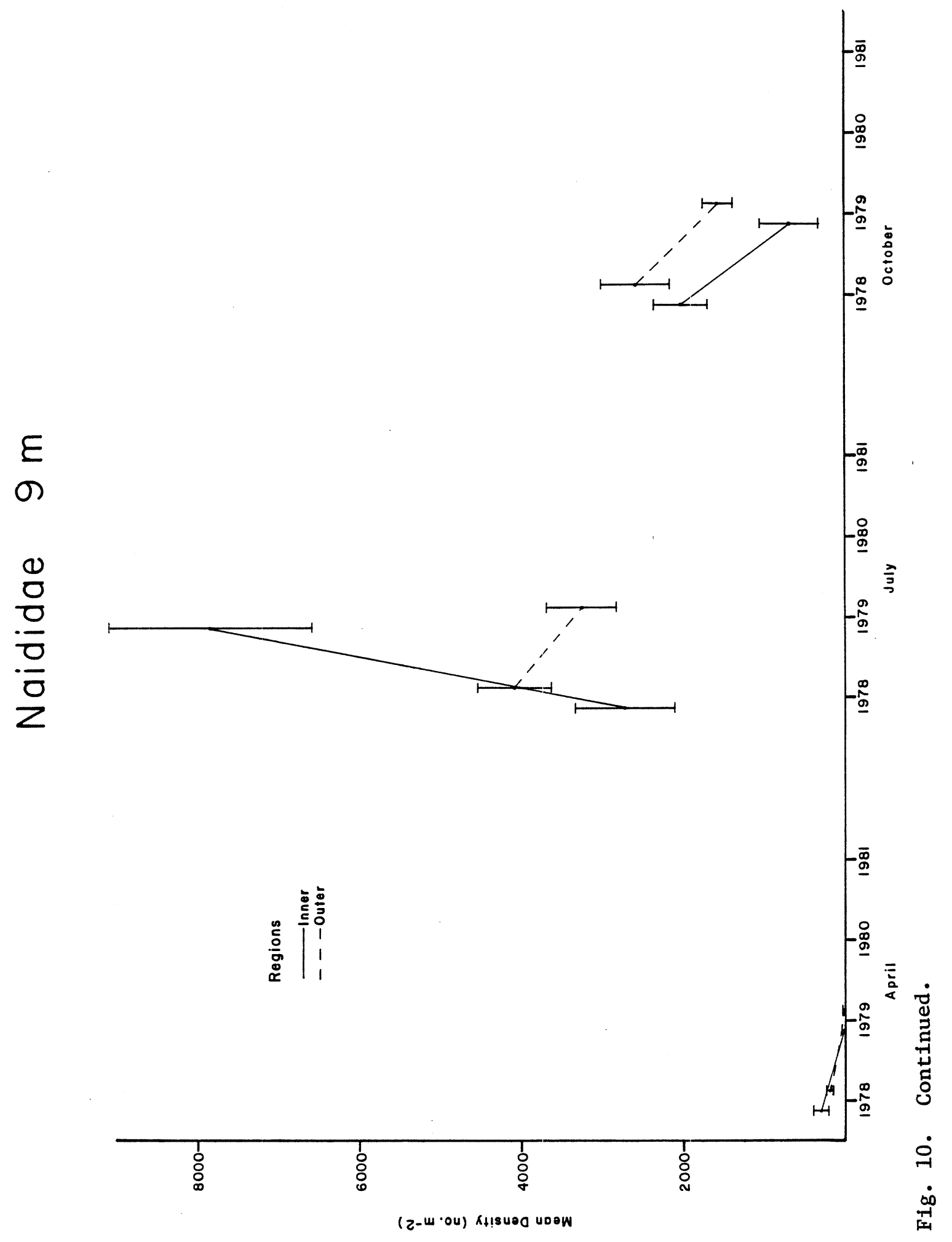




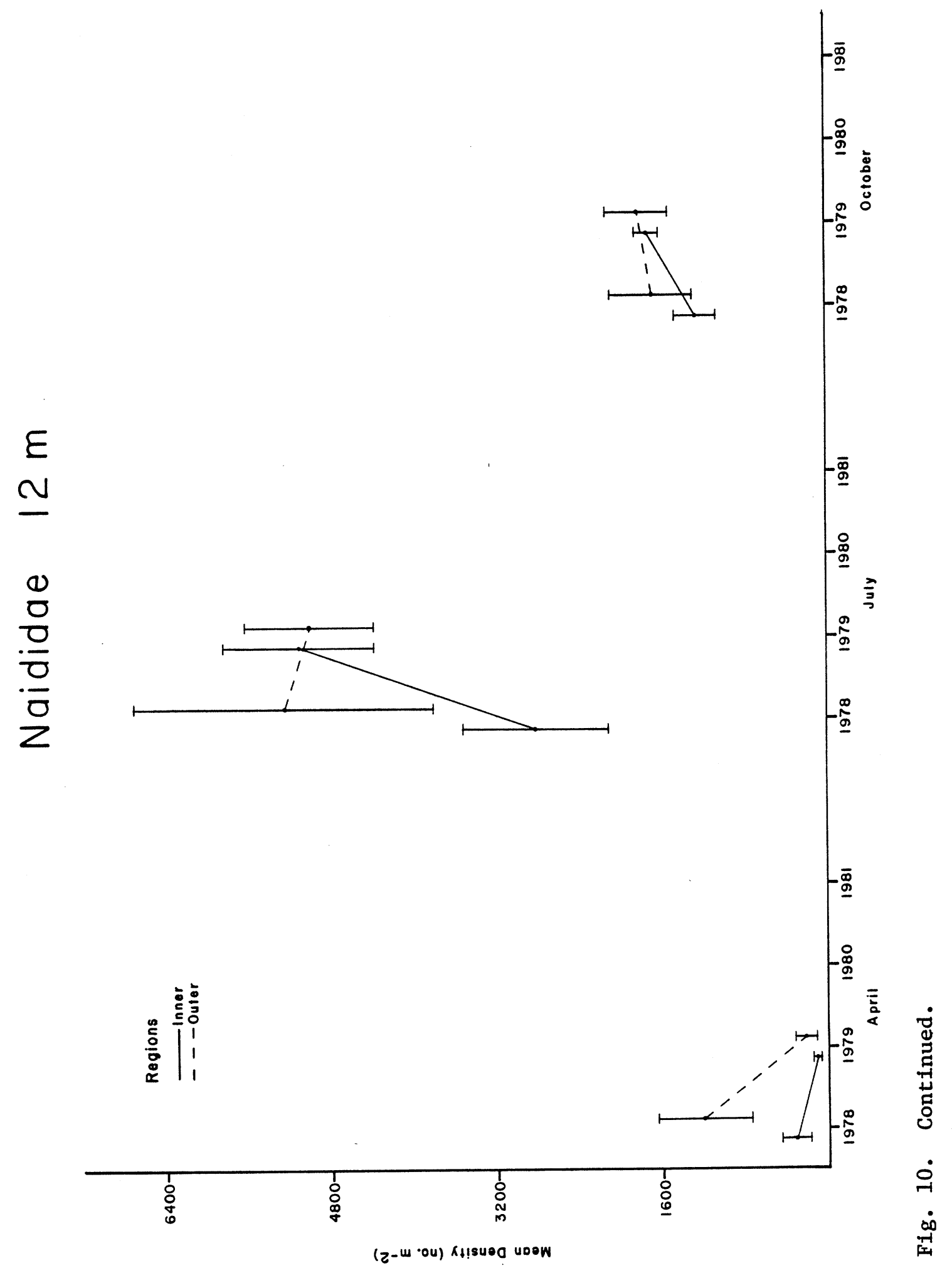




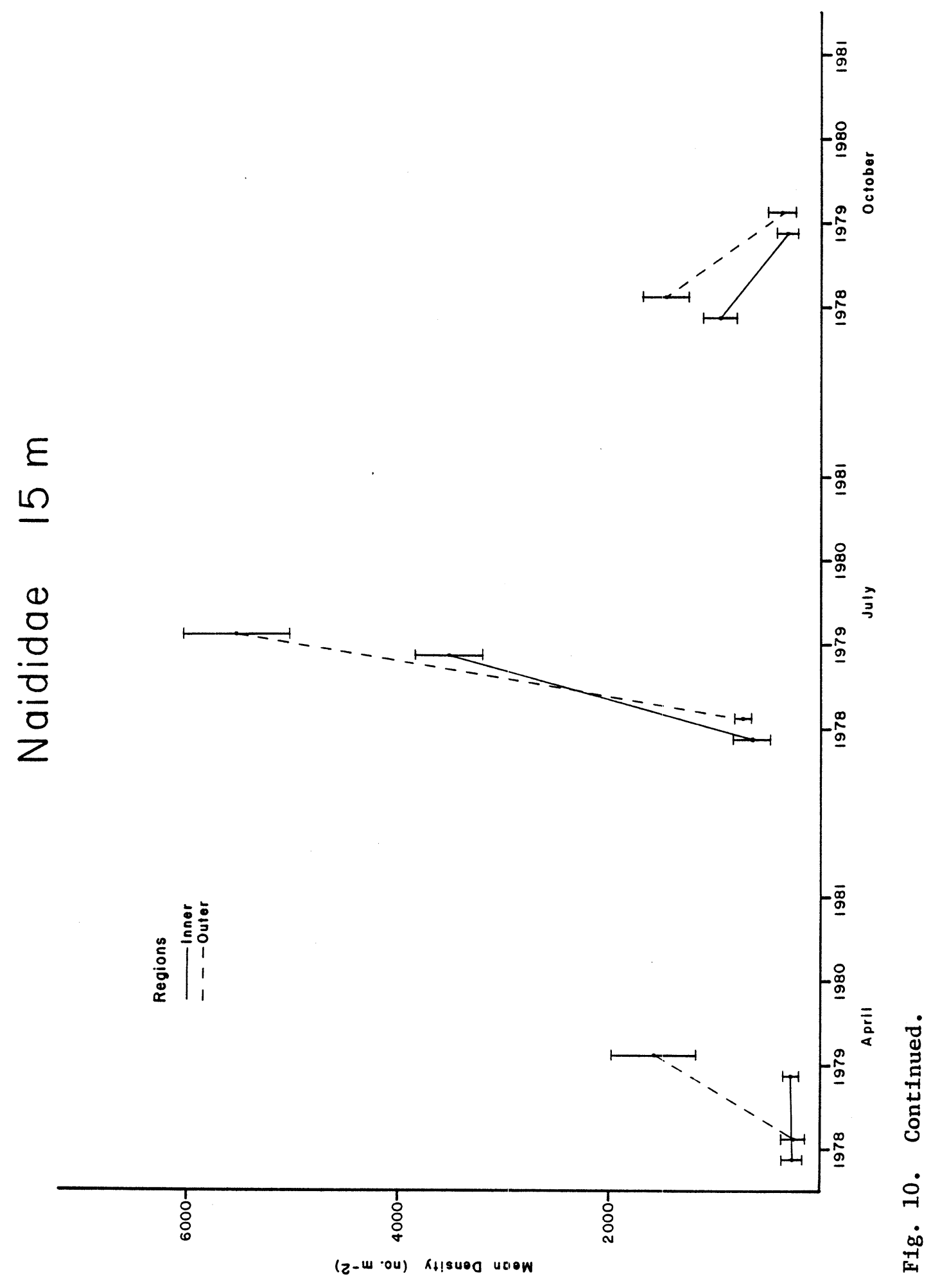


much greater numbers of $\underline{\mathrm{P}}$. michiganensis present in the outer region compared with the inner region. Exclusive of the above observed differences, all other comparisons were not significantly different and exhibited consistently increasing or decreasing trends across regions.

\section{TUB IF IC IDAE}

Tubificids comprised 9\% of the 1979 annual mean benthic density and occurred in $64 \%$ of the samples collected (Table 11). Thirteen species of tubificids have been identified from 1977 to 1979 (Table 3). The most numerous of nine tubificid species collected in 1979 was Potamothrix moldaviensis, having an annual mean density of $21 \mathrm{~m}^{-2}$. Although tubificids were more numerous in $1978\left(859 \mathrm{~m}^{-2}\right)$ than during $1979\left(735 \mathrm{~m}^{-2}\right)$, there was no significant difference between estimated annual densities (Table 6). While the depth distribution of tubificids was similar between years, there were significantly more tubificids present at $9 \mathrm{~m}$ in 1978 when compared with 1979 and at $15 \mathrm{~m}$ in 1979 compared with 1978 (Fig. 11, Table 6). The tubificid density difference found at 9 and $15 \mathrm{~m}$ between years was related to yearly regional depth differences. Monthly mean densities for 1978 and 1979 followed similar seasonal abundance trends with no significant differences noted among respective monthly tubificid abundance comparisons (Fig. 12).

Tubificids exhibited similar abundances in the outer region from 1978 to 1979 and in the inner region from 1978 to 1979 (Tables 7 and 8). In the outer region tubificids were significantly more numerous at 9 and $15 \mathrm{~m}$ in 1979 than in 1978. Overall, the outer region had significantly more tubificids (1485 $\mathrm{m}^{-2}$ ) than did the inner region $\left(903 \mathrm{~m}^{-2}\right.$ ) based on a yearly average over the combined depths $9-15 \mathrm{~m}$.

The difference between 1979 inner and outer regions was most apparent during July (averaged over 9-15 m) and at $15 \mathrm{~m}$ (averaged over all months) 


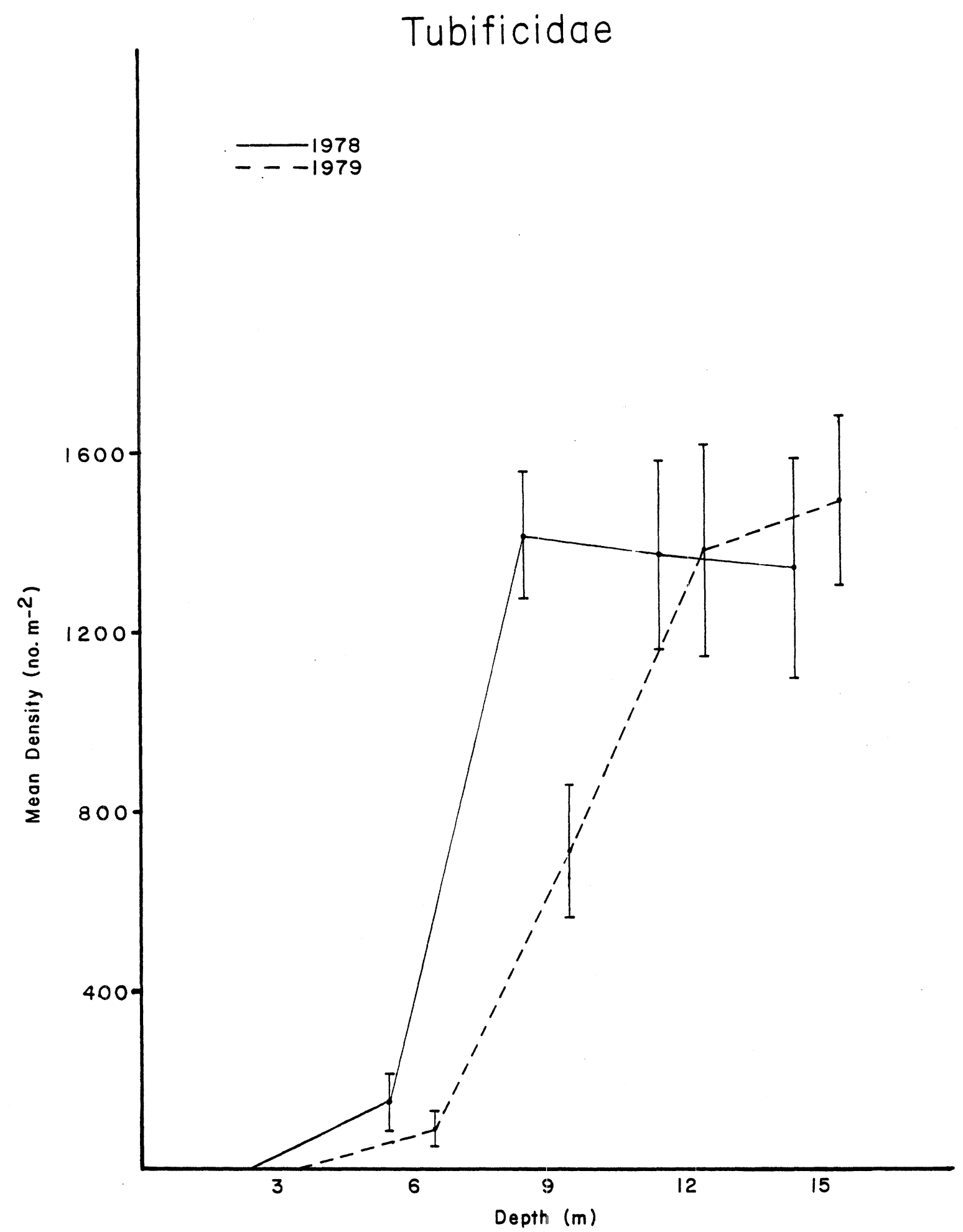

Fig. 11. Mean density (number $\mathrm{m}^{-2}$ ) of tubificids collected at 3-15 $\mathrm{m}$ during 1978 and 1979 in eastern Lake Michigan near the J. H. Campbell Plant. Density estimates at each depth were computed by averaging over all months within each year $(n=36)$. Standard error denoted by vertical bar. 


\section{Tubificidae}

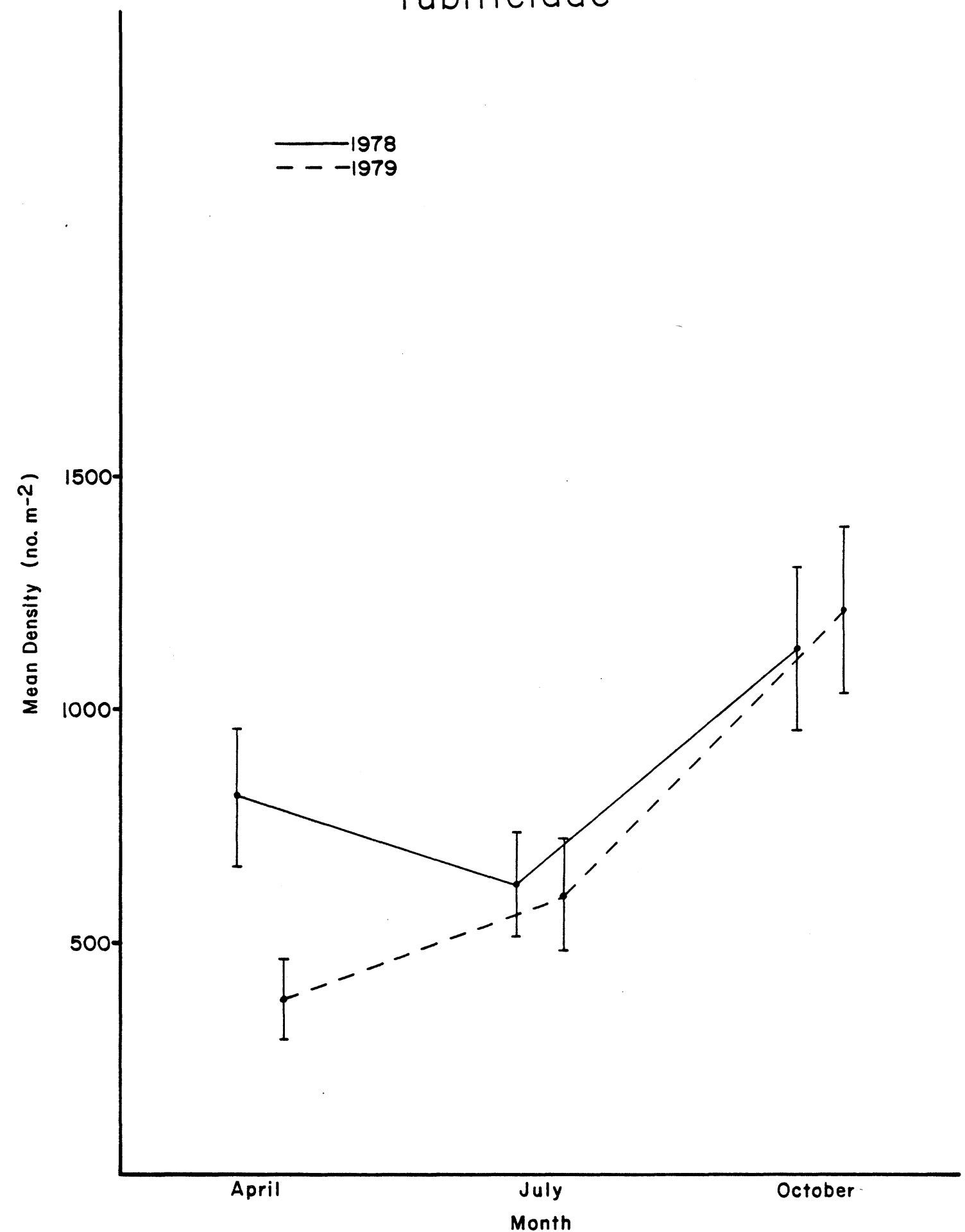

Fig. 12. Mean density (number $\mathrm{m}^{-2}$ ) of tubificids collected during April, July and October 1978 and 1979 in eastern Lake Michigan near the J. H. Campbell Plant. Density estimates for each month were computed by averaging over all depths within each year $(n=60)$. Standard error denoted by vertical bar. 
(Fig. 13). During July, there were significantly more tubificids observed in the outer region for the combined depths 9-15 m when compared with the inner region (Table 9). Averaging over months, the greatest density difference was observed at $15 \mathrm{~m}$ where outer region tubificids were more numerous than those in the inner region. Specific comparisons between 1979 inner/outer tubificid densities within each month at each depth sampled indicated that only at $15 \mathrm{~m}$ during April and October were there significant density differences (Table 10). Inner/outer trends paralleled one another from 1978 to 1979 at 9 and $12 \mathrm{~m}$, but were in opposing directions during April and October 1.979 at $15 \mathrm{~m}$ (Fig. 13).

\section{TURBELLARIA}

Turbellarians occurred in $64 \%$ of the samples collected during 1979 (Table 11), but comprised only 6\% of the 1979 annual mean density of macroinvertebrates. Two morphologically different turbellarian species were identified, with species 1 found primarily at $3-9 \mathrm{~m}$ and species 2 at 9-15 m during all months (Appendix 1). Compared with 1978, there were significantly more turbellarians collected during 1979, which may reflect increased recognition of nearshore species 1 turbellarians. Turbellarian density differences between 1978 and 1979 were significant at 3, 6, and 15 m (Fig. 14). In addition, during April and July, significant increases in turbellarian mean density were observed (Fig. 15, Table 6); however, with respect to 1979 monthly inner/outer regional mean density comparisons over all depths combined $(3-15 \mathrm{~m})$, no difference in turbellarian abundance was found. When turbellarian abundance was averaged over all months at each depth in 1979, the only significant difference occurred at $3 \mathrm{~m}$ where the outer region mean density was greater than the inner region mean density (Table 9). Inner/outer density trends tended to be in the same direction from 1978 to 1979 (Fig. 16). 


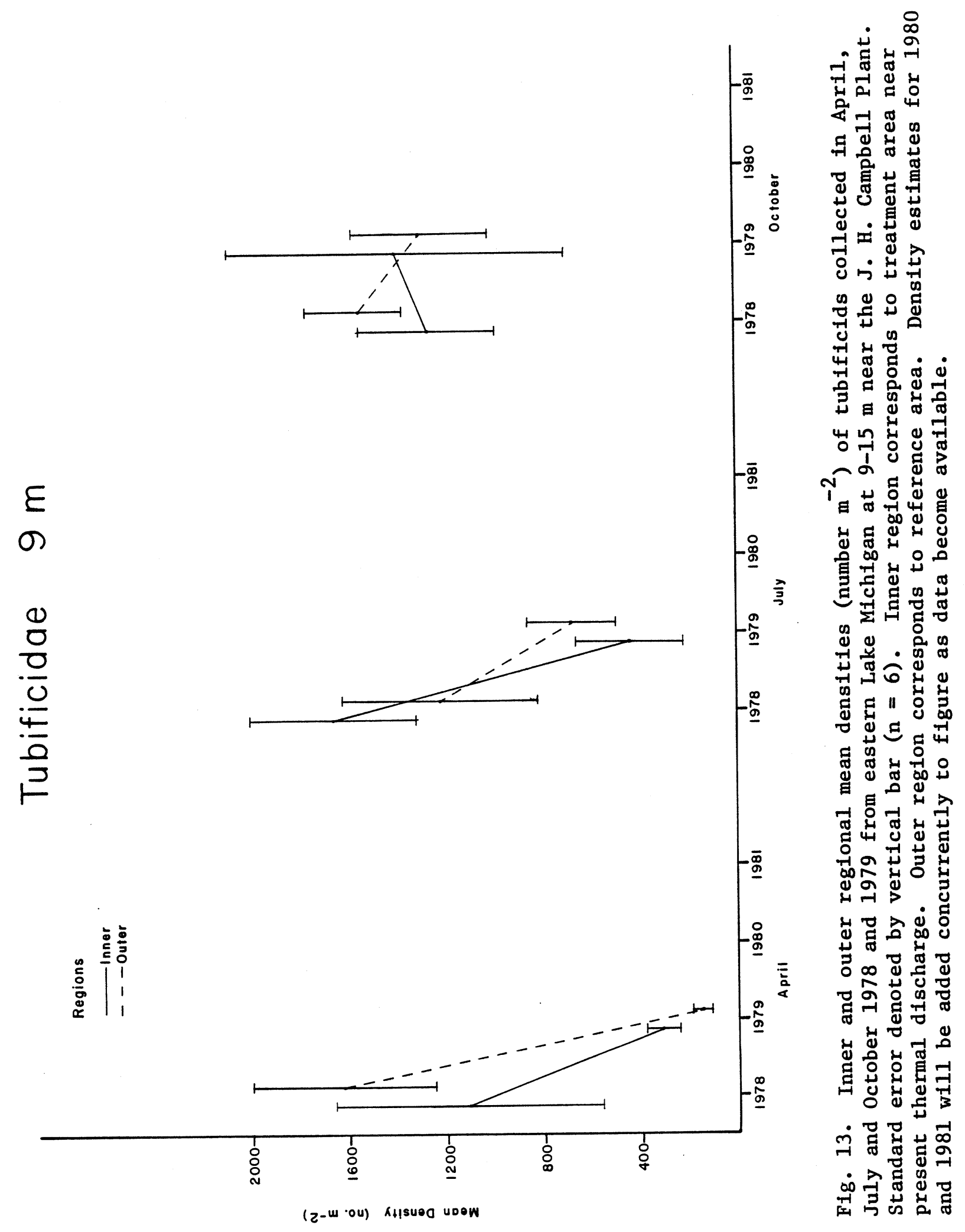



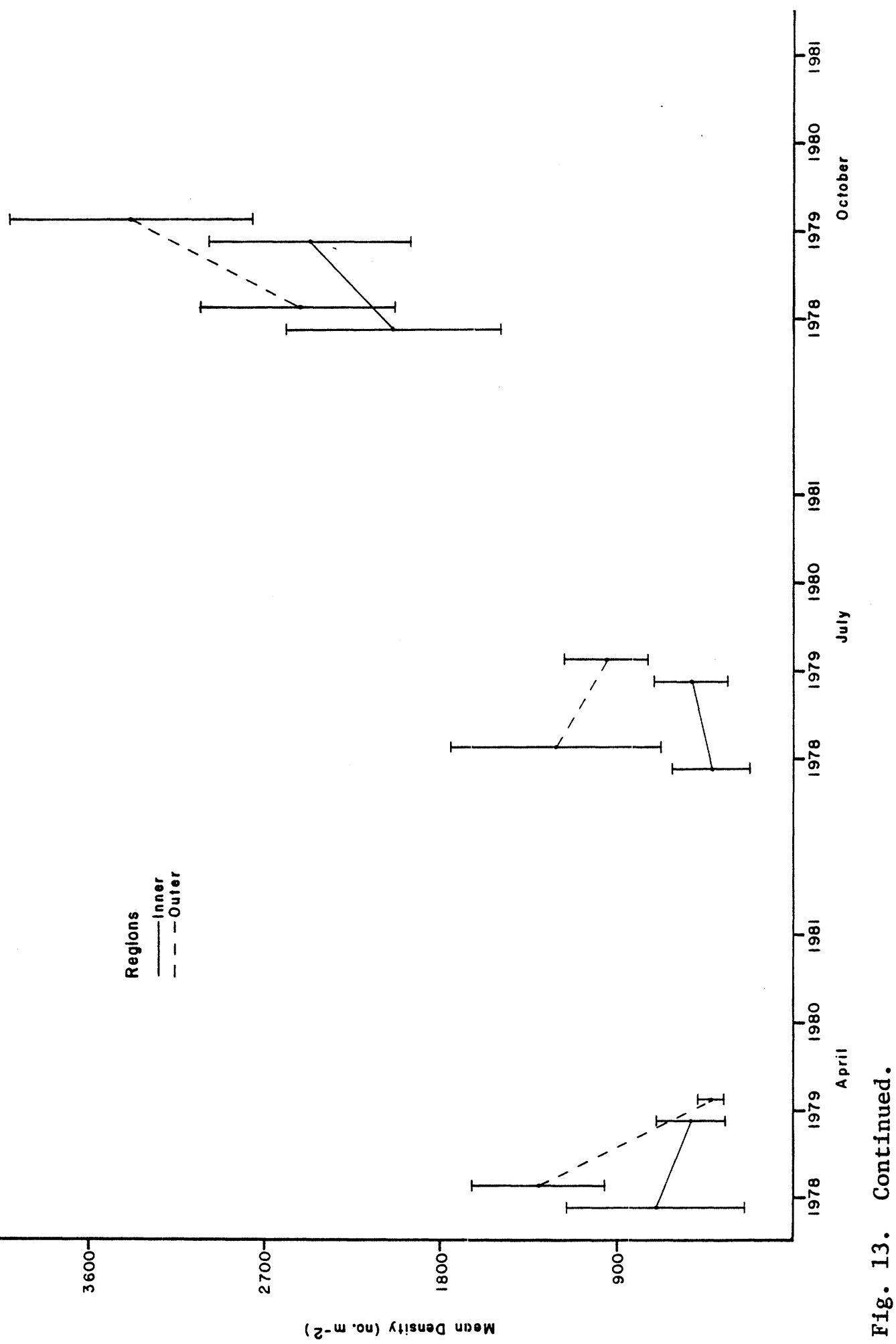


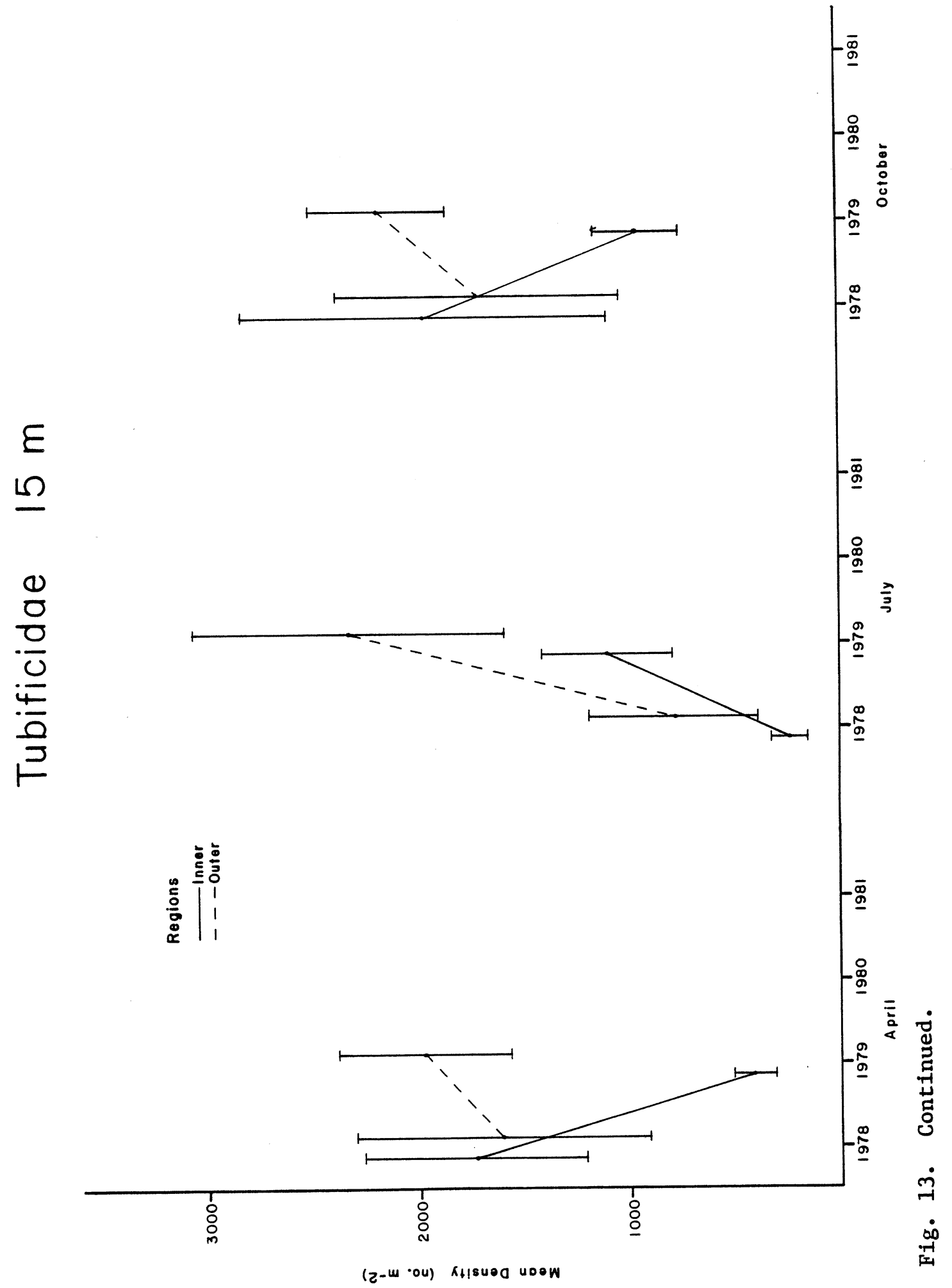




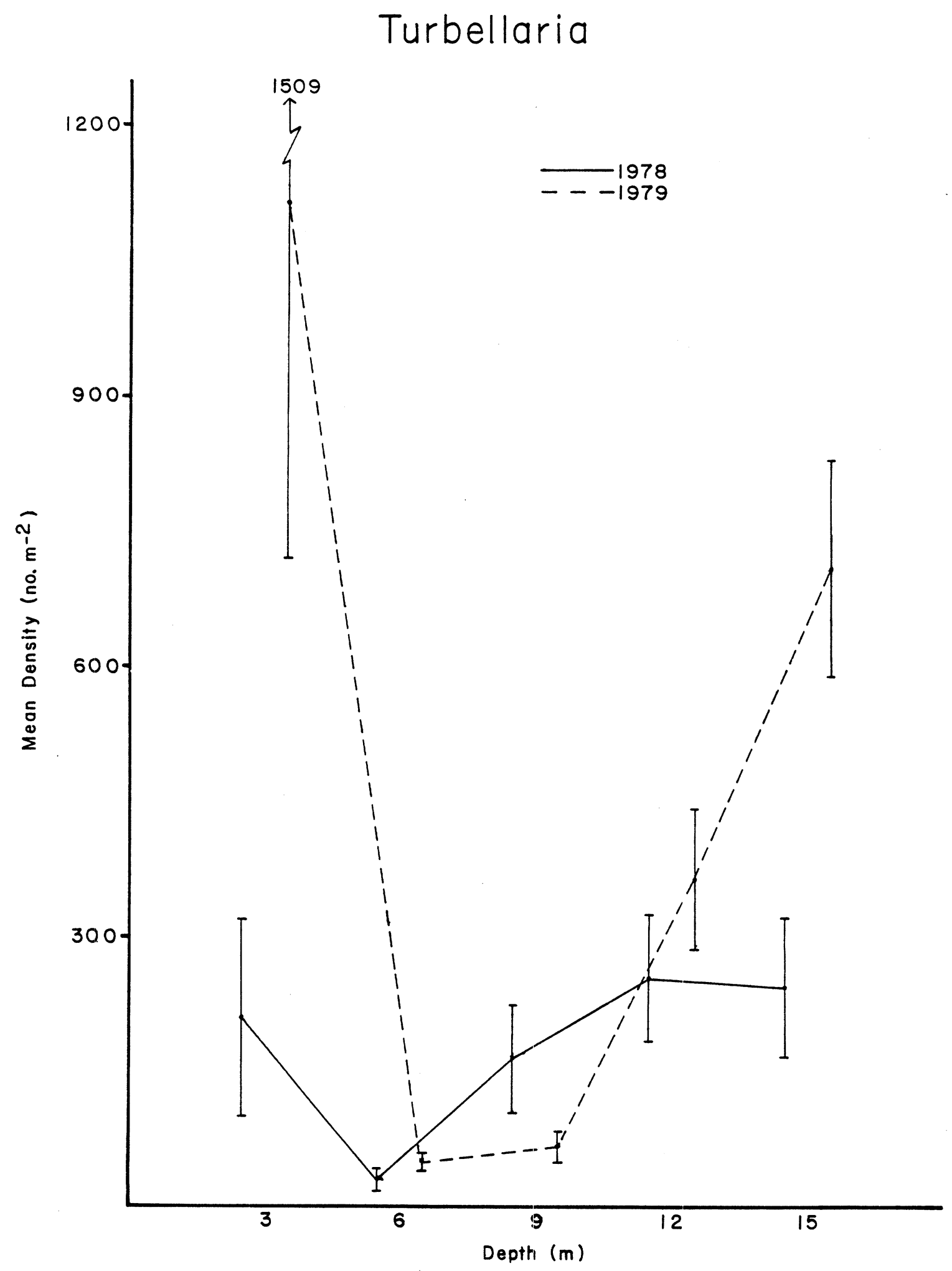

Fig. 14. Mean density (number $\mathrm{m}^{-2}$ ) of turbellarians collected at 3-15 m during 1978 and 1979 in eastern Lake Michigan near the J. H. Campbell Plant. Density estimates at each depth were computed by averaging over all months within each year $(n=36)$. Standard error denoted by vertical bar. 


\section{Turbellaria}

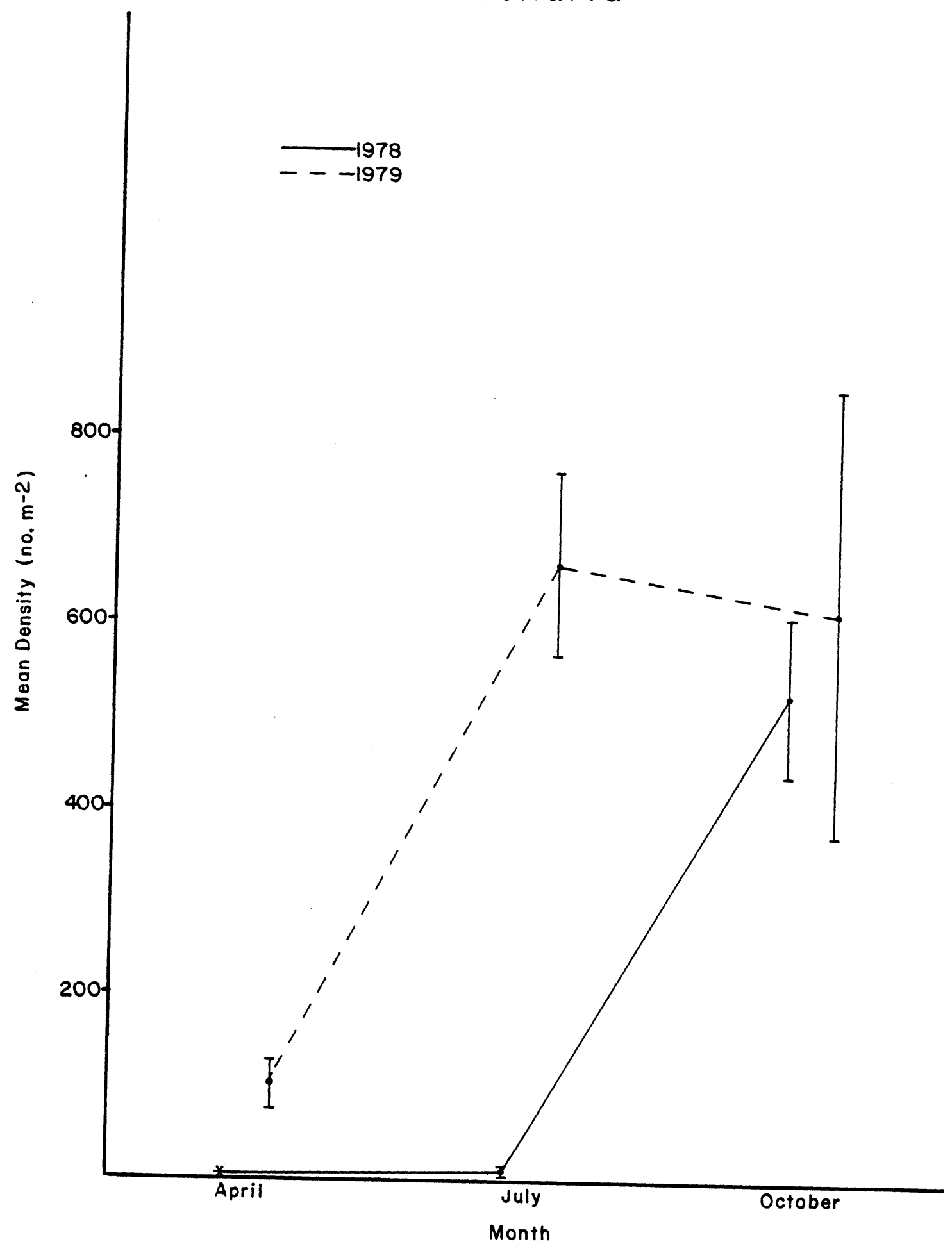

Fig. 15. Mean density (number $\mathrm{m}^{-2}$ ) of turbellarians collected during April, July and October 1978 and 1979 in eastern Lake Michigan near the J. H. Campbell Plant. Density estimates for each month were computed by averaging over all depths within each year $(n=60)$. Standard error
denoted by vertical bar. 


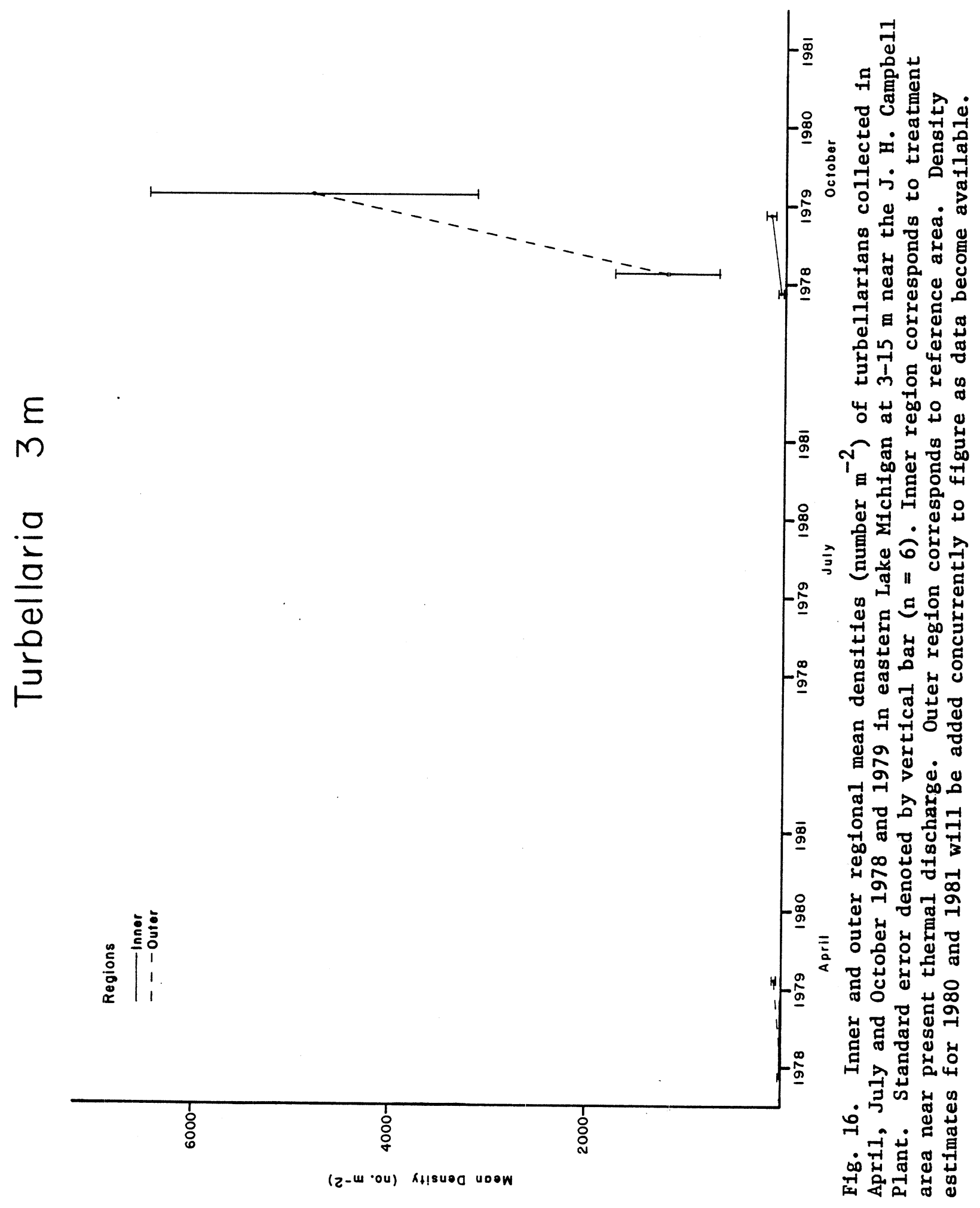




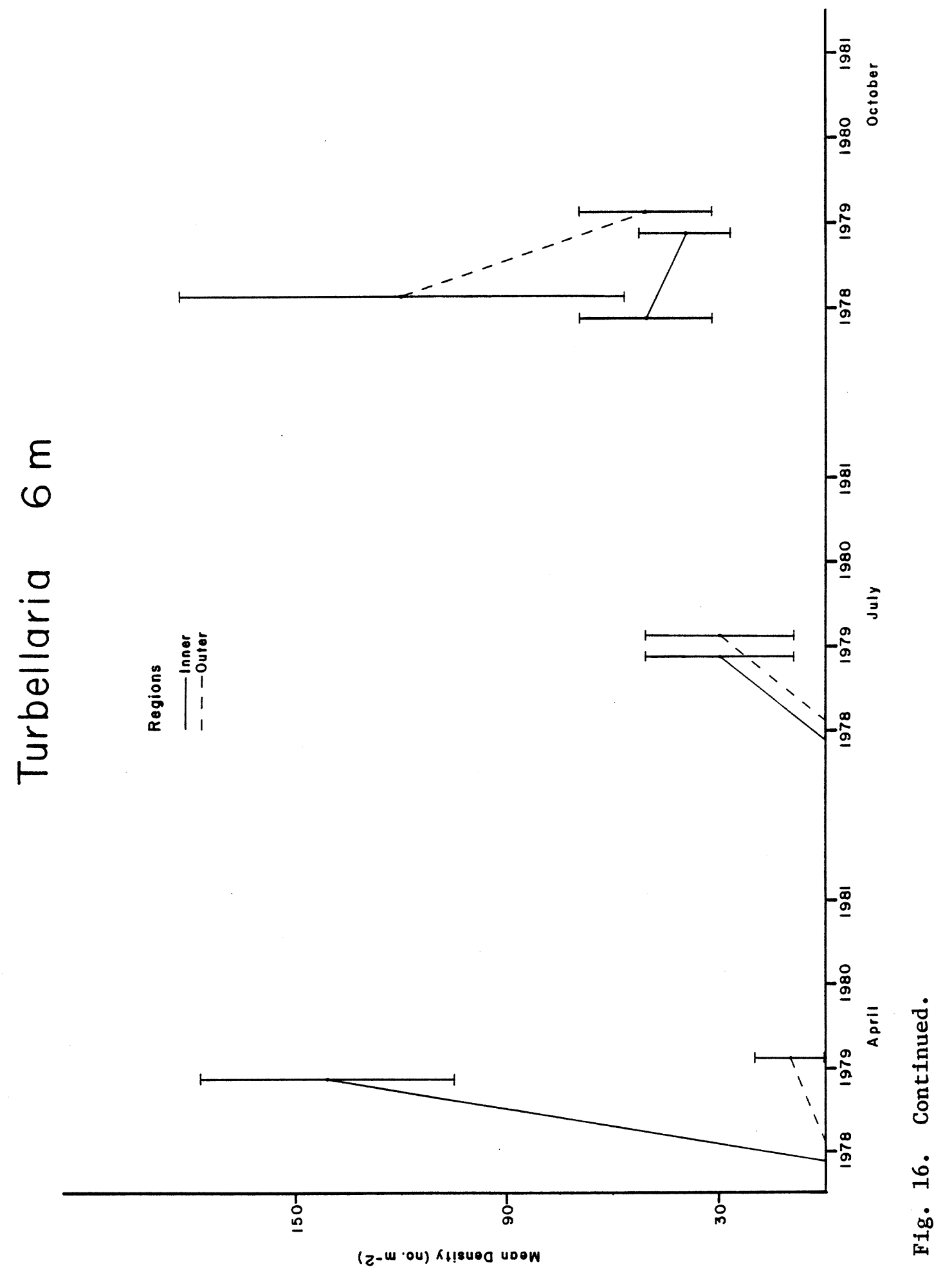



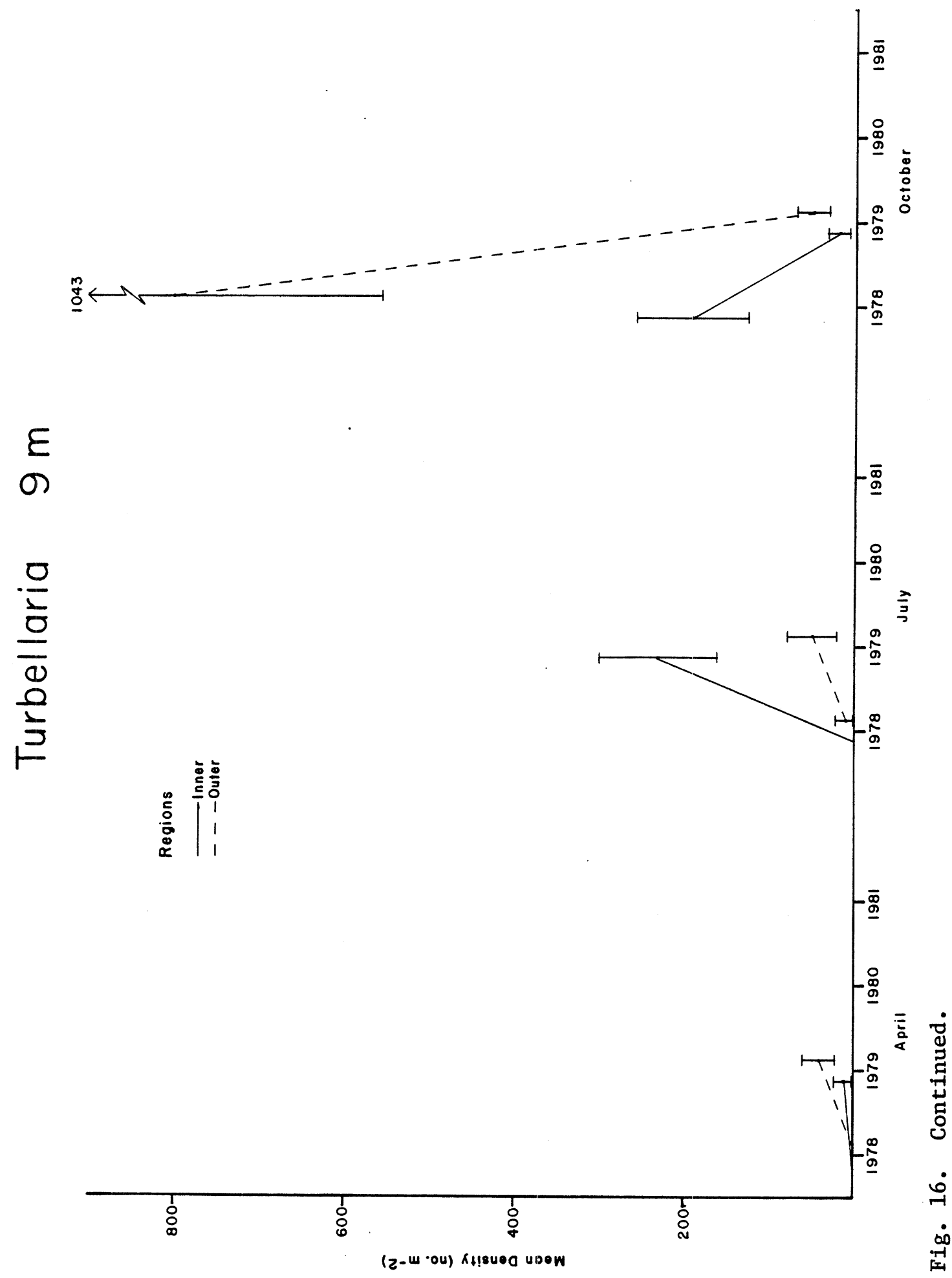


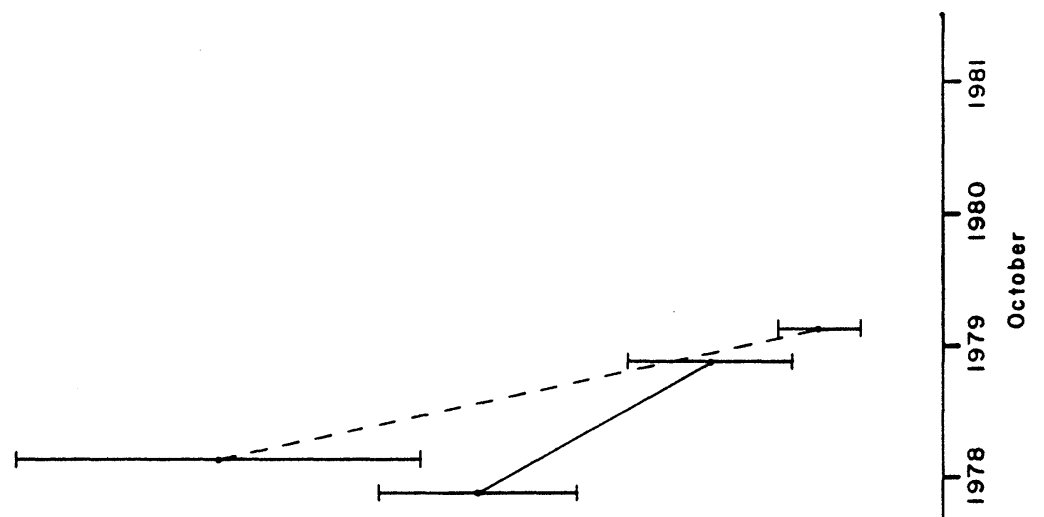

$E$
$\simeq$
$ㅁ$
$\frac{0}{1}$
$\frac{\overline{0}}{0}$
$\frac{0}{\partial}$

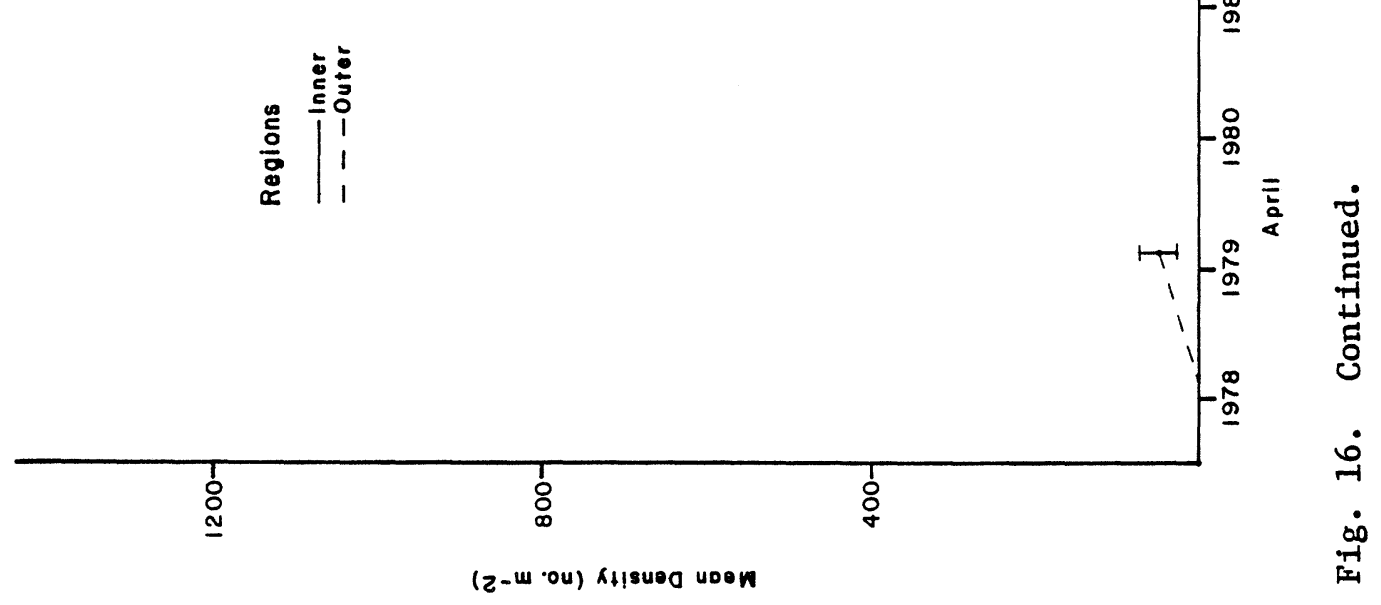




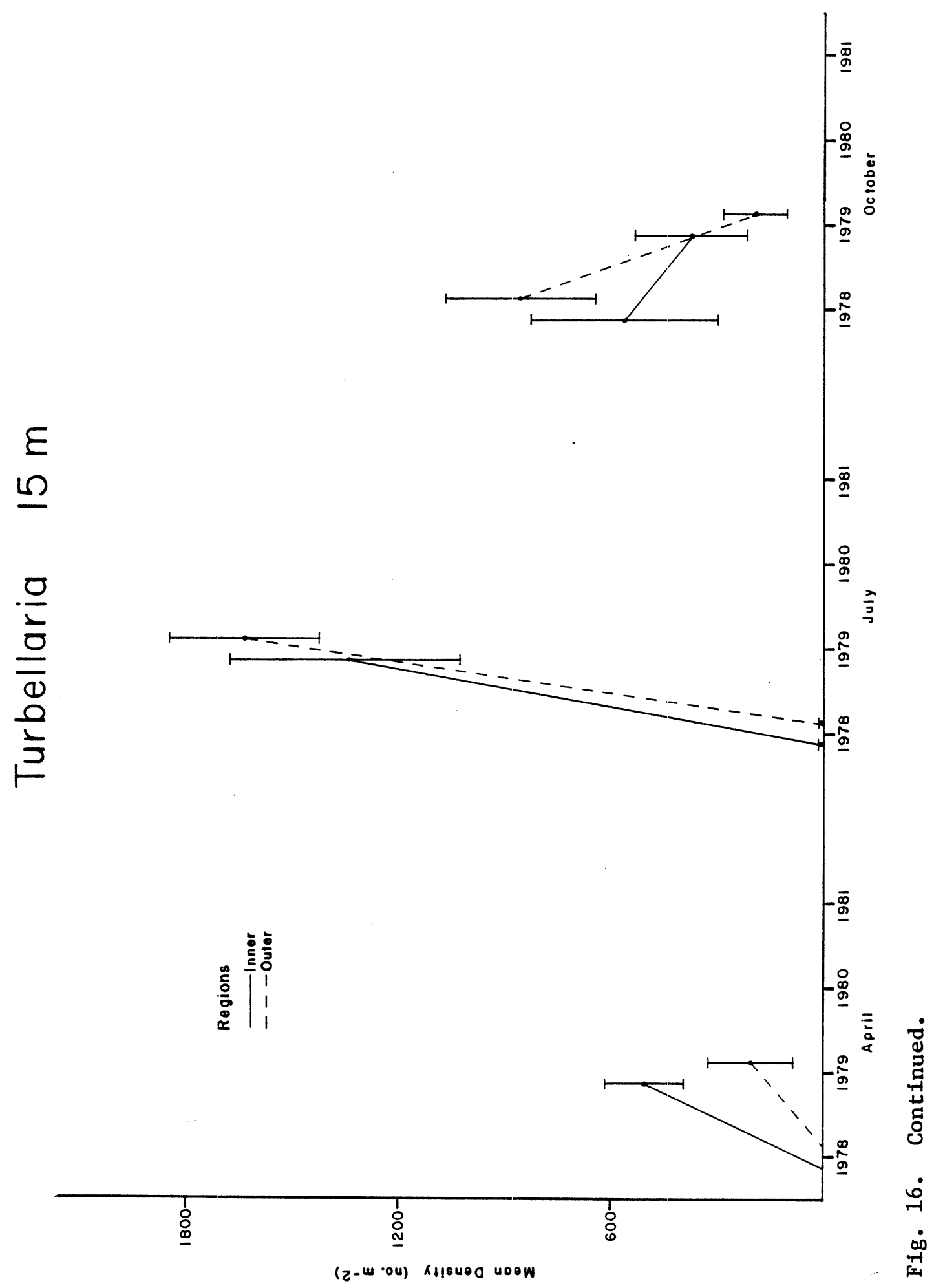




\section{ENCHYTRAEIDAE}

Occurring much more frequently in samples collected during 1979 (43\%) than during 1978 (14\%) (Table 11), enchytraeids comprised $2.4 \%$ of the annual 1979 benthic density and were significantly more numerous when compared with 1978 populations (Table 6). Although low abundance of enchytraeids was noted at 6-9 $\mathrm{m}$, regular occurrence and increased densities were observed primarily at 12-15 m (Fig. 17, Appendix 3). As in 1978, maximum abundance of enchytraeids occurred during October (Fig. 18). During 1979, significantly higher numbers of enchytraeids were observed at both 12 and $15 \mathrm{~m}$ and during April when compared with 1978 (Table 6). While a t test could not be computed for July data, it was obvious that July 1979 samples had significantly more enchytraeids than were present during July 1978. No enchytraeid density difference between years was observed in October.

Both the inner and outer regions during 1979 had significantly greater numbers of enchytraeids present when compared with their respective regions during 1978 (Tables 7 and 8). Comparison of 1979 inner and outer enchytraeid mean density at 12 and $15 \mathrm{~m}$ indicated no significant density differences between regions (Table 9). A similar comparison of monthly densities over the combined depth range 12-15 m indicated that only during July were there significant inner/outer differences, with the outer region having significantly more enchytraeids than the inner region. The July enchytraeid density difference was most evident at $12 \mathrm{~m}$ with outer region organisms significantly more numerous than in the inner region (Table 10). Increasing or decreasing enchytraeid density trends from 1978 to 1979 tended to be similar or have broadly overlapping standard errors for all comparisons made, with the exception of the 12-m July comparison (Fig. 19). 


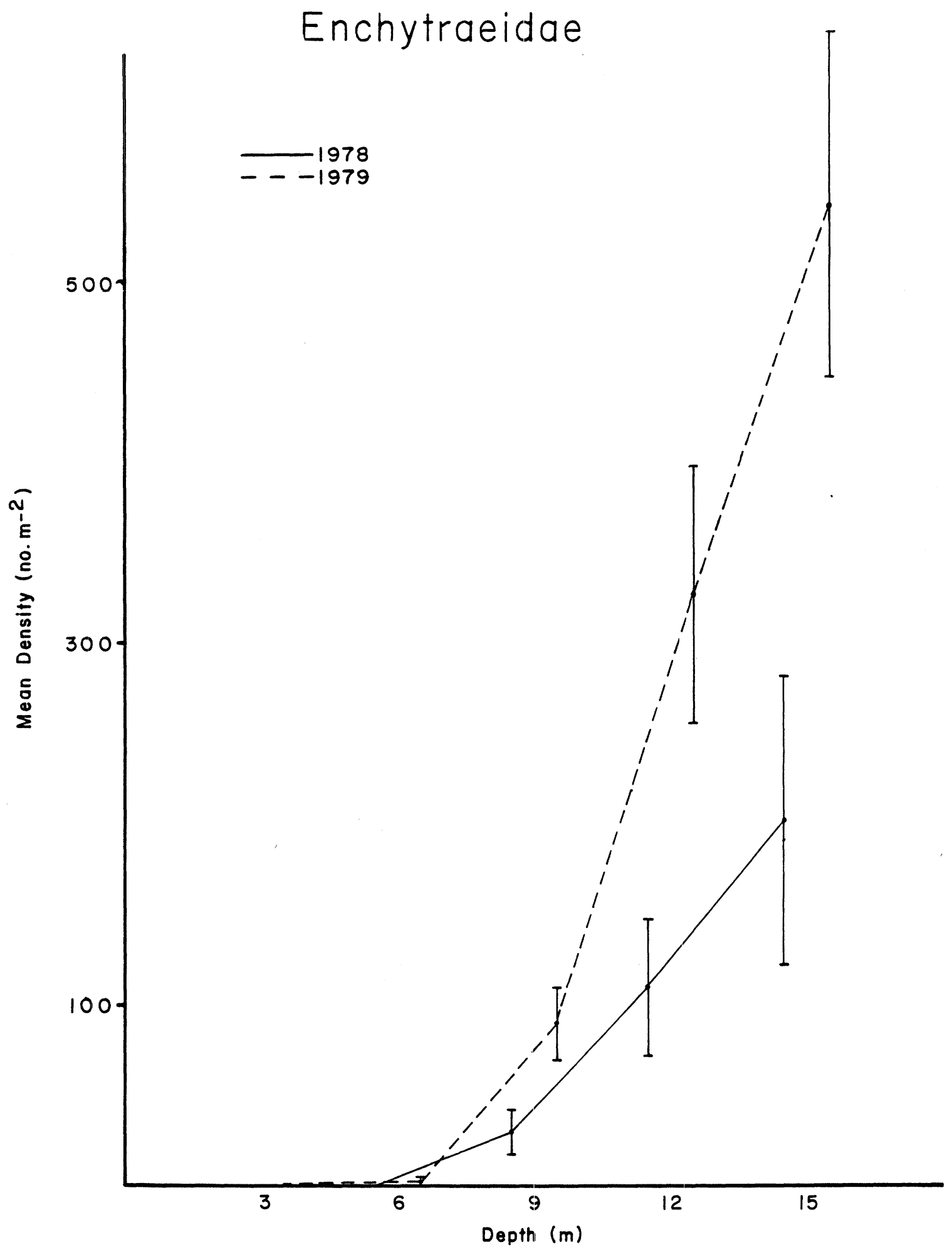

Fig. 17. Mean density (number $\mathrm{m}^{-2}$ ) of enchytraeids collected at 3-15 $\mathrm{m}$ during 1978 and 1979 in eastern Lake Michigan near the J. H. Campbell Plant. Density estimates at each depth were computed by averaging over all months within each year $(n=36)$. Standard error denoted by vertical bar. 


\section{Enchytraeidae}

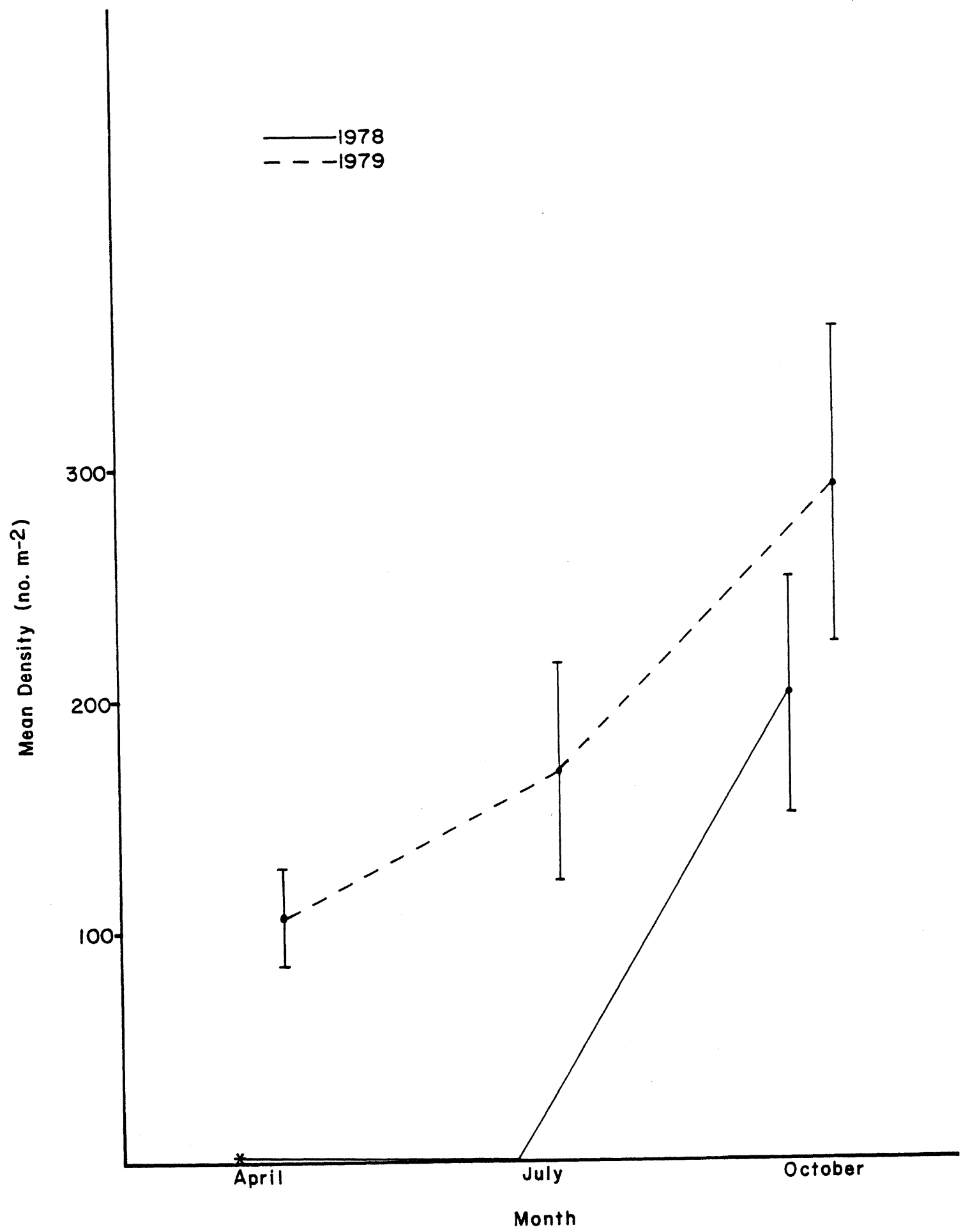

Fig. 18. Mean density (number $\mathrm{m}^{-2}$ ) of enchytraeids collected during April, July and October 1978 and 1979 in eastern Lake Michigan near the A. Campbell Plant. Density estimates for each month were computed . H. Camping over all depths within each year $(n=60)$. Standard error denoted by vertical bar. 


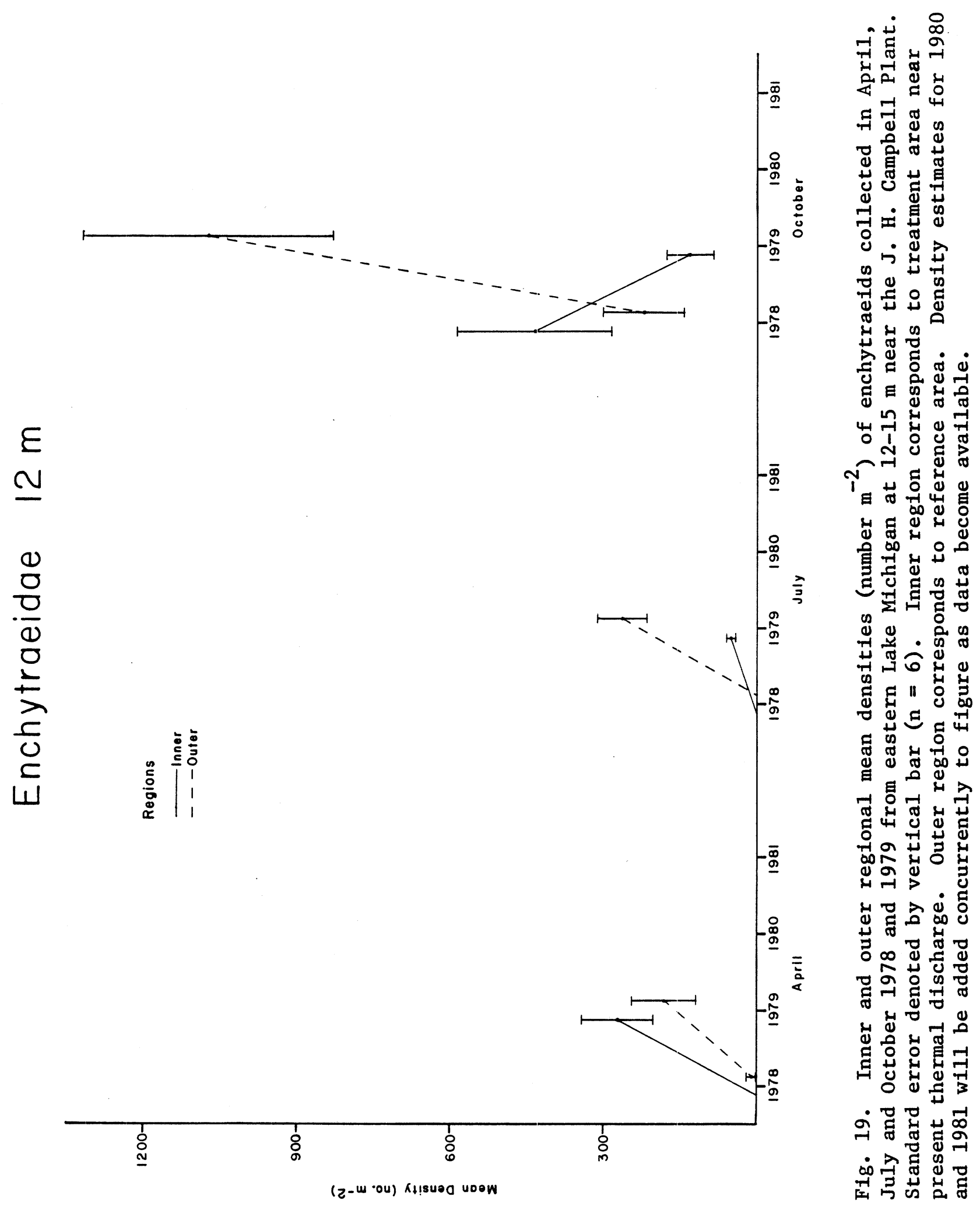



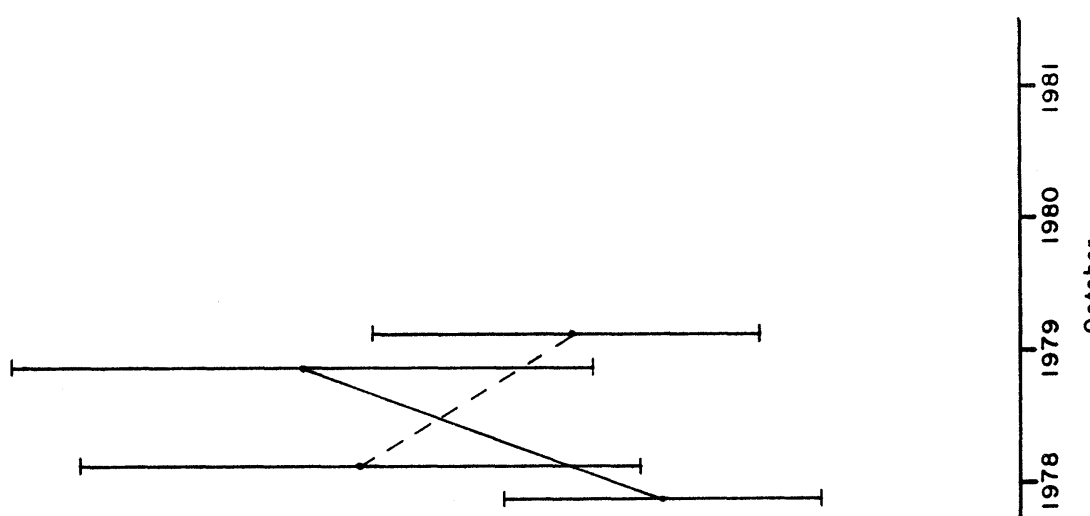

$\varepsilon$

0
0
$\frac{0}{0}$
0
\pm
$\frac{1}{0}$
$\frac{1}{\omega}$
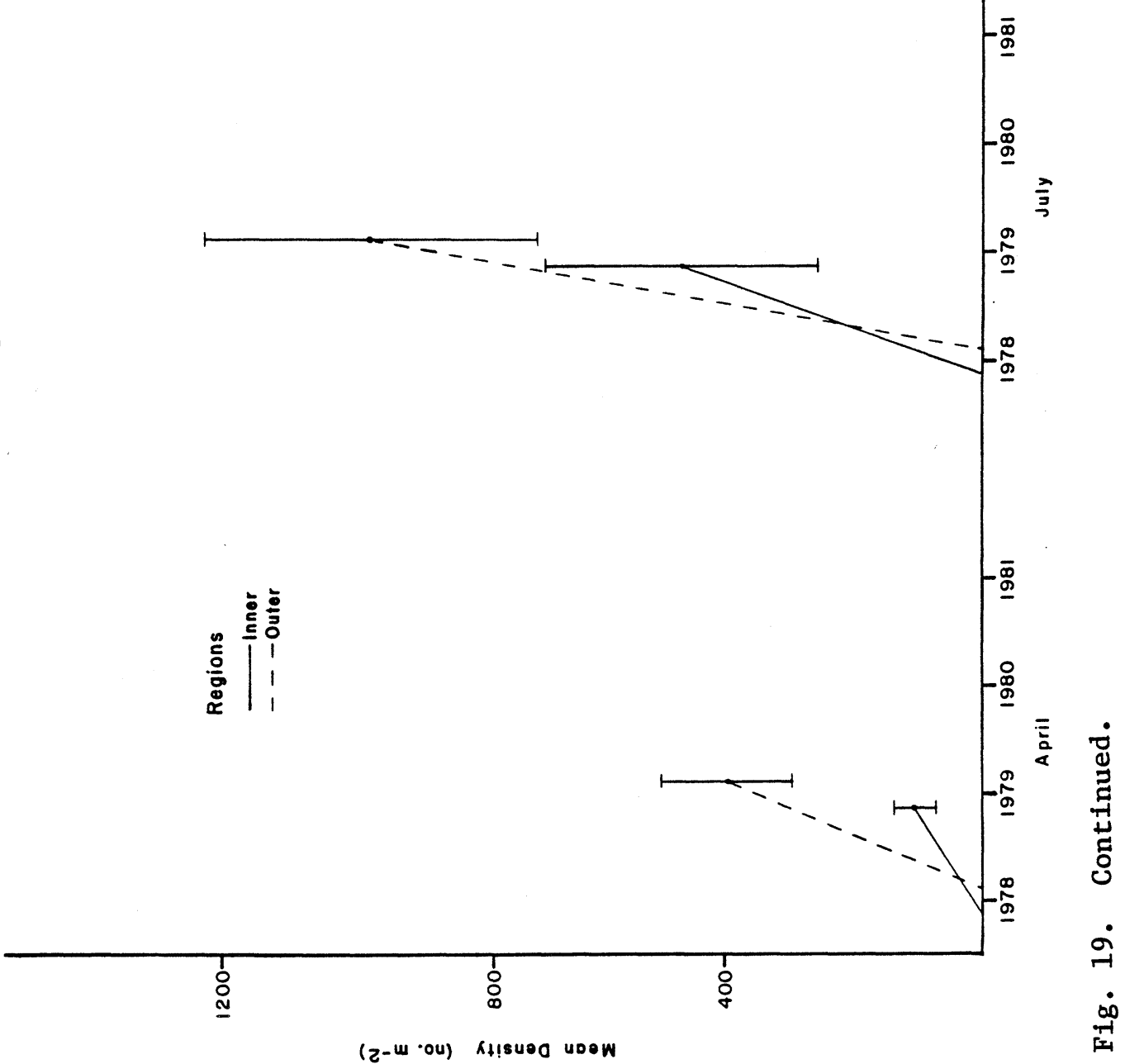
STYLODRILUS HERINGIANUS

Stylodrilus heringianus was found in $14 \%$ of the samples collected and comprised $1.2 \%$ of the macrobenthos during 1979 (Table 11). In 1978, S. heringianus was found at 9 and $12 \mathrm{~m}$ in very low densities, with the major occurrence during both years at $15 \mathrm{~m}$ (Fig. 20). In 1979, s. heringianus occurred only at $15 \mathrm{~m}$ (Appendix 3). Month1y distribution of $\underline{\mathrm{s}}$. heringianus in 1979 was very similar to that observed during 1978, with low densities in April increasing to a maximum in October (Fig. 21). Annual density comparisons for year, month, and depth $(15 \mathrm{~m})$ indicated there were no significant density differences even though there were fewer individuals collected during 1979. Most year, depth, and month comparisons for $\underline{s}$. heringianus indicated there were few significant regional density differences (Tables 7-10), except during October when the 1978 inner region had significantly more $\underline{\text { s. heringianus than }}$ did the 1979 inner region. When comparing regions in 1979, it was noted that the inner region had significantly fewer $\underline{\mathrm{S}}$. heringianus when compared with the outer region, and that this difference was most pronounced during October at $15 \mathrm{~m}$ (Table 10, Fig. 22).

\section{$\underline{\text { PISIDIUM }}$}

Pisidium comprised $6 \%$ of the benthic invertebrates collected during 1979 and occurred in $52 \%$ of the samples (Table 11 ). The pisidia were represented by 13 species in 1979, bringing the total number of Pisidium species identified from the survey area to 16 (Table 3 ). Based on annual mean density, Pisidium casertanum $\left(130 \mathrm{~m}^{-2}\right)$, Pisidium fallax $\left(89 \mathrm{~m}^{-2}\right)$, and Pisidium nitidum $\left(80 \mathrm{~m}^{-2}\right)$ were the most abundant pisidia during 1979 (Appendix 4).

During 1978, Pisidium nitidum $\left(83 \mathrm{~m}^{-2}\right)$, Pisidium casertamun $\left(62 \mathrm{~m}^{-2}\right)$, and Pisidium fallax $\left(28 \mathrm{~m}^{-2}\right)$ were the three most abundant pisidia based on annual 


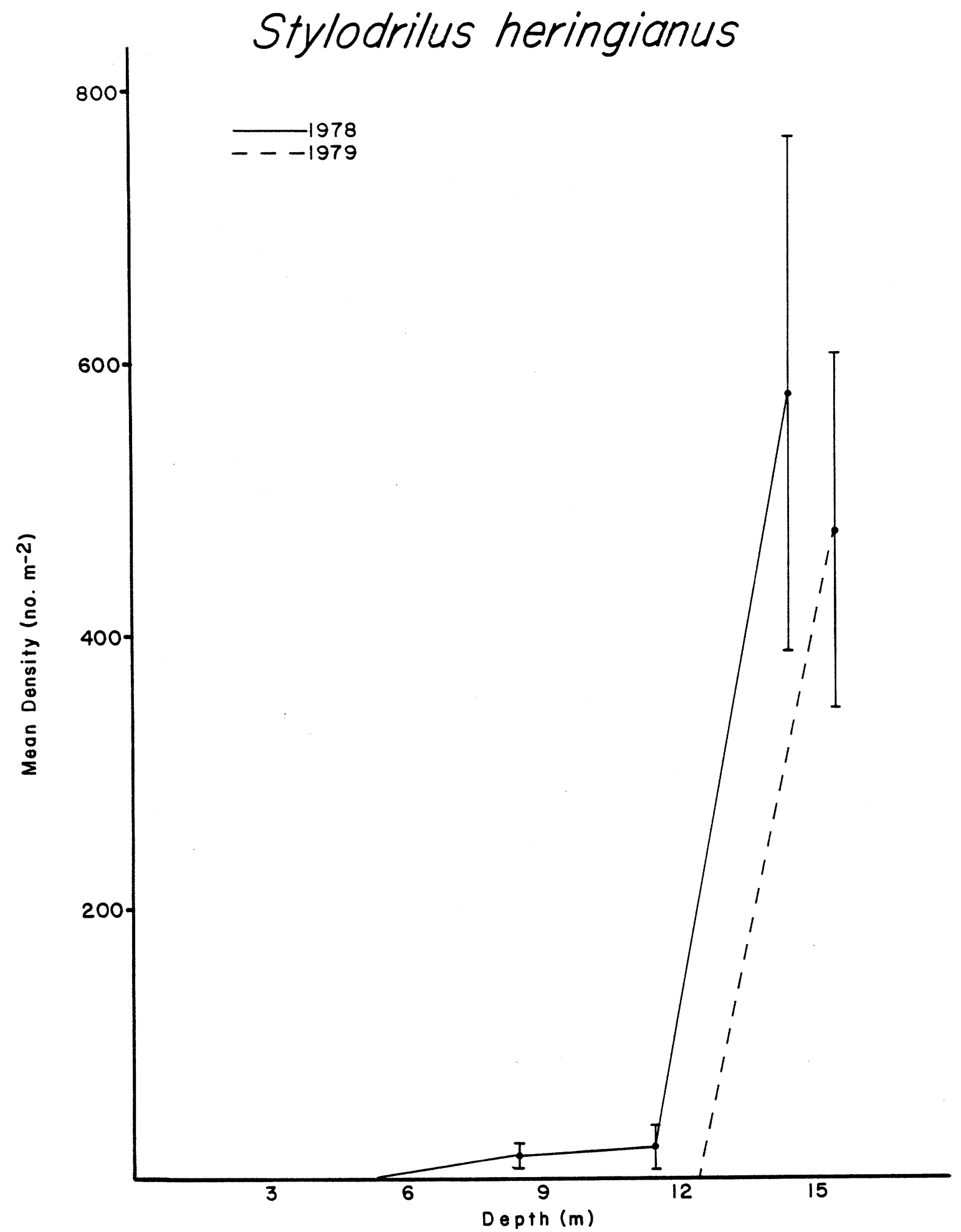

Fig. 20. Mean density (number $\mathrm{m}^{-2}$ ) of $\mathrm{s}$. heringianus collected at 3-15 m during 1978 and 1979 in eastern Lake Michigan near the J. H. Campbell Plant. Density estimates at each depth were computed by averaging over all months within each year $(n=36)$. Standard error denoted by vertical bar. 


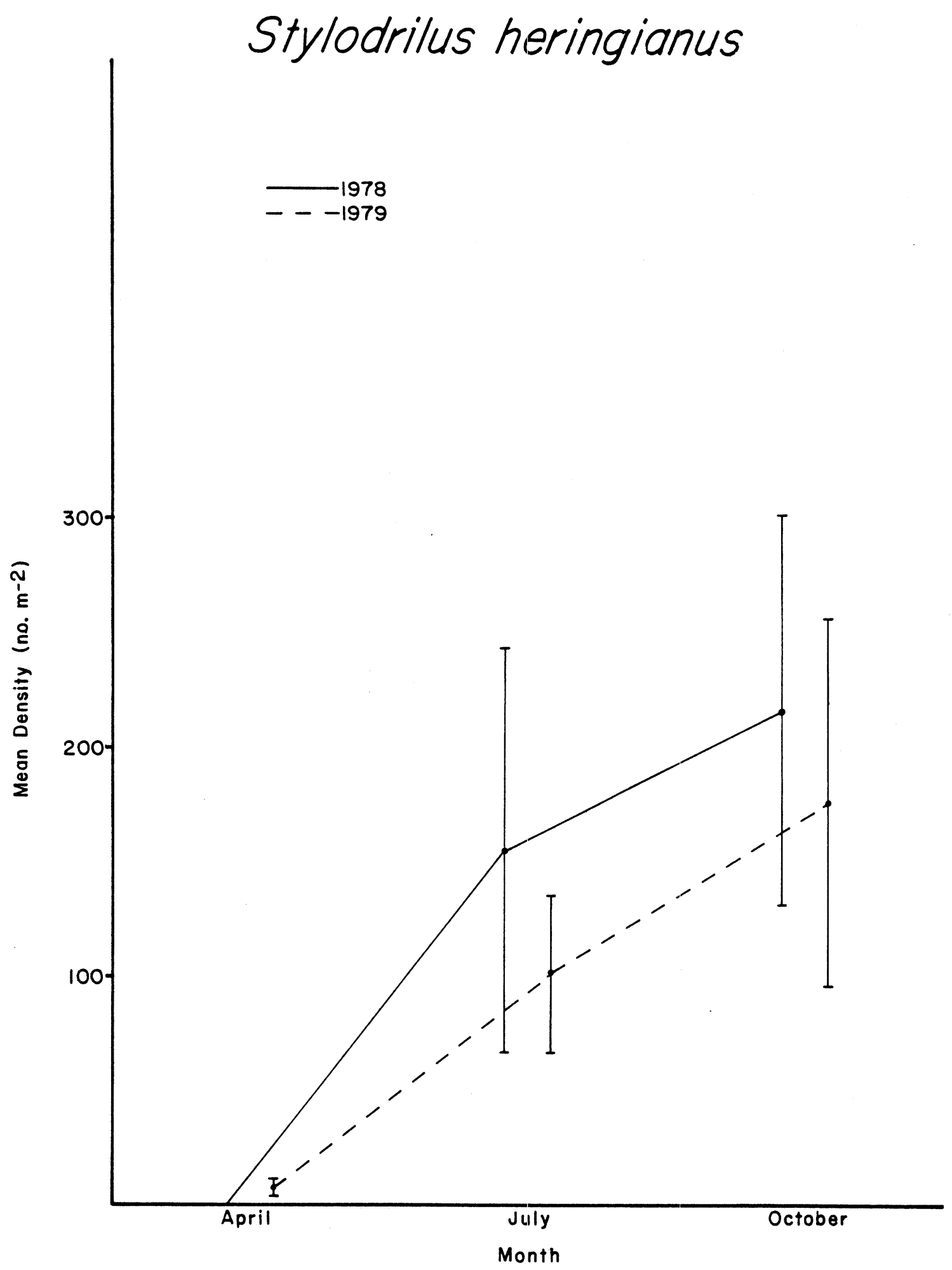

Fig. 21. Mean density (number $\mathrm{m}^{-2}$ ) of $\underline{\mathrm{s}}$. heringianus collected during April, July and October 1978 and 1979 in eastern Lake Michigan near the J. H. Campbell Plant. Density estimates for each month were computed by averaging over all depths within each year $(n=60)$. Standard error denoted by vertical bar. 


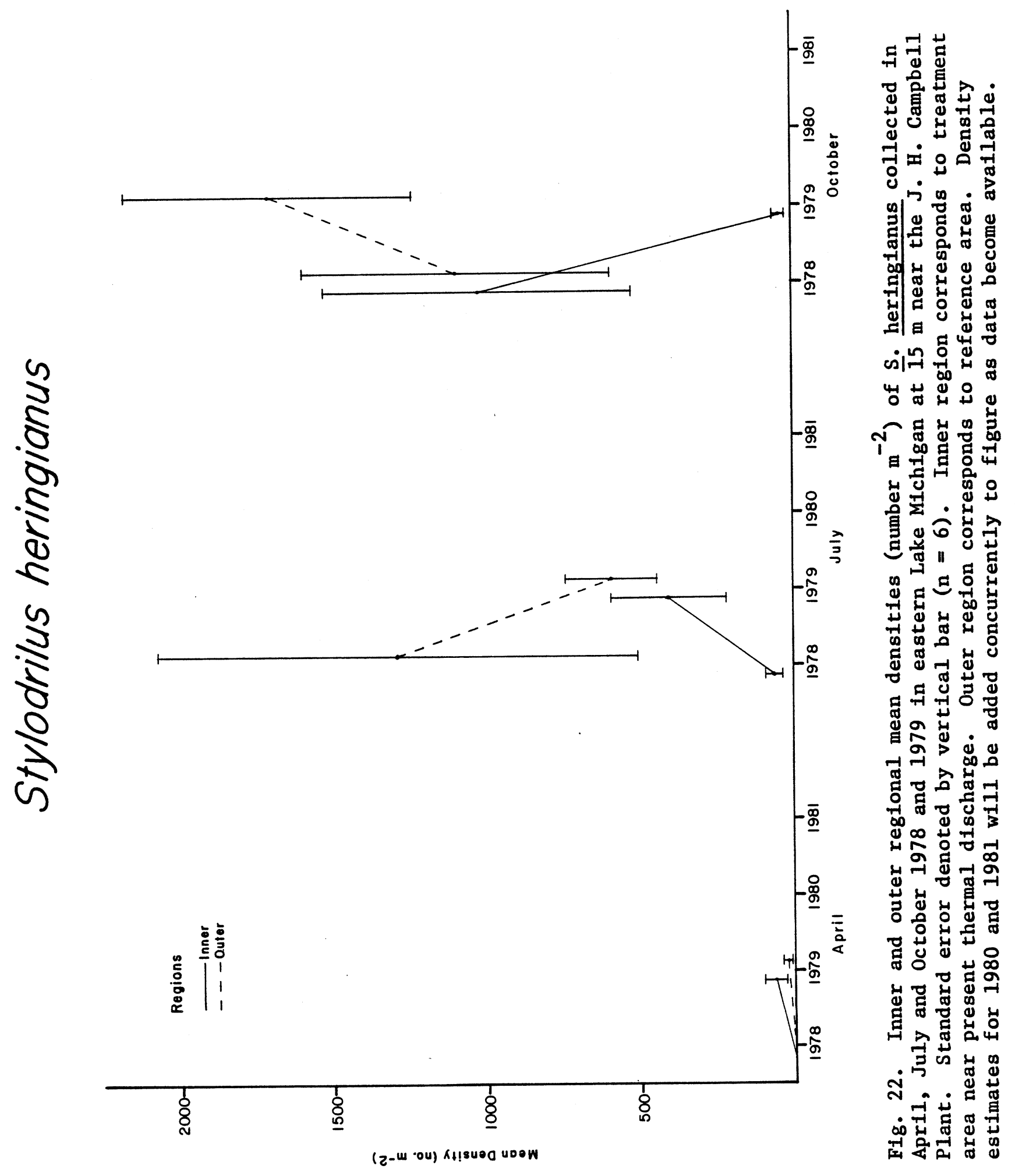


mean density. While $\underline{\mathrm{p}}$. nitidum annual mean density $\left(80 \mathrm{~m}^{-2}\right)$ was similar between years, the 1979 density of $\underline{P}$. casertanum $\left(130 \mathrm{~m}^{-2}\right)$ and $\underline{P} \cdot \underline{\text { fallax }}$ $\left(89 \mathrm{~m}^{-2}\right)$ increased greatly. Comparison of percent composition of the three dominant Pisidium spp. between regions in 1978 indicated each region was composed of these three species in very similar proportions; $\underline{P}$. nitidum $(31-33 \%), \underline{P} \cdot \underline{\text { casertanum }}(20-26 \%)$, and $\underline{P} \cdot \underline{\text { fallax }}(10-11 \%)$. In the 1979 inner region, the percentage of $\underline{P}$. nitidum (10\%) was reduced when compared with the 1979 outer region percentage (22\%) and when compared with 1978 inner region percentage (33\%). However, the 1979 regional difference in relative abundance of $\underline{\underline{P}}$. nitidum appeared to be related primarily to a large percent increase in $\underline{P}$. nitidum during october in the outer region. Remaining monthly, inner, and outer regional percent comparisons of the three dominant Pisidium spp. were very similar within 1979. Overall, during 1979 the relative dominance of

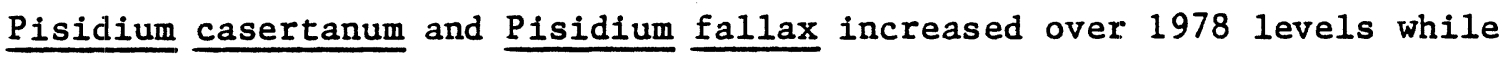
Pisidium nitidum decreased.

When annual mean density in $1979\left(480 \mathrm{~m}^{-2}\right)$ was compared with that of 1978 $\left(266 \mathrm{~m}^{-2}\right)$, there was no significant difference in the average number of Pisidium collected (Table 6). However, while the depth distribution pattern observed between years was similar for Pisidium, significantly more were collected at 9 m during 1978 than during 1979 with the opposite pattern observed at $12 \mathrm{~m}$ (Fig. 23). In addition, there was a significantly greater number of pisidia collected during October 1979 when compared with October 1978 (Fig. 24). Both regions had significantly more pisidia in 1979 when compared to 1978 at 12 m during October (Tables 7 and 8 ).

Inner and outer regional comparisons for Pisidium collected during 1979 indicated there were no inner/outer regional mean density differences within any month averaged over the depths 9-15 m combined, or within any depth 


\section{Pisidium}

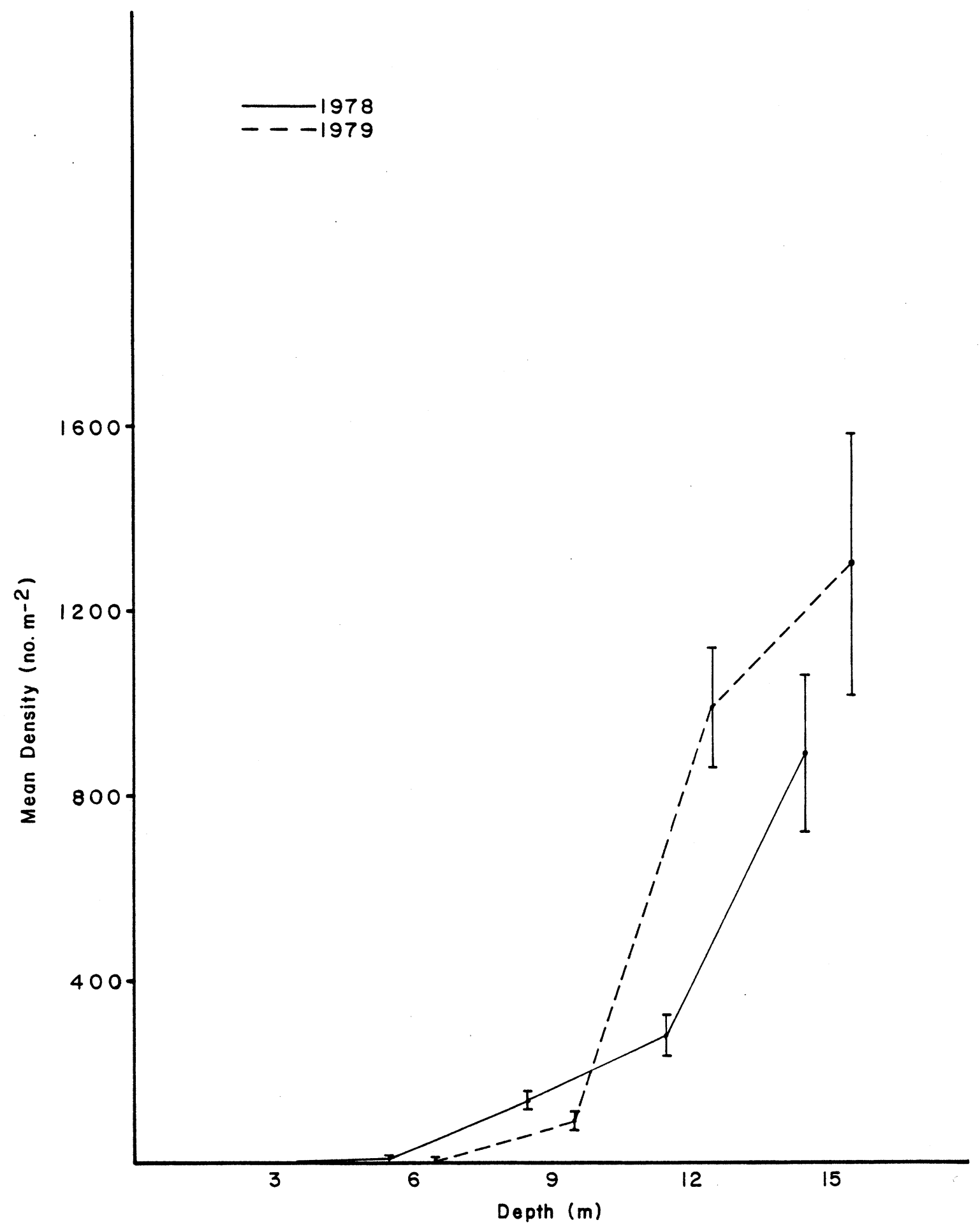

Fig. 23. Mean density (number $\mathrm{m}^{-2}$ ) of Pisidium collected at 3-15 m during 1978 and 1979 in eastern Lake Michigan near the J. H. Campbell Plant. Density estimates at each depth were computed by averaging over all months within each year $(n=36)$. Standard error denoted by vertical bar. 


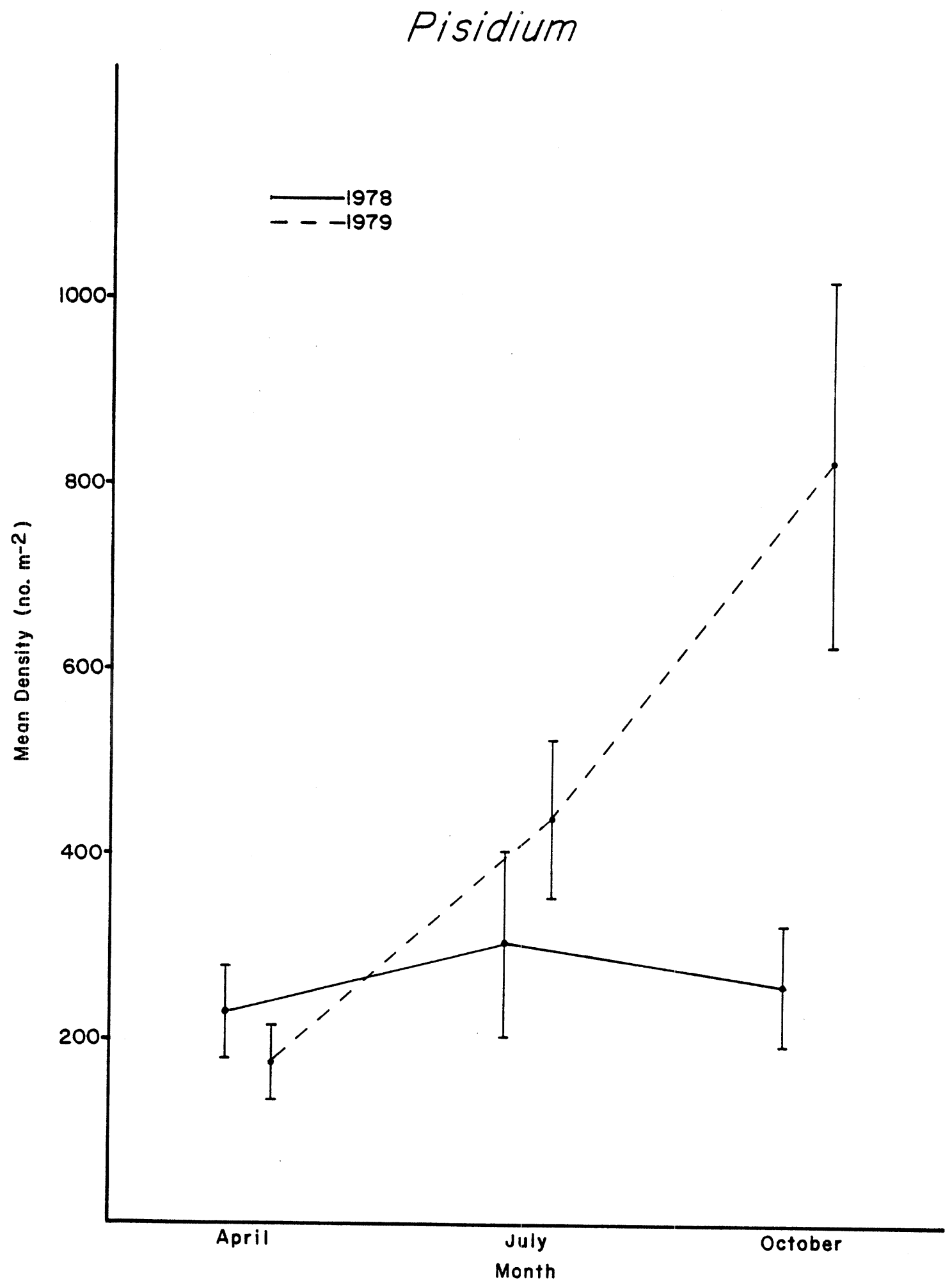

Fig. 24. Mean density (number $\mathrm{m}^{-2}$ ) of Pisidium collected during April, July and October 1978 and 1979 in eastern Lake Michigan near the J. H. Campbell Plant. Density estimates for each month were computed by averaging over all depths within each year $(n=60)$. Standard error denoted by vertical bar. 
averaged over all months (Tables 7 and 8 ). However, inner/outer regional comparisons made within each month and depth sampled indicated that, although both regional mean densities increased during October at $12 \mathrm{~m}$, the inner region Pisidium density was significantly greater than that observed in the outer region; the opposite trend was noted at $15 \mathrm{~m}$ during October (Fig. 25, Table 10). Remaining inner/outer regional comparisons of Pisidium mean densities indicated similar density trends or widely overlapping standard errors.

\section{SPHAERIUM}

Sphaerium occurred in 6\% of all samples collected in both 1978 and 1979 (Table 11). In addition, very low annual mean densities of Sphaerium were recorded $\left(4-5 \mathrm{~m}^{-2}\right)$ during both years. A similar depth distribution pattern was observed in 1978 and 1979 (Fig. 26). Sphaerium striatinum exhibited highest abundance among Sphaerium in both years. Although Sphaerium transversum was not observed in the inner or outer region during 1978, it was collected in equal densities from both regions $\left(1 \mathrm{~m}^{-2}\right)$ during 1979 and was the second-most numerous Sphaerium species (Appendix 4). Sphaerium nitidum annual mean density decreased during $1979\left(0.3 \mathrm{~m}^{-2}\right)$ when compared with $1978\left(1.3 \mathrm{~m}^{-2}\right)$. Since all three species occurred infrequently in the survey area, it was difficult to assess the significance of annual changes. Inner/outer regional comparisons were not made for Sphaerium.

\section{GASTROPODA}

Gastropods were found in $38 \%$ of the samples taken in 1979 (Table 11) which was similar to the frequency of occurrence noted for 1978 (32\%). The benthos was comprised numerically of only $1.2 \%$ gastropods, with the majority of gastropods occurring from 12 to $15 \mathrm{~m}$. Of the five species of gastropods 


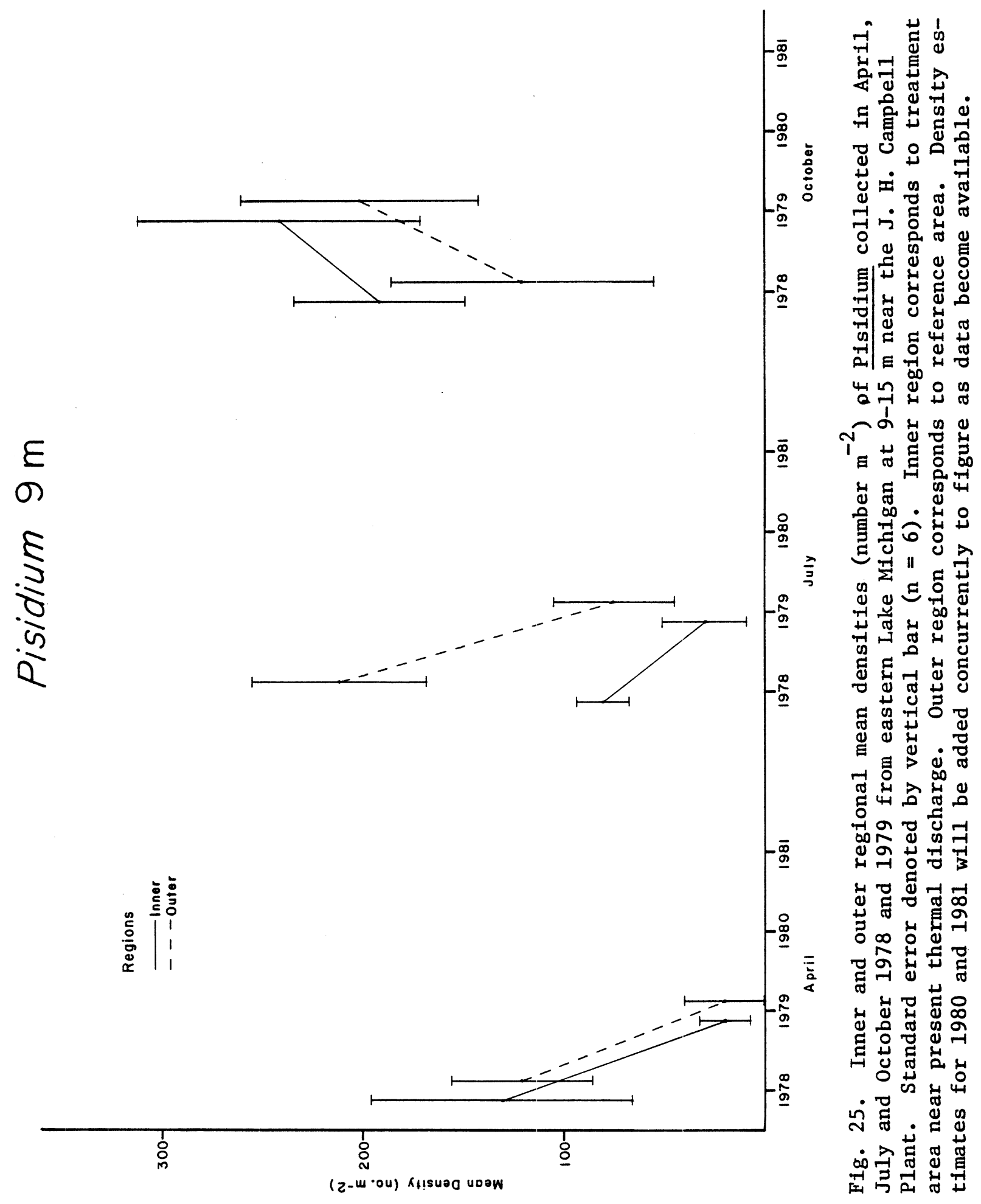




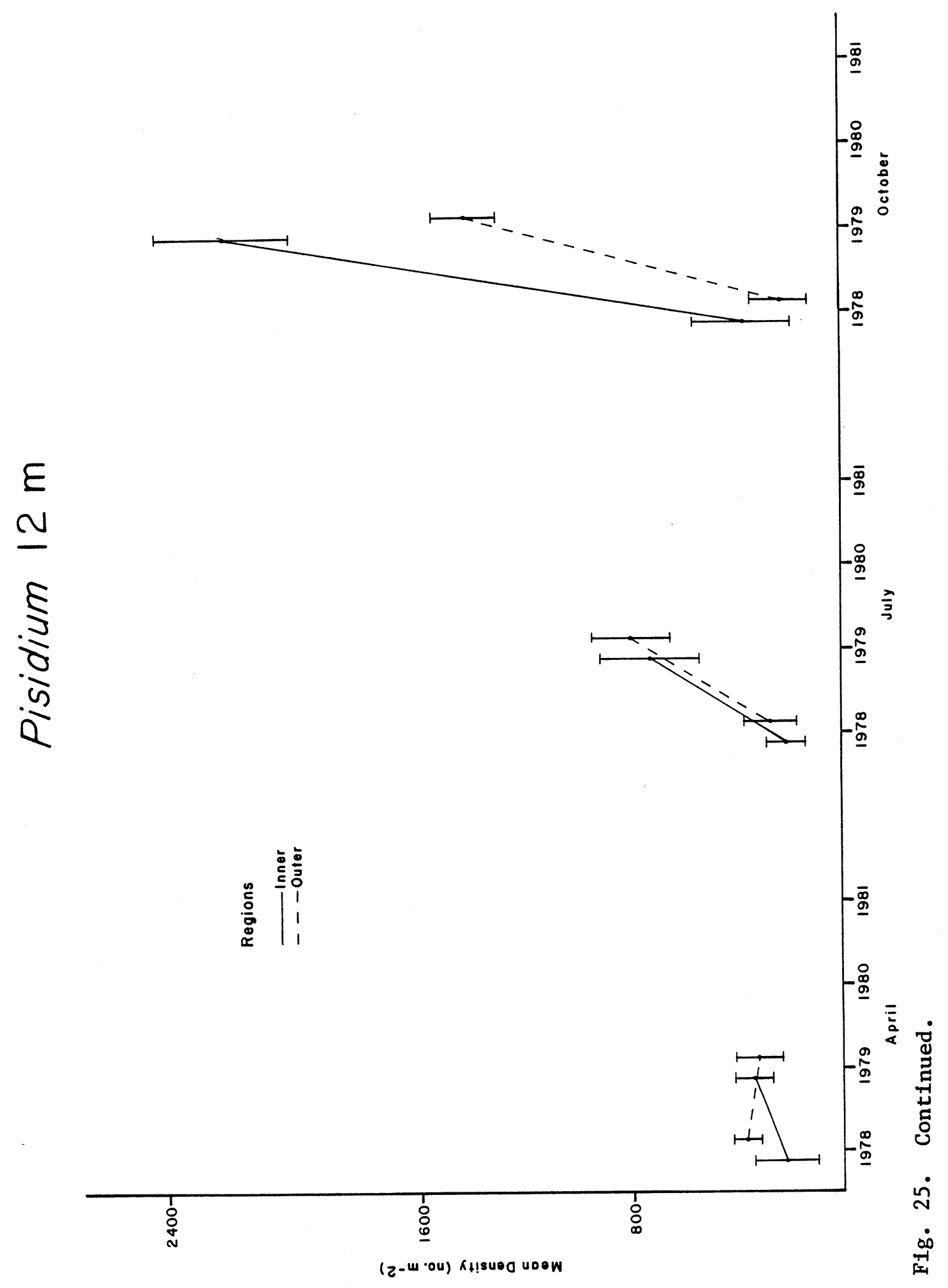




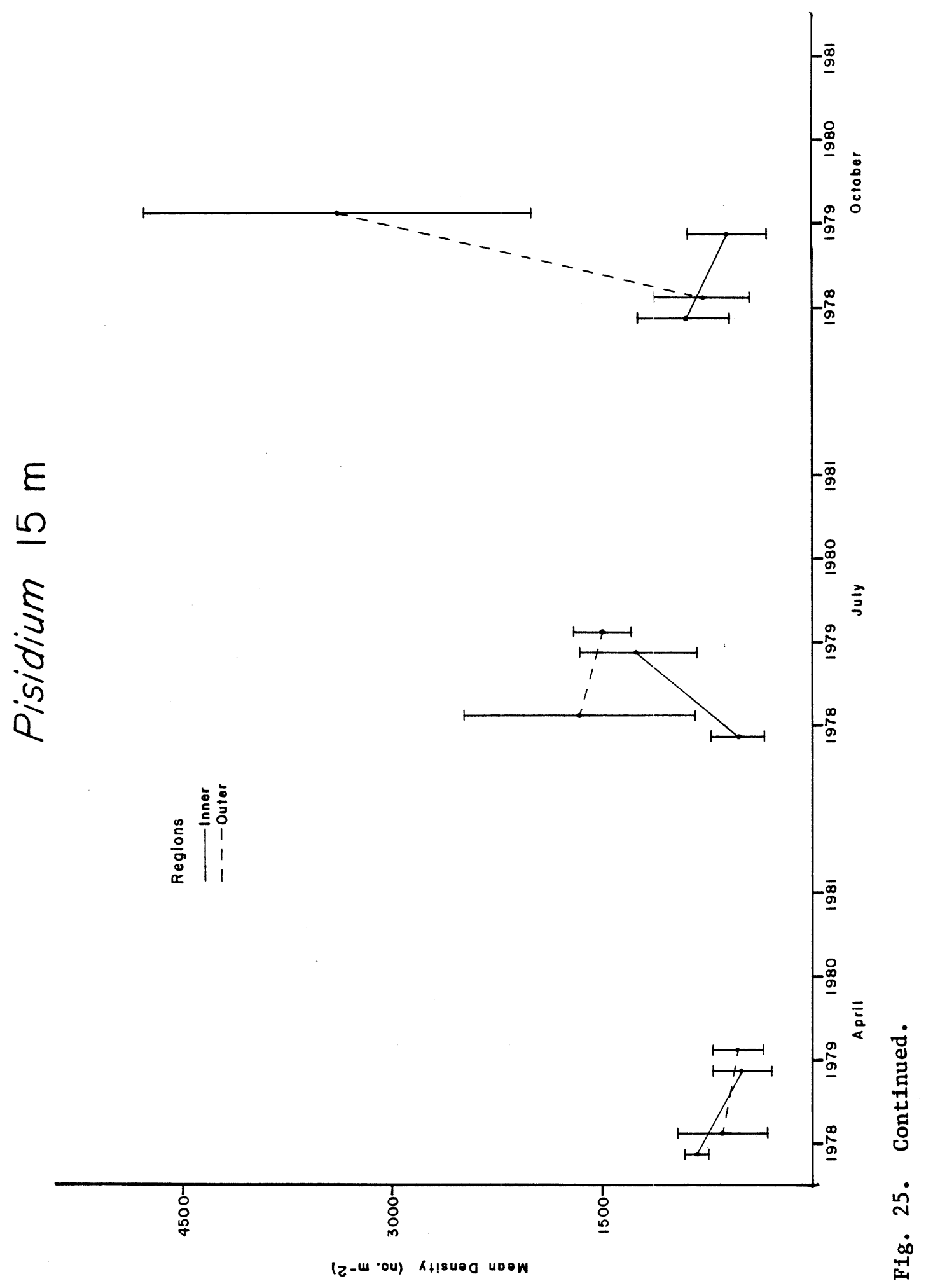


Sphaerium

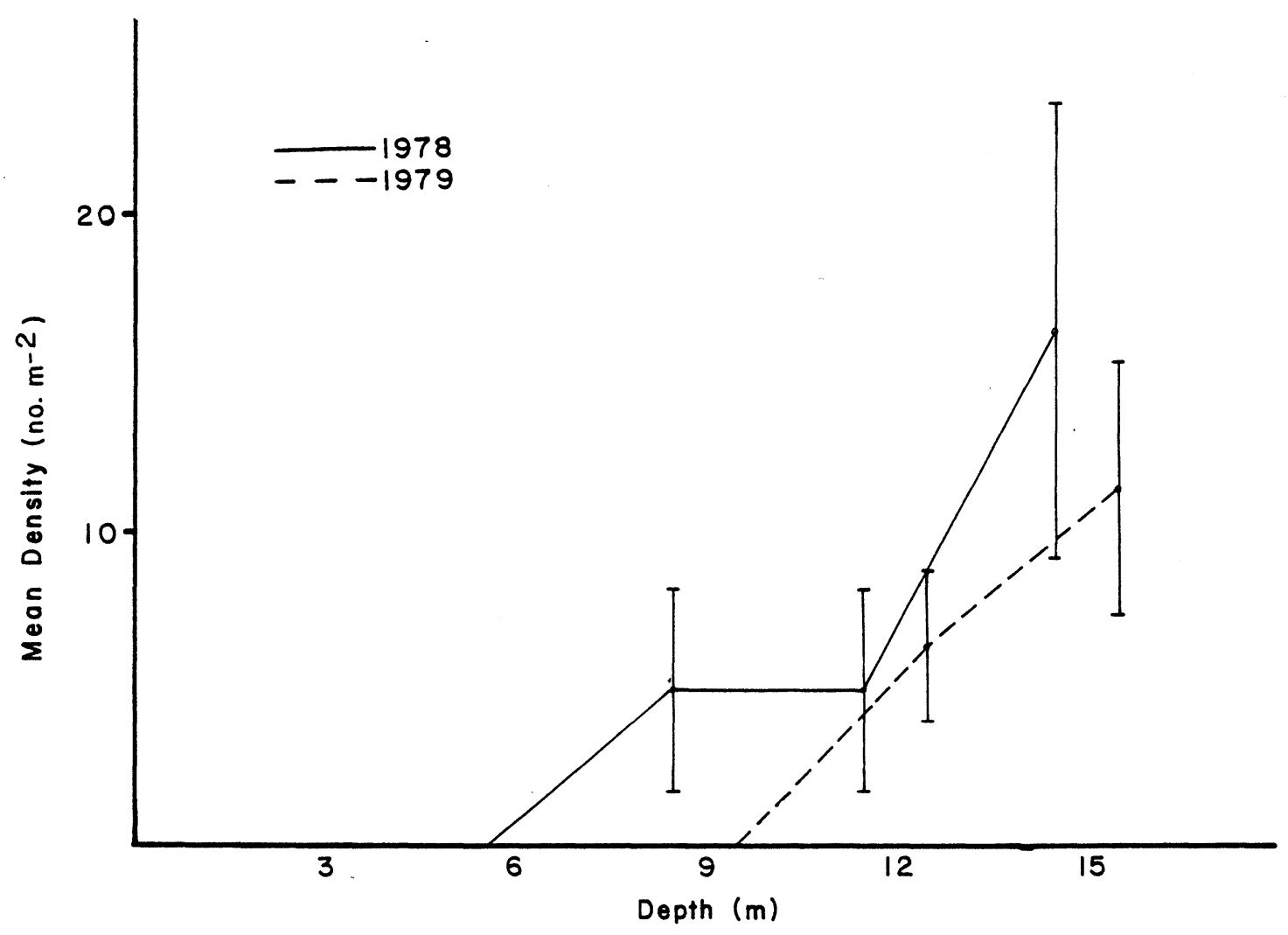

Fig. 26. Mean density (number $\mathrm{m}^{-2}$ ) of Sphaerium collected at 3-15 $\mathrm{m}$ during 1978 and 1979 in eastern Lake Michigan near the J. H. Campbell Plant. Density estimates at each depth were computed by averaging over all months within each year $(n=36)$. Standard error denoted by vertical bar. 
identified during 1979, only Somatogyrus sp. was not identified in 1978 (Table 3). However, the distinction between Somatogyrus sp. and small individuals of Amnicola sp. is difficult, subject to error, and was not made in 1978. Although each individual identified as Somatogyrus sp. definitely had a shell aperature greater than one-half the longitudinal length of shell height, distinction between Somatogyrus sp. and small individuals of Amnicola sp. still remains questionable.

Valvata sinera was the dominant snail found in $1978(73 \%)$ and 1979 (57\%) in both regions. The second-most numerous gastropod in 1978 was Amnicola sp., comprising $23 \%$ of the gastropod population over the year. However, from 1978 to 1979 there was a shift from Amnicola sp. (9\%) to Lymnaea sp. (27\%) as the second-most numerous snail (Appendix 4). Even if Somatogyrus sp. was added to Amnicola sp., Amnicola sp. would only comprise $12 \%$ of the snail population, or approximately one-half its relative composition in 1978. As in 1978, both regions had similar percent occurrences of the three most abundant gastropods.

Although there was no significant difference between annual mean densities of gastropods from $1978\left(70 \mathrm{~m}^{-2}\right)$ to $1979\left(94 \mathrm{~m}^{-2}\right)$, depth and month differences were observed (Table 6). Gastropods followed the same depth distribution pattern during both years, i.e., few snails at 3-6 m, some at $9 \mathrm{~m}$, and the great majority of specimens at $12-15 \mathrm{~m}$; there were significantly more at $12 \mathrm{~m}$ in 1979 than in 1978 (Fig. 27). During April 1979 there were significantly fewer gastropods than during April 1978. No difference was observed in gastropod numbers between years in July, but a significantly greater number of gastropods was collected in October 1979 when compared with October 1978 (Fig. 28).

Annual comparisons made between regions at $12-15-m$ depths combined indicated that when there were significant differences in either region, the 


\section{Gastropoda}

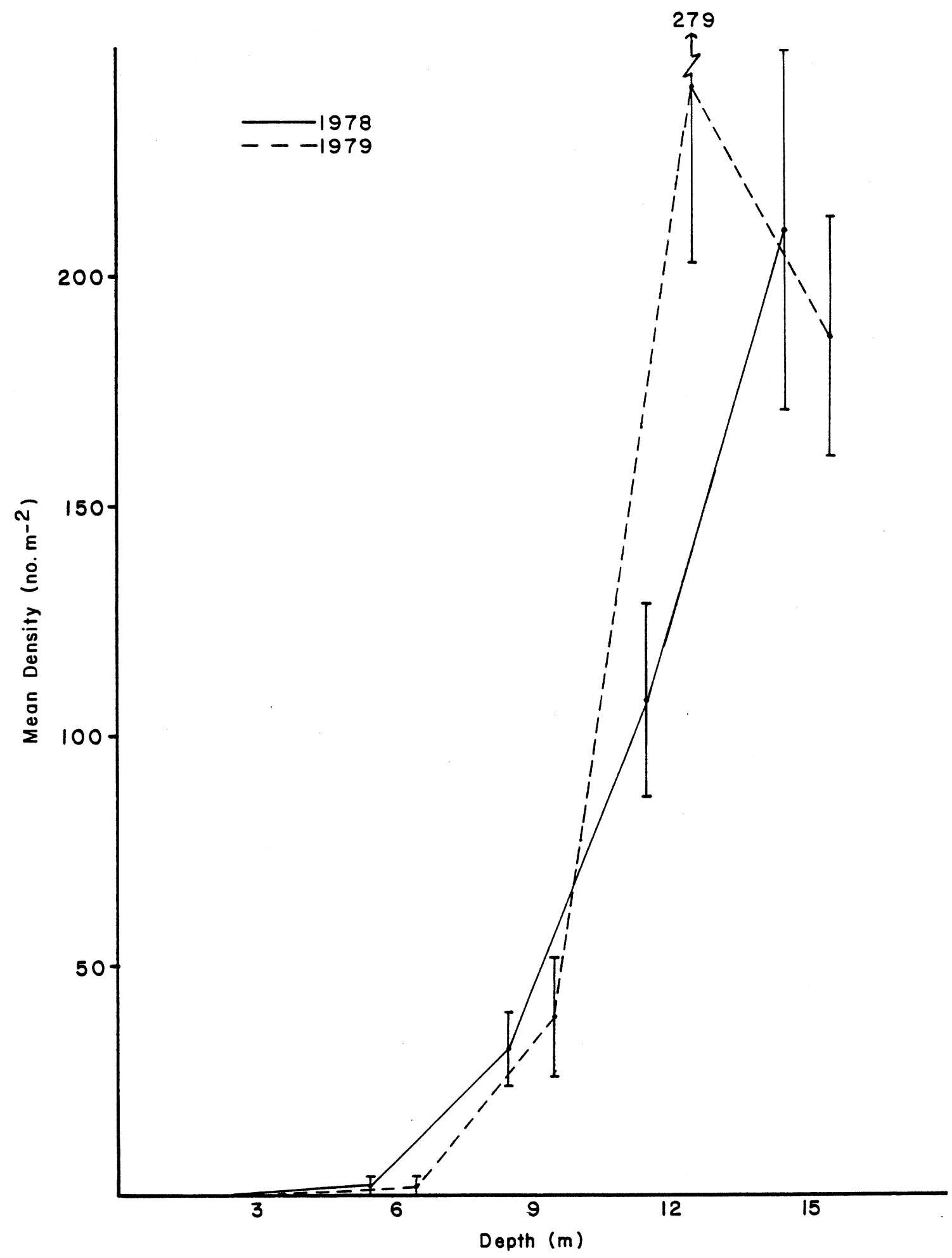

Fig. 27. Mean density (number $\mathrm{m}^{-2}$ ) of gastropods collected at 3-15 $\mathrm{m}$ during 1978 and 1979 in eastern Lake Michigan near the J. H. Campbell Plant. Density estimates at each depth were computed by averaging over all months within each year $(n=36)$. Standard error denoted by vertical bar. 


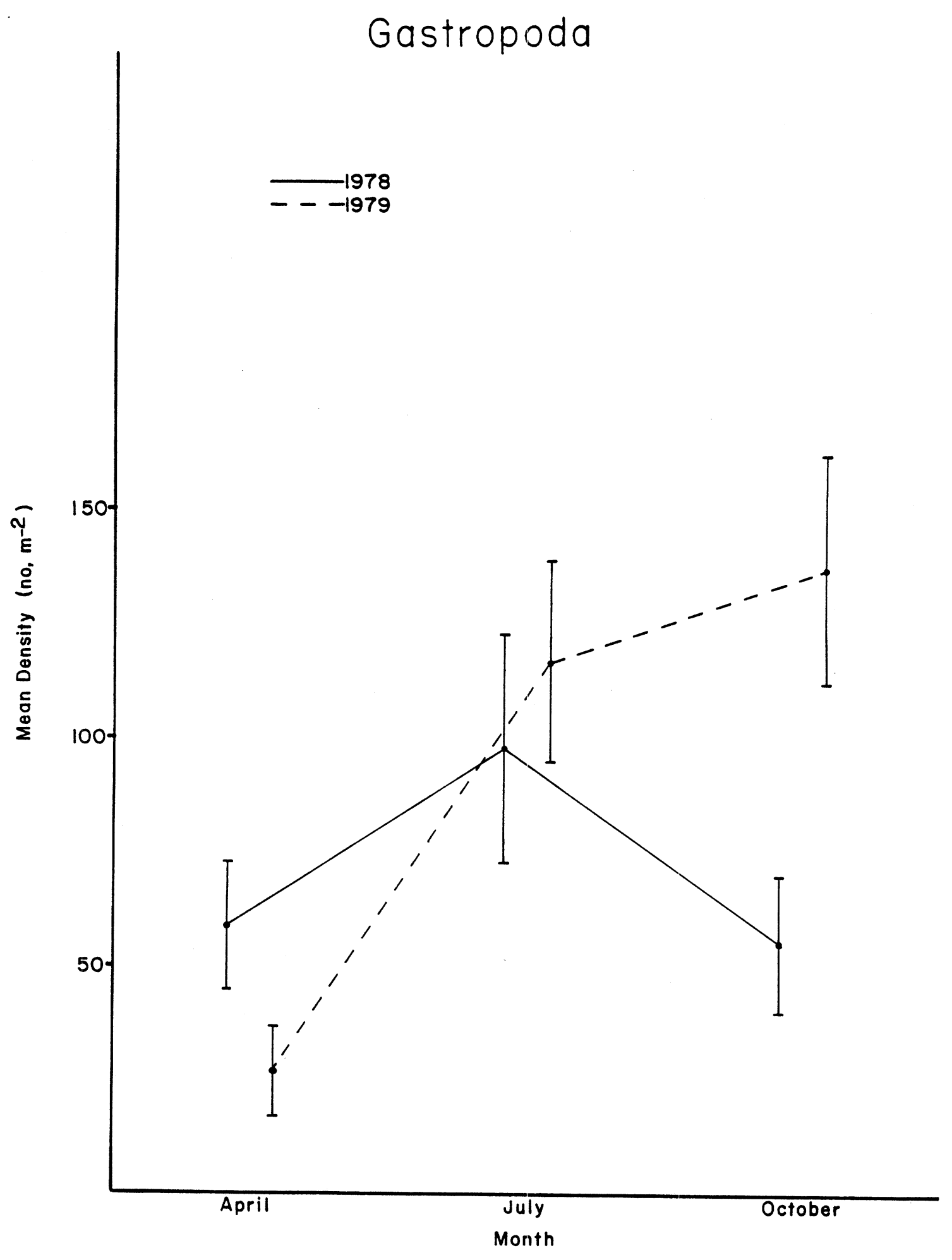

Fig. 28. Mean density (number $\mathrm{m}^{-2}$ ) of gastropods collected during April, July and October 1978 and 1979 in easternn Lake Michigan near the J. H. Campbell Plant. Density estimates for each month were computed by averaging over all depths within each year $(n=60)$. Standard error denoted by vertical bar. 
1979 density estimates were always the highest. Within the inner region there were no yearly mean difference or monthly mean difference, but there were significantly more gastropods at $12 \mathrm{~m}$ in 1979 than in 1978 (Table 8). In the outer region, while there were no yearly differences, July and October averaged over 12-15 m had a greater gastropod density in 1979 than during 1978 (Table 7). In addition, more snails were present in the outer region at $15 \mathrm{~m}$ in 1979 than in 1978. However, within the year 1979, comparisons between inner and outer regions for year, month, and depth showed no apparent differences (Table 9). All inner/outer regional density estimates had the same increasing or decreasing density trends from 1978 to 1979 except at 15 m during October (Fig. 29).

PONTOPOREIA HOYI

Pontoporeia hoyi was more prevalent in 1979 samples (79\%) (Table 11) than in 1978 samples (62\%) and comprised a greater percentage of the benthic population in the survey area in 1979 compared with 1978 (36\% and 25\%, respectively). Annual mean density for $\underline{\mathrm{p}}$. hoyi during 1978 was $1602 \mathrm{~m}^{-2}$, while the 1979 estimate was $2883 \mathrm{~m}^{-2}$, an $80 \%$ increase from 1978 to 1979 (Appendix 1). The difference between years for $\underline{P}$. hoyi density was highly significant $(p \leq .001)$ (Table 6$)$. Although within each region the total number of animals collected increased $22 \%$, the inner region $\underline{P}$. hoyi abundance increased $58 \%$ while outer region $\underline{P}$. hoyi density increased $110 \%$ from 1978 to 1979.

Although having similar depth and monthly distribution patterns in 1978 and 1979 (Figs. 30 and 31), $\underline{P}$. hoyi densities were significantly greater at 9 and $15 \mathrm{~m}$ averaged over the year and during October averaged over all depths when compared with 1978 densities (Table 6). Differences in yearly $\underline{p}$ - hoyi densities were less apparent in the inner 1978 to 1979 regional comparisons 


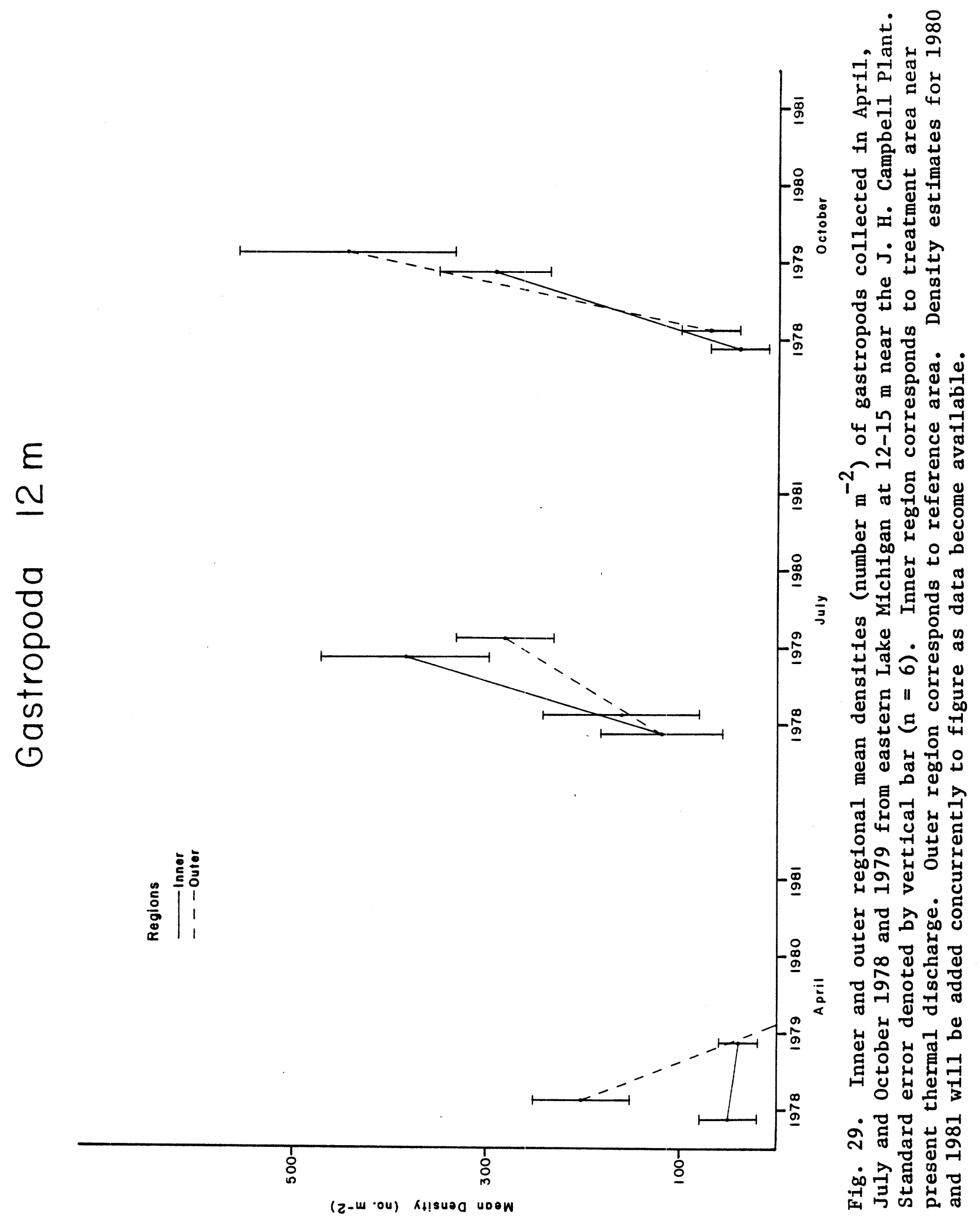




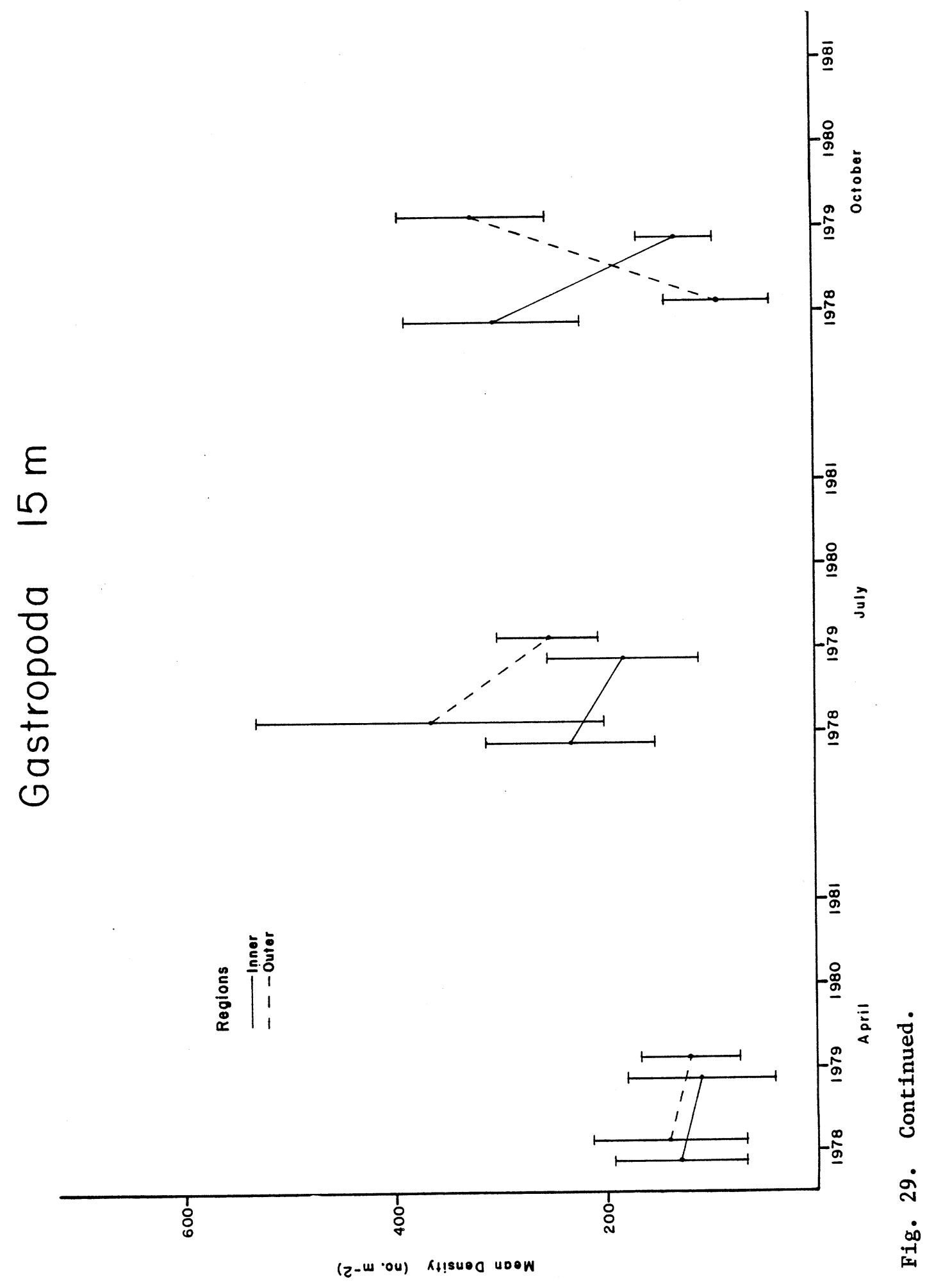




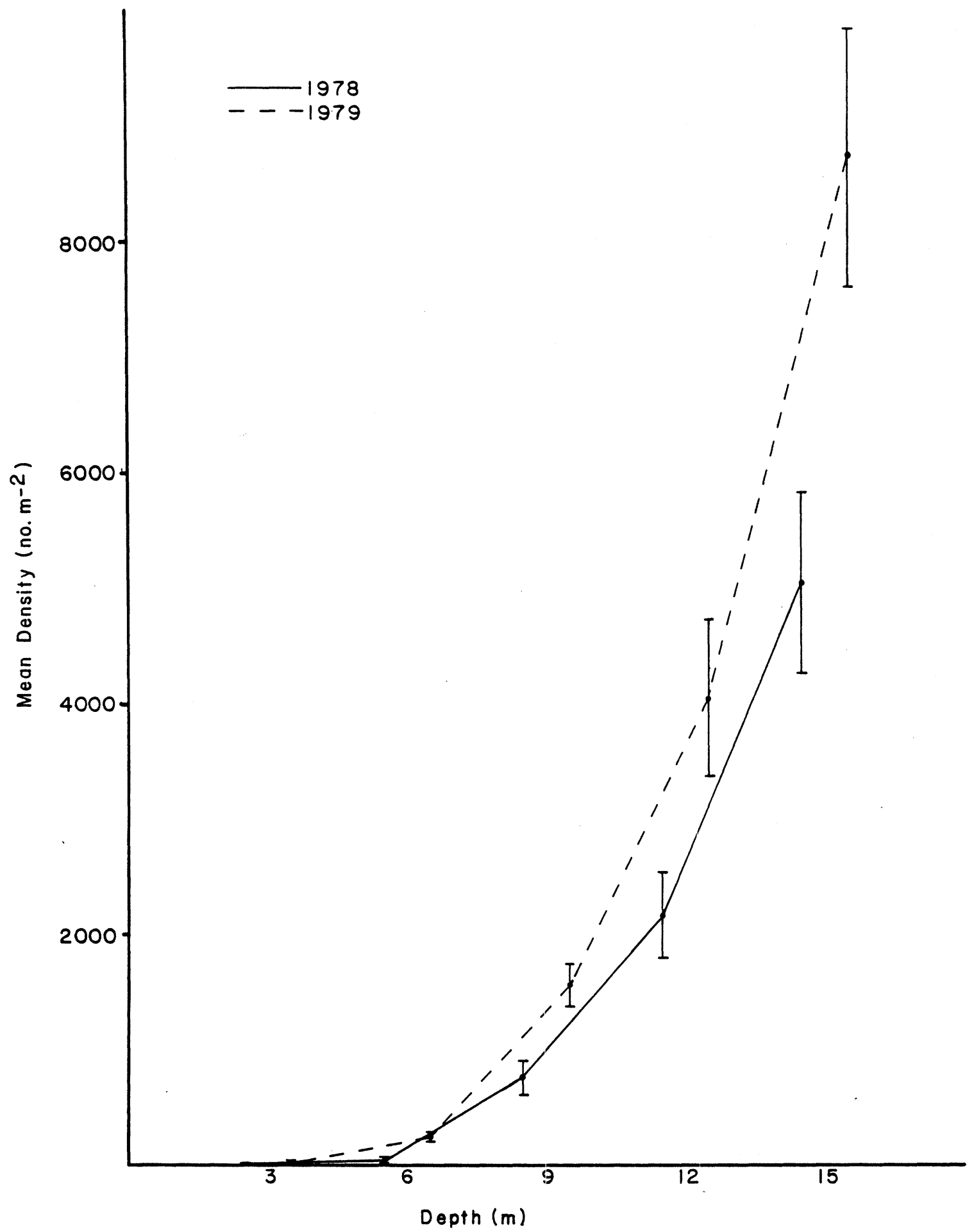

Fig. 30. Mean density (number $\mathrm{m}^{-2}$ ) of $\mathrm{F}$. hoyi collected at $3-15 \mathrm{~m}$ during 1978 and 1979 in eastern Lake Mi.chigan near the J. H. Campbell Plant. Density estimates at each depth were computed by averaging over all months within each year $(n=36)$. Standard error denoted by vertical bar. 


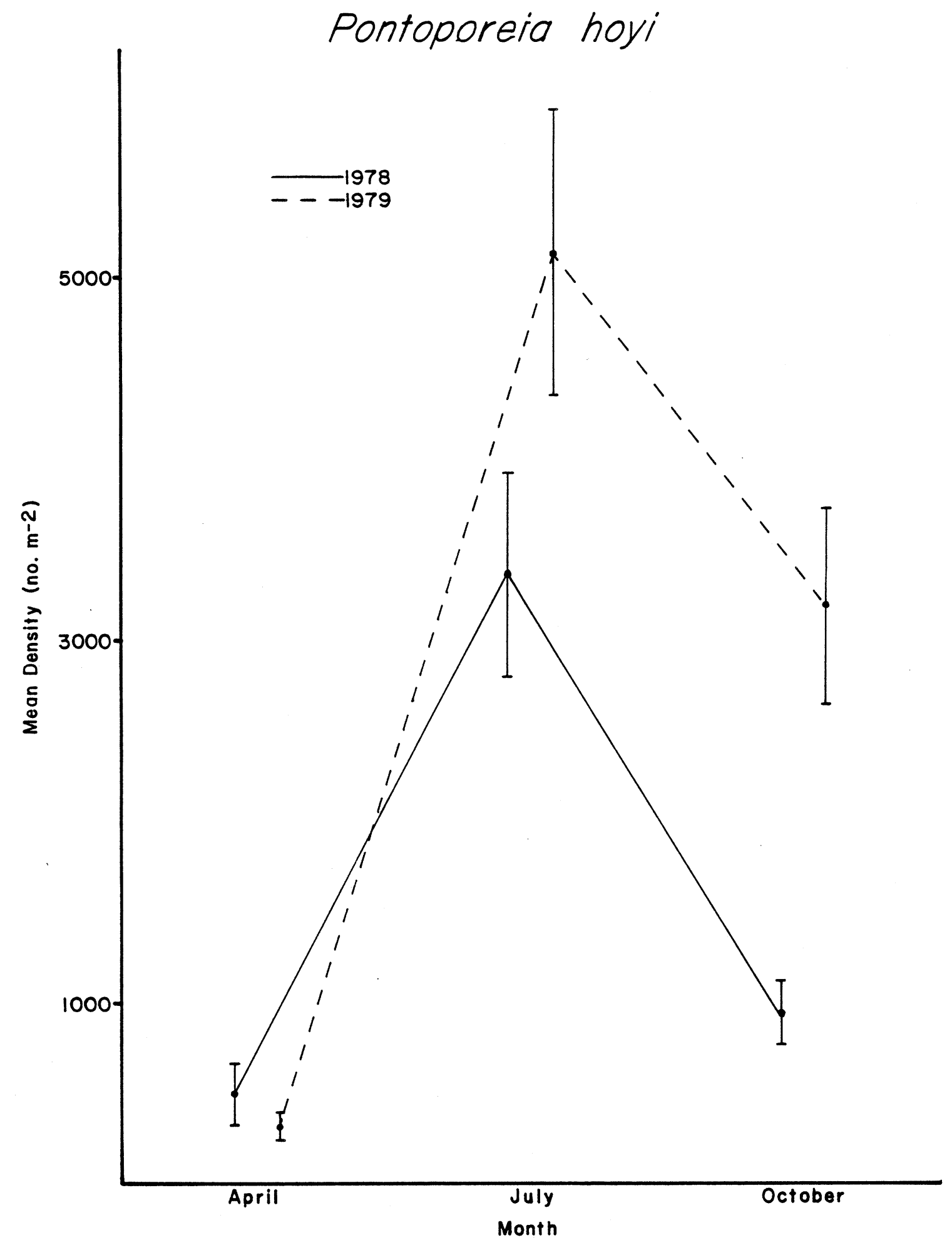

Fig. 31. Mean density (number $\mathrm{m}^{-2}$ ) of $\underline{\mathrm{p}}$. hoyi collected during April, July and October 1978 and 1979 in eastern Lake Michigan near the J. H. Campbell Plant. Density estimates for each month were computed by averaging over all depths within each year $(n=60)$. Standard error denoted by vertical bar. 
than in outer 1978 to 1979 regional comparisons when averaged over months, combined depths $9-15 \mathrm{~m}$, or both (Tables 7 and 8 ). In fact, only the outer region showed an overall significant increase in $\underline{\underline{P}}$. hoyi density between years, which was most evident in April and October. While yearly within-region changes were extensive, 1979 regional comparisons of $\underline{P}$. hoyi mean density for months, depths, and regions indicated there were no significant regional differences in 1979 (Table 9). However, analysis of each month and depth sampled in 1979 indicated that at 12 and $1.5 \mathrm{~m}$ during July $1979 \underline{\mathrm{p}}$. hoyi mean density was significantly greater in the inner region when compared with the outer region (Table 10). While the outer region generally had a greater abundance of $\underline{P}$. hoyi in 1979 , only at $15 \mathrm{ml}$ in October did the outer region density significantly exceed inner region density (Table 10, Fig. 32).

Analysis of $\underline{P}$. hoyi size classes in 1.978 indicated a large percentage of $\underline{P}$. hoyi in the inner region was one size class larger than in the outer region (Fig. 33). This trend was particularly evident during April at 9-15 $\mathrm{m}$ and in July at 9-12 m, but not at these depths in. October 1978.

Analysis of $\underline{P}$. hoyi size classes in 1.979 suggested a pattern similar to but not exactly like that observed during 1978. During April 1979, $\underline{P} \cdot \underline{\text { hoyi }}$ individuals in the outer region at 9-15 m were primarily gravid having not released their brood as of 19 April. While this same condition prevailed at 12 and $15 \mathrm{~m}$ in the inner as well as the outer region, individuals collected at $9 \mathrm{~m}$ in the inner region were either spent females (i.e., having already released their young) or young, recently released $\underline{\mathrm{P}}$. hoyi $(<3 \mathrm{~mm})$.

Subsequent collections made in July further suggested that there was an inner/outer $\underline{P}$. hoyi size-class difference, not only at $9 \mathrm{~m}$ but at 12 and $15 \mathrm{~m}$ also. However, the percent composition differences for a given size class were not as extreme as those observed during April at $9 \mathrm{~m}$. It was also noted at 


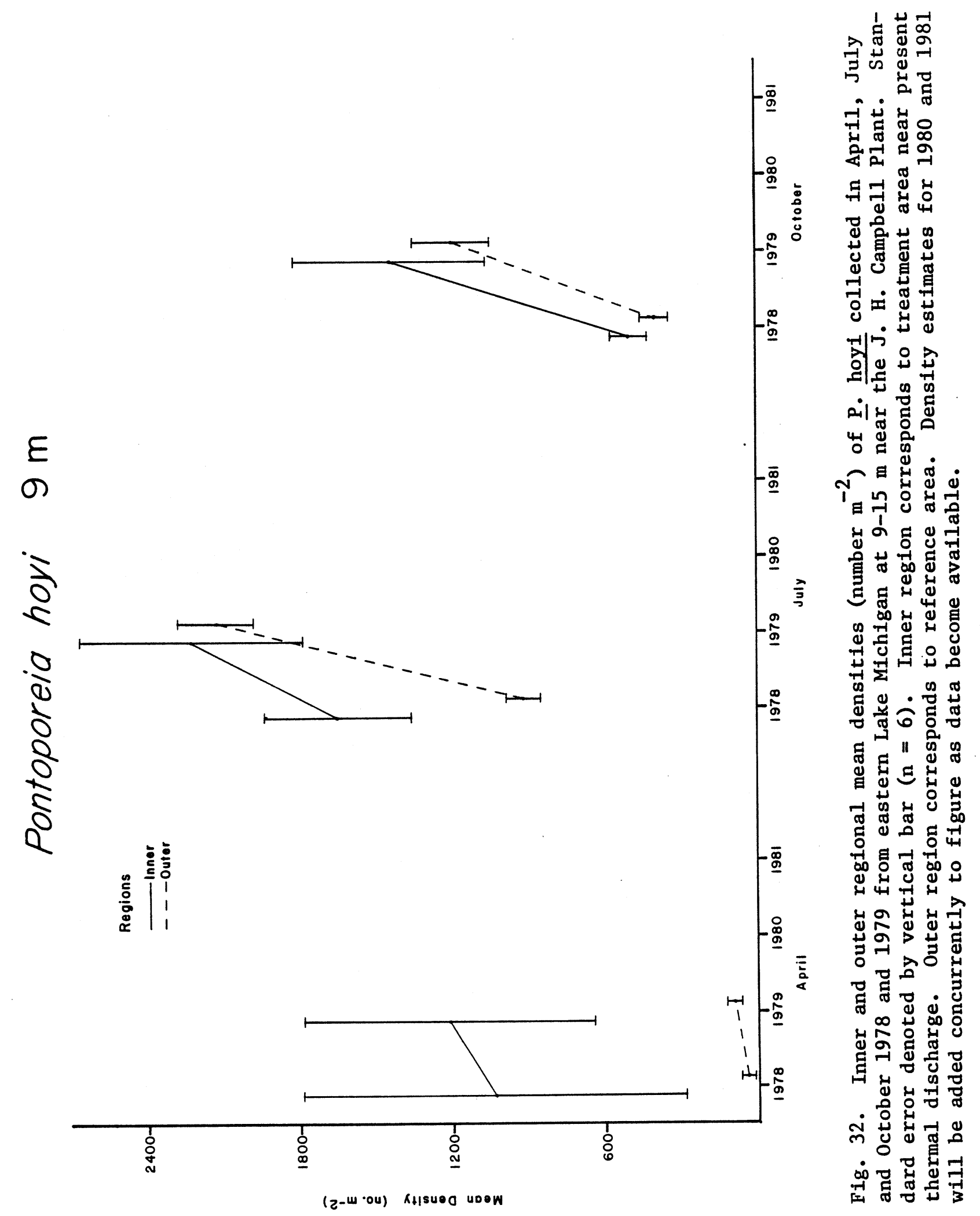




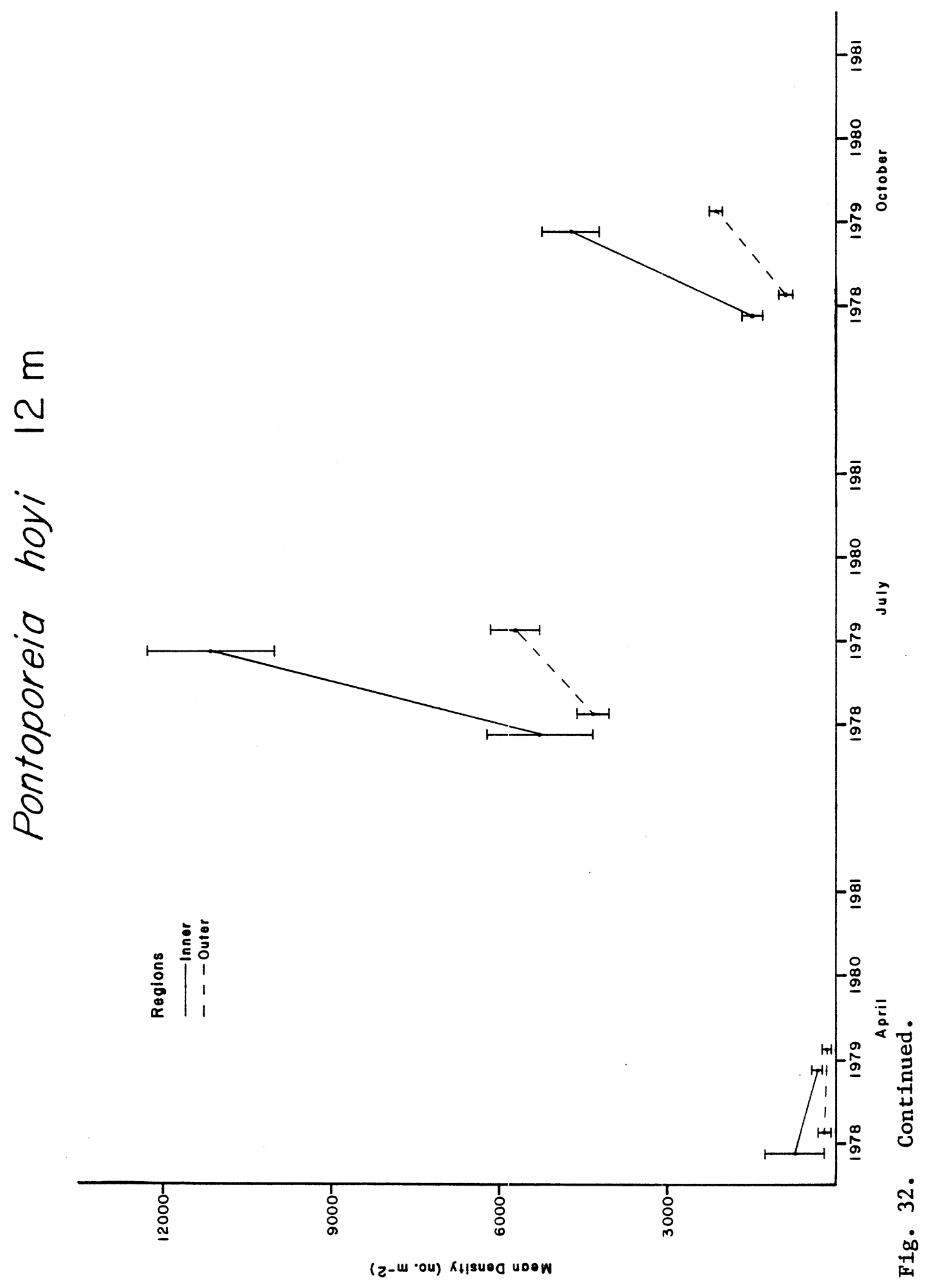




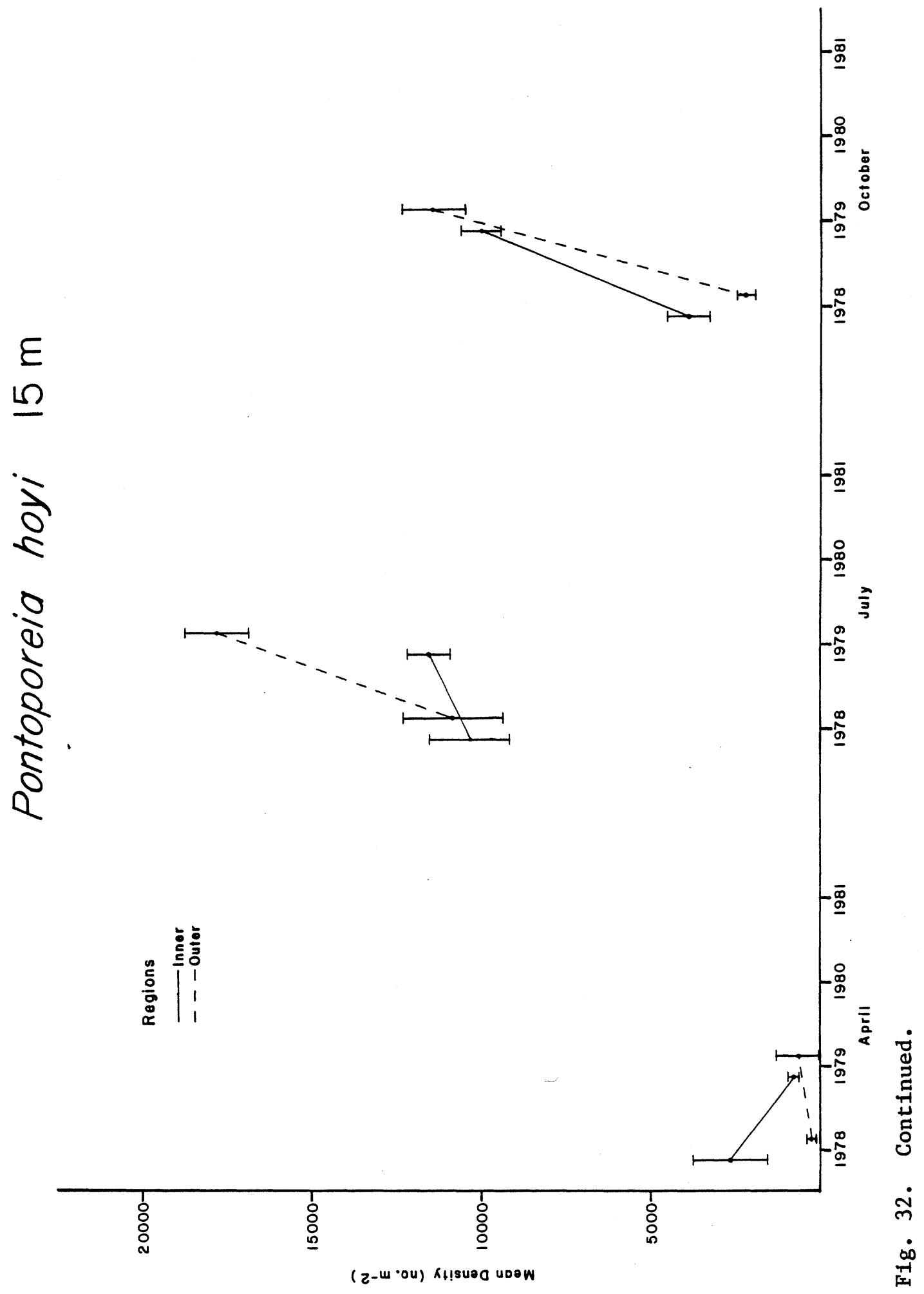




\section{Pontoporeia hoyi}
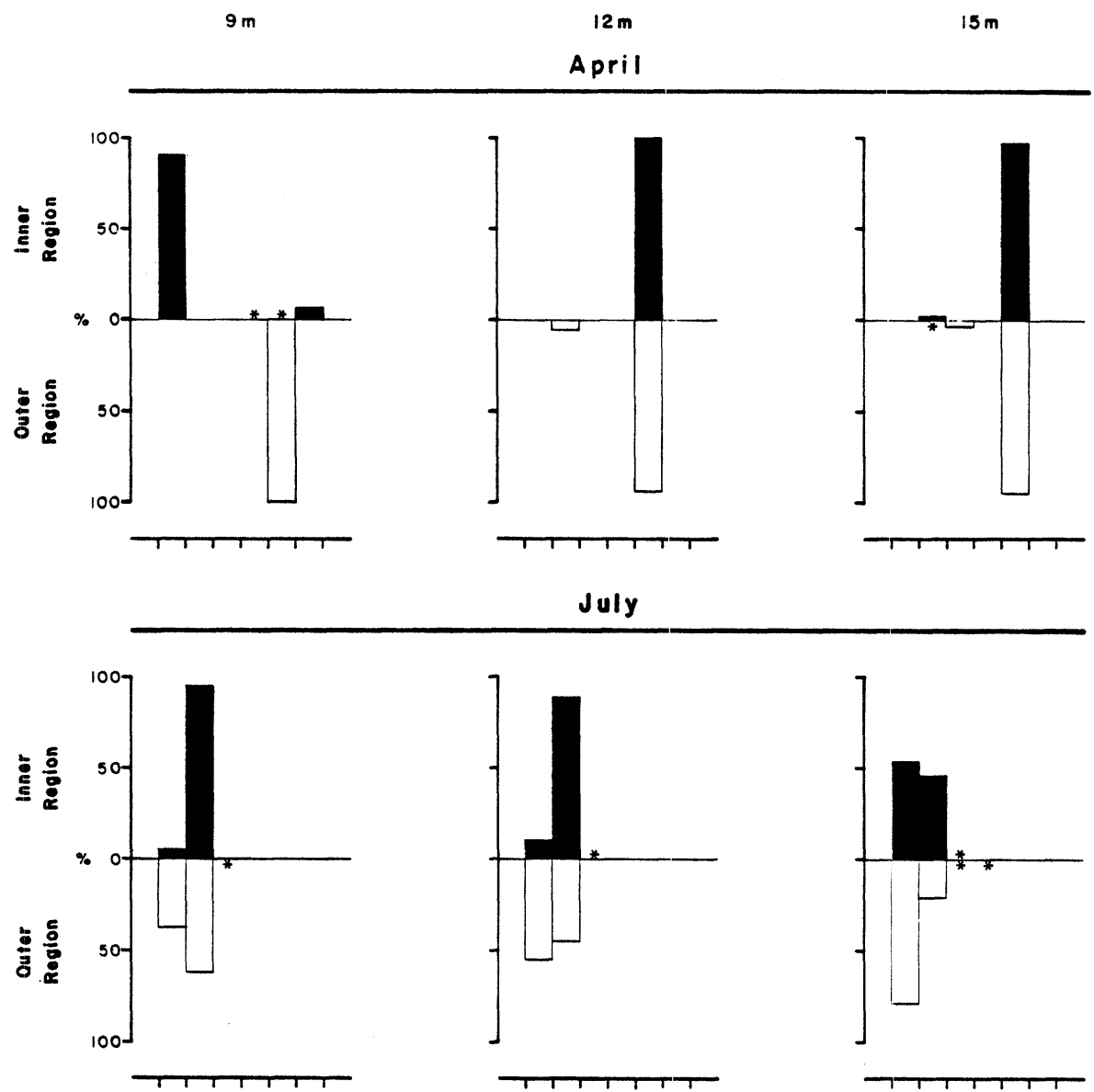

Size Classes

$1=<3 \mathrm{~mm}$

$2=3-5 \mathrm{~mm}$ $3=5-7 \mathrm{~mm}$

$4=>7 \mathrm{~mm}$

$5=$ Gravid

6. Spent

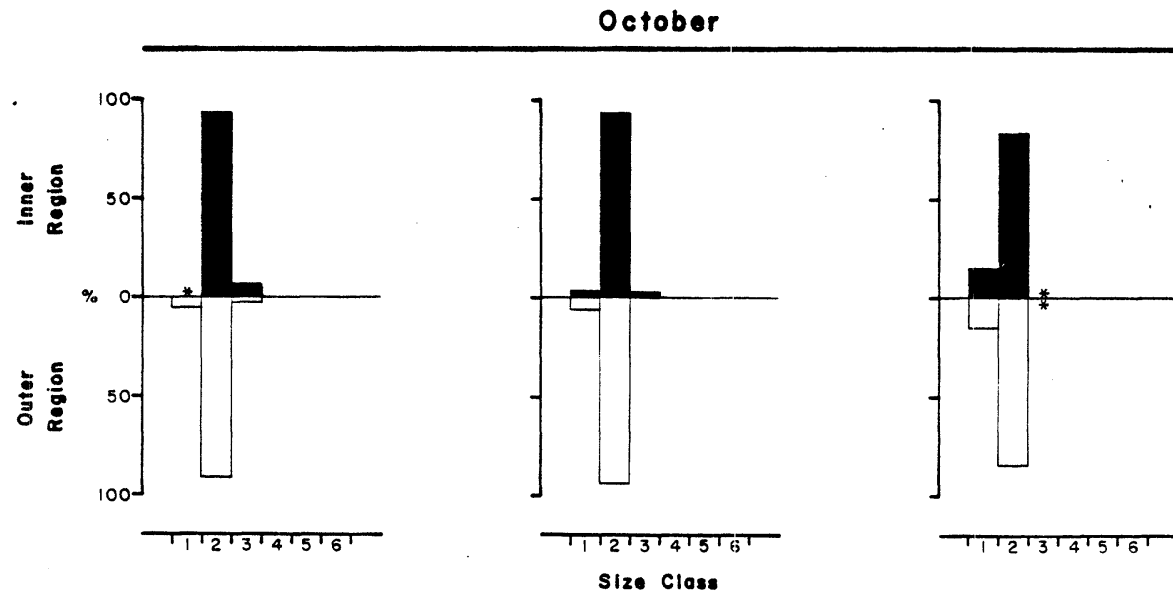

Fig. 33. Percent distribution of $\mathrm{P}$. hoyi size classes in the inner and outer regions at 9-15 m during April, July and October 1979. Samples were collected from eastern Lake Michigan near the J. H. Campbell Plant. $(*=<2 \%)$. 
9-15 $\mathrm{m}$ in 1979 that $\underline{\mathrm{P}}$. hoyi individuals were more advanced in their life cycle in the shallower depths when compared with those from deeper water in the inner region during April, in both regions during July, and only very slightly in both regions during October. A similar pattern was observed during 1978 for both regions in April and July, but not October. Finally, in 1979 as well as in

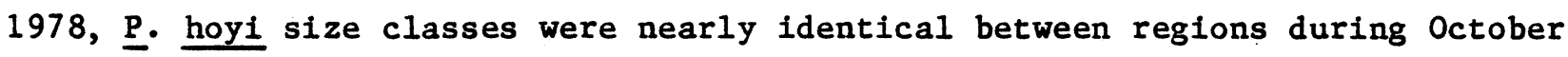
at $9-15 \mathrm{~m}$.

It appeared that growth and development of $\underline{P}$. hoyi occurring in both regions at 9-15 m on 19 April 1979 were reduced relative to 18 April 1978 . By 18 April 1978, the majority of $\underline{P}$. hoyi individuals were either spent females or newly released young. However, on 19 April 1979 when compared with 18 April 1978, there were more gravid specimens, fewer spent ones and fewer newly released individuals in samples.

\section{SEDIMENT DISTRIBUTION}

The general sediment distribution pattern near the Campbell Plant during 1979 was similar to that observed during 1978. Sediments collected during both years were described as well to moderately sorted, fine sand. Depth zonation of sediment types (i.e., grain size as measured by weight percent distribution among phi size classes) was evident. The 3-m zone was characterized by medium and fine sands, $6 \mathrm{~m}$ by coarse to fine sands, $9 \mathrm{~m}$ by fine sand, $12 \mathrm{~m}$ by fine to very fine sands, and $15 \mathrm{~m}$ by medium to very fine sands. Composition of sediments from the 6- and 9-m depths during 1979 deviated distinctly from those same depths sampled in 1978. In 1979, 6-m sediments tended toward a finer type than observed in 1978. The 1979 9-m depth had only small amounts of very fine sand and large amounts of fine sand and was consequently slightly coarser than was found in 1978 (Table 12). 


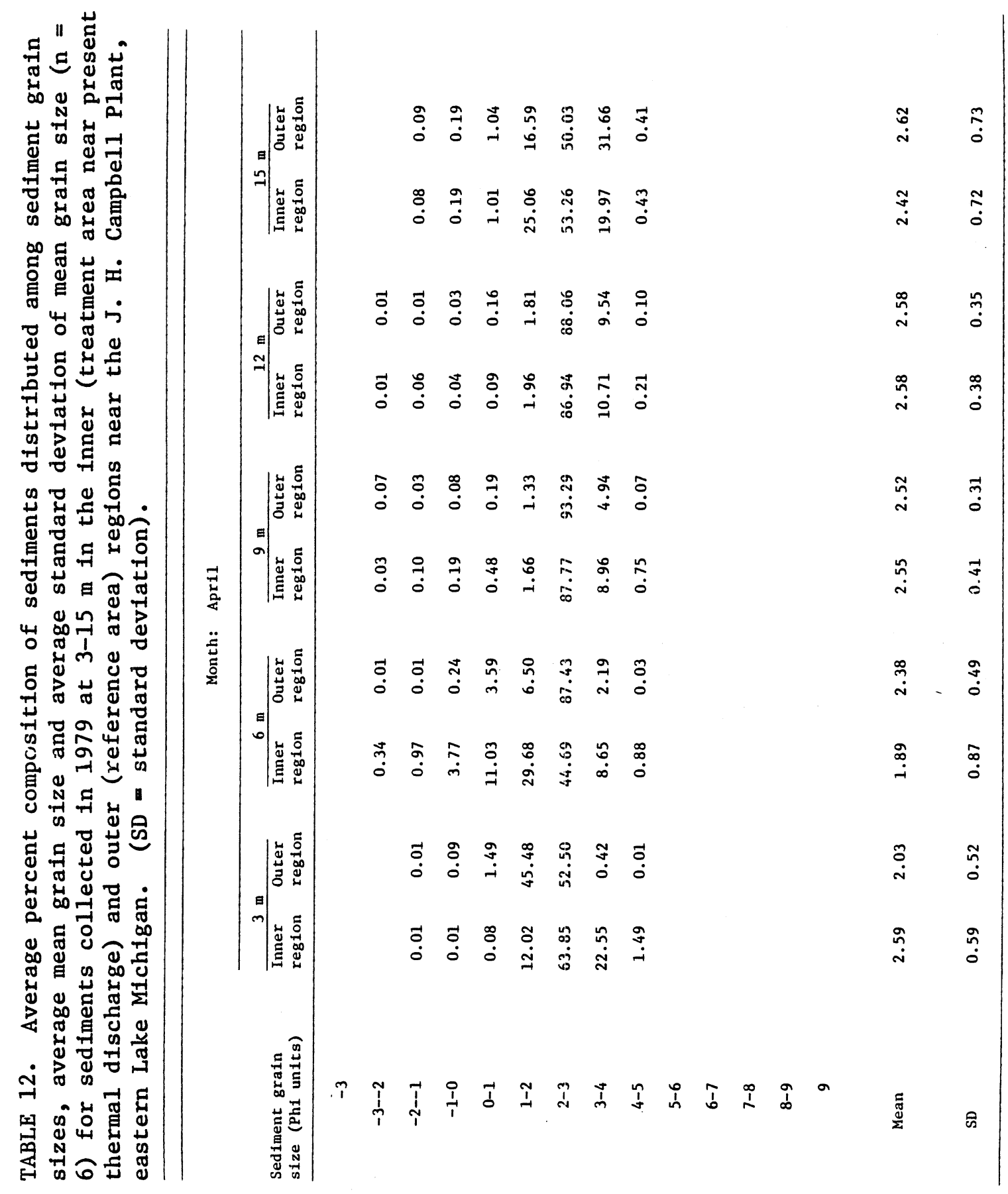




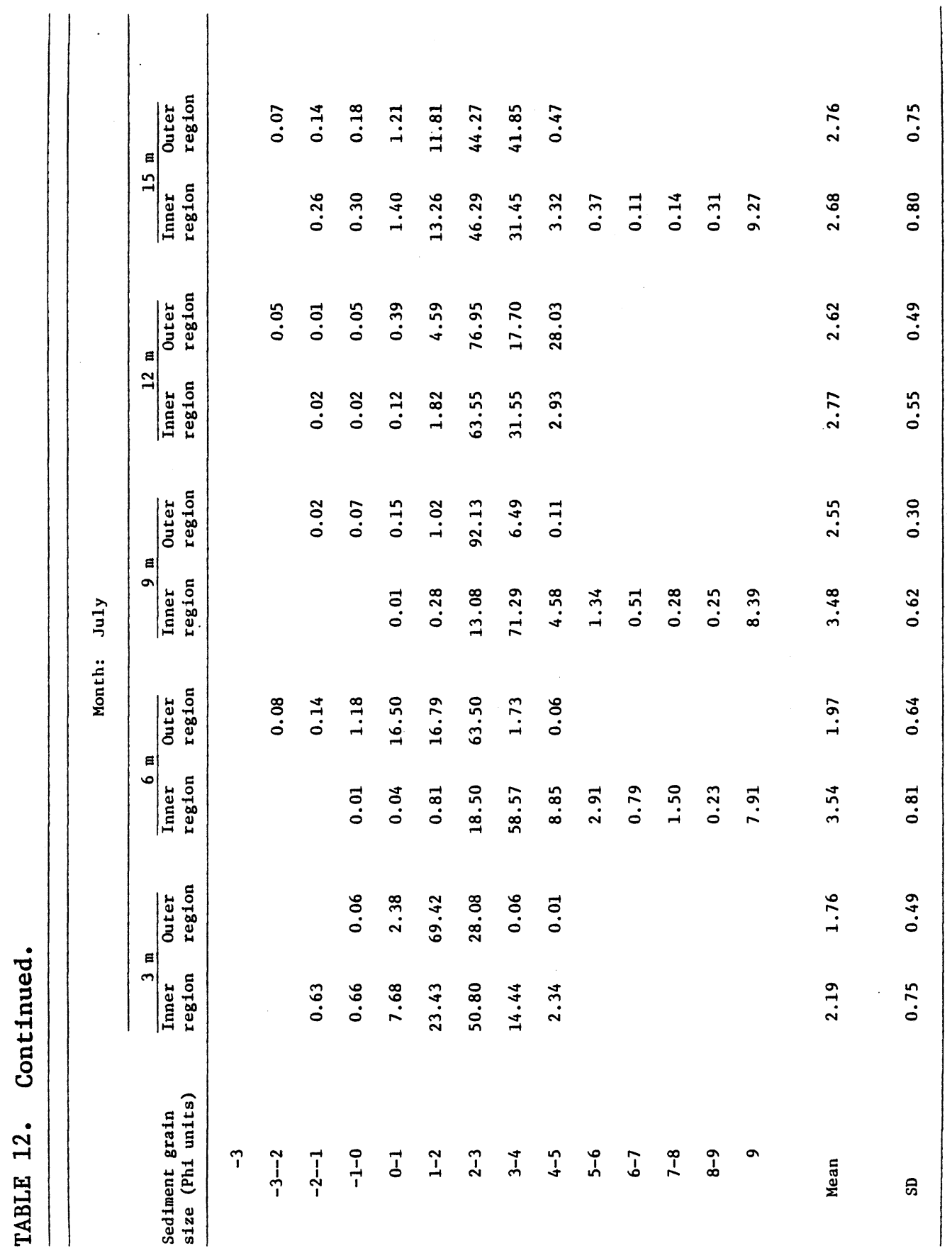




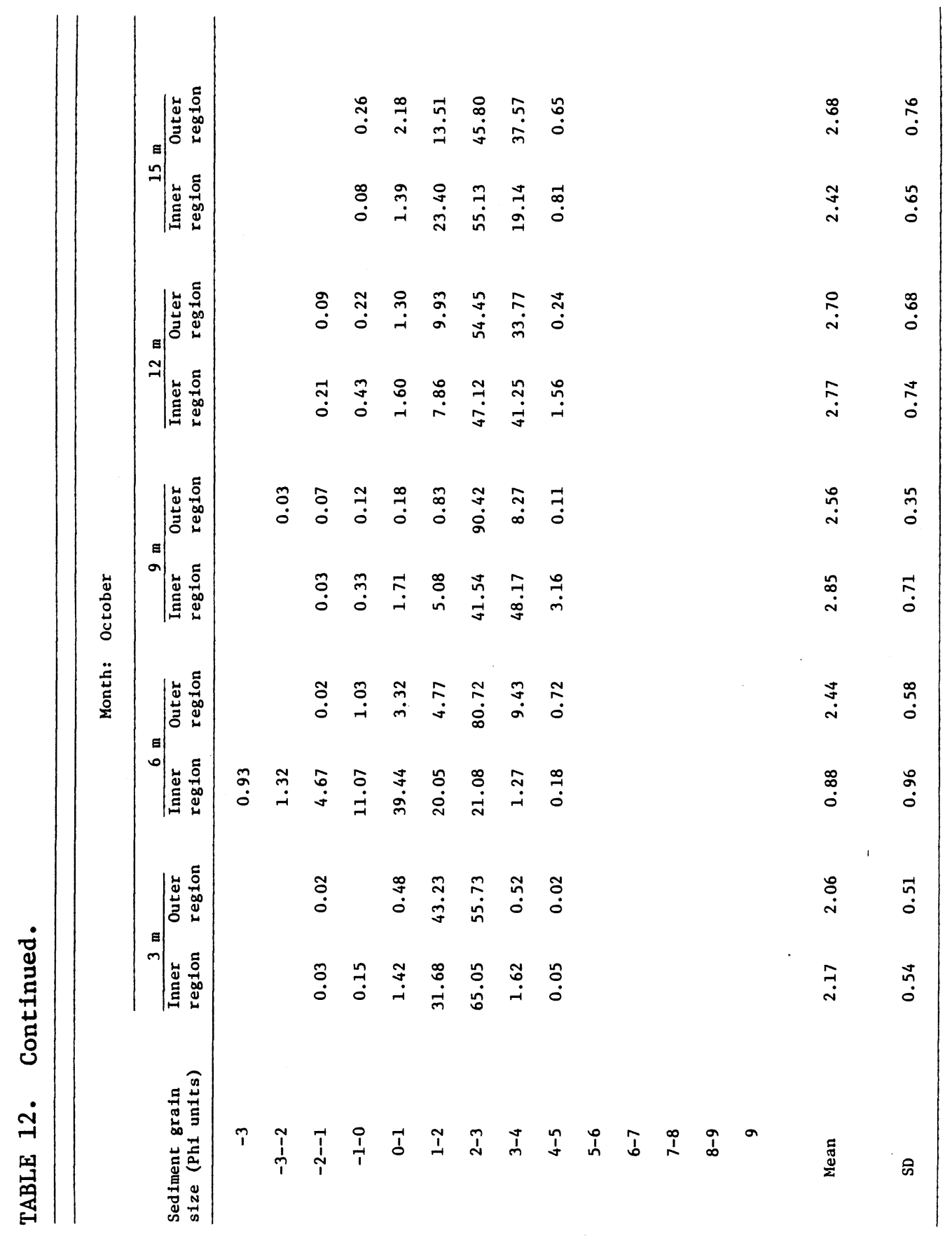


The most striking sediment distribution pattern was observed in the inner region during July 1979. Since dredging operations were being conducted concurrent with installation of offshore intake and discharge units, sediment samples were collected at approximately $0.16 \mathrm{~km}$ north of the present onshore discharge canal. Sediments collected in the inner region in 1979 were decidedly uncharacteristic of the 1978 sediment types at 3,6 , and $9 \mathrm{~m}$, and in particular at the outer region during July 1979. While 6- and 9-m inner region depths were characterized as predominantly moderately sorted, very fine sand with an unusually high amount of silt and clay, sediments collected at $3 \mathrm{~m}$ contained a large amount of very fine sand (14\%) and silt (2.3\%) compared with previous months. In addition to uncommon amounts of very fine sand (approximately 60-70\%) at the 6-m and 9-m depths, these depths were comprised of approximately $14.1 \%$ and $6.7 \%$ silt and $8.1 \%$ and $8.6 \%$ clay, respectively. While no abnormal sediments were noted at $12 \mathrm{~m}$ in the inner region, increased amounts of silt (3.9\%) and clay (9.6\%) were present at $15 \mathrm{~m}$. Samples collected during October required a relocation of the inner transect slightly north to avoid a wide sand bar in the inner region that altered expected lake depth from 6 to $9 \mathrm{~m}$ to approximately $3 \mathrm{~m}$. Since samples could not have been collected at 3-9-m depths, for purposes of comparability and safety precautions regarding operation of the $\mathrm{R} / \mathrm{V}$ Mysis ( $\mathrm{i} . \mathrm{e}$. , the vessel draws $1.8 \mathrm{~m}$ leaving only $1.2 \mathrm{~m}$ clearance along an uncertain lake bottom), the inner transect was relocated. Although sediments collected along the relocated inner transect were generally similar to those collected along the outer transect in October, both the 9- and 12-m inner region depths had noticably higher quantities of silt $(3.2 \%$ and $1.6 \%$, respectively) than did the same depths along the outer transect $(0.1 \%$ and $0.2 \%$, respectively) (Table 12 ). 


\section{DISCUSSION}

Several differences were observed in the survey area when 1978 findings were contrasted with 1979 regarding benthic macroinvertebrate and sediment parameters. The most prominent differences were an increase in the abundance of total macrobenthos, increased density of Pontoporeia hoyi, enchytraeids, and turbellarians, continued Pontoporeia hoyi size-class differences between regions, decreased chironomid density, a shift of dominant taxa within specified depth/time regimes for chironomids, naidids, Pisidium, and gastropods, and increased amounts of finer sediment types present in the inner region of the study area.

The entire survey area had an increase in the number of macrobenthos from 1978 to 1979, with the total increase not apparent in one region more than the other. Turbellarians, enchytraeids, $\underline{P} \cdot \underline{\text { hoyi }}$, and chironomids contributed most to the change in macrobenthic increased density observed from 1978 to 1979. From 1978 to 1979, the major difference found in the inner region was a significant decline in the abundance of chironomids. Although the density of P. hoyi increased in the inner region, it was not a significant increase.

Within the outer region from 1978 to 1979, the primary difference noted was a significant increase in the density of $\underline{\underline{P}}$. hoyi. While there was a decline in the number of chironomids in the outer region, the decrease was not significant. Both regions had similar significant increases in the number of turbellarians and enchytraeids.

In 1979, primary regional differences were observed with chironomid and tubificid densities and $\underline{P}$. hoyi size classes. Sediment type changes and species dominance differences were also documented. Chironomid populations were significantly reduced in the inner region while tubificid populations were 
significantly higher in the outer region. $\underline{P}$. hoyi in the outer region were approximately one size class behind those in the inner region during April $(9 \mathrm{~m})$ and July $(9-15 \mathrm{~m})$.

While the entire survey area in 1979 experienced an increased benthic density over 1978 levels, chironomids declined in number in both regions. Factors such as winter harshness, storm and wave activity, poor availability of food, adverse weather conditions for adult breeding swarms in 1978, or natural year-to-year variability may have caused decreased abundance of chironomids. However, since the decline in 1979 within the inner region was more extensive than in the outer region, whether comparing 1978 with 1979 or regions within 1979, other factors may have contributed to the inner region decline in chironomid populations. Even though both regions in 1979 had a significant decrease in the number of chironomids present during July but not during April or October, the outer region still had significantly more chironomids than did the inner region, particularly at $3-9 \mathrm{~m}$. While a general decline in chironomid abundance may have been caused by any of the factors previously mentioned, a portion of the difference noted for chironomids between regions appeared to be related to the change in sediment type noted during July 1979 at 3-9 $\mathrm{m}$. With a finer sediment type present in the inner region during July, chironomid taxa usually found at 3-9 $\mathrm{m}$ were found in greater density in the outer than the inner region. In addition, chironomids normally found in the finer sediments at 9-15 m were now found more frequently in higher numbers at $3-9 \mathrm{~m}$ in the inner region than in the outer region. Thus, it appeared that construction activities altered the usual chironomid community structure at 3-9 $\mathrm{m}$ and reduced the density of chironomids in the inner region. Although chironomid and sediment differences were observed during October as well, they were less extreme, thereby suggesting recovery from construction activities as normal 
sediment conditions returned.

Concurrent with the chironomid community structure changes, naidid community structure also appeared to be al.tered at 3-9 m during July 1979 when comparing inner and outer region densities. Within the entire survey area, Vejdovskyella intermedia density increased, but a proportionally higher increase in densities was observed in the inner region, particularly at 3-9 m in July. Outer region naidid community structure, although having more $\underline{V}$. intermedia present in 1979 than 1978, resembled the 1978 naidid community structure much more closely than did the inner region in 1979. It would appear that there were natural decreases and increases for certain naidid species in the survey area that altered naidid community structure. Regardless of what may have been natural changes in naidid community structure, changes in the inner region were more extreme than those recorded in the outer region at 3-9 m in July. It seems reasonable to hypothesize that construction activities may also have altered naidid community structure in the inner region in addition to whatever natural changes were inherently in progress in the entire survey area.

It is yet unresolved why differences were observed among Pontoporeia hoyi size classes. Based on 2 yr of observations it does appear that gravid $\underline{P}$. hoyi present in the 9-15-m inner region during April tended to release their brood sooner than their counterparts in the outer region ( $5 \mathrm{~km}$ north). Possibly, warmer water and increased food availability in the inner region caused slightly more rapid development of $\underline{P}$. hoyi. The size-class difference was also present during July at 9-15 m, but not in October. Since no size-class difference was noted in October, the end result of regional $\underline{P}$. hoyi size-class differences appeared to be minimal as both regions had similar densities and size-class distributions of $\underline{P}$. hoyi. The same conclusion was reached after examining $1978 \underline{\mathrm{P}}$. hoyi data and was first noted by Mozley (1974) near the D.C. 
Cook Nuclear Power Plant. He stated that early or late released $\underline{P} \cdot \underline{\text { hoyi }}$ result in a similar size-class structure by late summer to fall. This conclusion appeared to be applicable to $\underline{P}$. hoyi collected from the Campbell survey area during 1979. Although the average yearly $\underline{P}$. hoyi density was significantly greater in 1979 when compared with 1978, during 1979 there was no statistical difference between overall mean regional $\underline{P}$. hoyi densities even though the inner region density of the amphipod was greater than the outer region abundance. However, the outer region experienced highly significant $\underline{P}$. hoyi density increases from 1978 to 1979, in particular during April and October. The inner region also had highly significant density increases for $\underline{P} \cdot \underline{\text { hoyi }}$ during October. Whether natural or other conditions favored a disproportionate increase in the outer region from 1978 to 1979 or prevented proportionally similar increases in the inner region is unknown given current knowledge. During July, when construction activities appeared to affect benthos to the greatest degree, $\underline{P}$. hoyi densities in the inner and outer regions were not only similar to each other, but also to 1978 densities, thereby indicating no detectable difference due to this aspect of construction activities. Based upon normal sediment distribution patterns, it would have been expected that

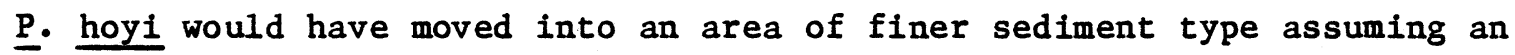
appropriate bacterial fauna was established (Marzolf 1965) as silty sands have been shown to be preferred by $\underline{P}$. hoyi (Alley 1968, Henson 1970, Mozley and Alley 1973, and Mozley and Howmiller 1977). However, increased physical stress by wave action, increased light, and temperature regimes, coupled with questionable availability of food material on freshly deposited fine sediments and very high sedimentation rates, may have functioned to keep $\underline{P} \cdot \underline{\text { hoyi }}$ densities similar from 1978 to 1979 in the inner region during July. Density and community structure changes for chironomids and naidids 
appeared to be related to construction activities, particularly at 3-9 m during July. Sediment descriptions from samples collected in the inner region at 3-15 m during July were very different from either the previous year or the outer region. Although sedimentary changes in the inner region did not appear to affect the density of $\underline{P}$. hoy 1 , there was a proportionately greater increase in $\underline{P}$. hoyi in the outer region than in the inner region. In addition, there was a $\underline{P}$. hoyi size-class difference evident in 1979 similar to that observed in 1978. $\underline{P}$. hoyi occurring in the inner reglon were generally one size class advanced during April $(9 \mathrm{~m})$ and July $(9-1.5 \mathrm{~m})$ when compared with outer region

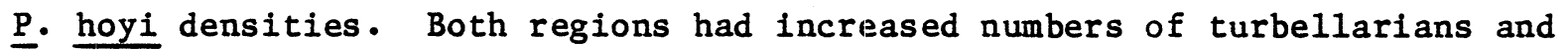
enchytraeids as well as $\underline{P}$. hoyi that helped contribute to an overall increase in the macrobenthos from 1978 to 1979. Although tubificid density differences were noted between regions, these differences appeared to be inconclusive and will require more data. While there was a change in gastropod community structure from V. sincera/Amnicola sp. dominance in 1978 to $\underline{\mathrm{V}}$. sincera/Lymnaea sp. dominance in 1979, and in the Pisidiun community structure from $\underline{P}$. $\underline{\text { nitidum, }}$

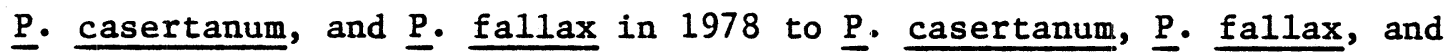

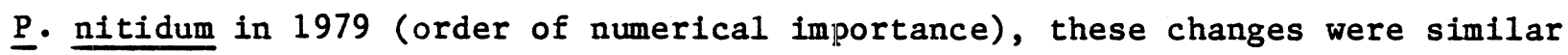
throughout the survey area and apparently were unrelated to construction processes. In conclusion, changes observed for chironomids and naidids were apparently related to construction activities, while density changes observed for $\underline{\mathrm{P}}$. hoyi, turbellarians, and enchytraeids and changes in gastropod and Pisidium community structure were apparently unrelated to plant processes. These changes are likely the result of natural or undetermined processes occurring across the whole survey area. Reasons for the $\underline{P}$. hoyi size-class differences observed between regions remain unexplained. Overall, 1979 data when contrasted with 1978 data indicated there was 
considerable year-to-year variability in preoperational data as might be expected (Mozley 1974, 1975). This was particularly evident not only for some major taxonomic groups, but for many species. Construction activities increased the complexity of interpreting results by introducing additional variability in addition to natural variability. Future analysis will need to reconsider conclusions reached once construction operations cease. With completion of 1980 data collection and analysis, permanency and impact of construction activities will become clearer. Based on observations made during October 1979, it appeared as though physical processes in the lake would cause a return to normal sedimentary patterns and presumably normal macrobenthic distributions. With increased wave or storm activity, much of the silt and clay as well as finer sands may well be moved offshore and deposited beyond the survey area. In addition, given a northerly current the finer sands, silt and clay may be transported along shore toward the outer region. It is likely that there is sufficient physical energy in the form of waves to transport the majority of these particles offshore as opposed to alongshore. If this is the case, effect of construction activities would likely be minimal and temporary in nature. Lake-wide processes affecting natural variability should have equal effects in both regions and, presuming that there were not thermal plume effects on benthos, then benthic populations will be affected equally in both regions . 
Alley, W.P. 1968. Ecology of the burrowing amphipod Pontoporeia affinis in Lake Michigan. Spec. Rep. No. 36. Great Lakes Res. Div., Univ. Mich., Ann Arbor, Mich. 131 pp.

Alley, W.P. and S.C. Mozley. 1975. Seasonal abundance and spatial distributions of Lake Michigan macrobenthos, 1964-67. Spec. Rep. No. 54. Great Lakes Res. Div., Univ. Mich., Ann Arbor, Mich. 103 pp.

Beck, E.C. and W.M. Beck, Jr. 1969. Chironomidae (Diptera) of Florida III. The Harnischia complex (Chironominae). Bull. Florida State Mus. (Biol. Sci.) 13: 277-313.

Chang, W.Y.B. and M.H. Winnell. 1980. Comment on the fourth root transformation. Can. J. Fish. Aquat. Sci. (in press). Coakley, J.P. and G.S. Beal. 1972. SEDAN - A computer program for sediment particle size analysis. Rep. Ser. No. 20, Canada Inland Water Directorate, Dept. Environ. 33 pp.

Cohen, J. 1969. Statistical Power Analysis for the Behavioral Sciences. Academic Press, New York. 415 pp.

Consumers Power Company. 1975. J.H. Campbell Plant Unit No. 3. Environ. Rep. Vo1. 1. Consumers Power Co. Jackson, Mich. (Unnum. pp•)

Curry, L.L. 1958. Larvae and pupae of the species Cryptochironomus (Diptera) in Michigan. Limnol. Oceanogr. 3: 77-95.

Dixon, W.J. and F.J. Massey, Jr. 1969. Introduction to Statistical Analysis. 3rd ed. McGraw-Hill, New York. 638 pp.

Elliott, J.M. 1971. Some methods for the statistical analysis of samples of benthic invertebrates. Sci. Publ. No. 25, Freshwater Biol. Assoc. 144 pp. 
Henson, E. B. 1970. Pontoporeia affinis (Crustacea, Amphipoda) in the Straits of Mackinac region. In Proc. 13th Conf. Great Lakes Res., pp. 601-610. Int. Assoc. Great Lakes Res.

Hiltunen, J.K. 1967. Some oligochaetes from Lake Michigan. Trans. Amer. Microsc. Soc. 86: 433-454.

Hirvenoja, M. 1973. Revision der Gattung Cricotopus van der Wulp und ihrer Verwandten (Diptera, Chironomidae). Ann. Zool. Fennici 10: 1-363. Jackson, G.A. 1977. Nearctic and palaearctic Paracladopelma Harnisch and Saetheria n. gen. (Diptera: Chironomidae). J. Fish. Res. Board Can. 34: 1321-1359.

Johnston, E.M. 1973. Effect of a thermal discharge on benthos populations: statistical methods for assessing the impact of the Cook Nuclear Plant. Benton Harbor Power Plant Limnological Studies, Part XVIII. Spec. Rep. 44. Great Lakes Res. Div., Univ. Mich., Ann Arbor, Mich. 20 pp. - 1974. Statistical power of a proposed method for detecting the effect of waste heat on benthos populations. Benton Harbor Power Plant Limnological Studies, Part XX. Spec. Rep. No. 44. Great Lakes Res. Div., Univ. Mich., Ann Arbor, Mich. 29 pp. Jude, D.J., B.A. Bachen, G.R. Heufelder, H.T. Tin, M.H. Winnell, F.J. Tesar, and J.A. Dorr III. 1978. Adult and juvenile fish, ichthyoplankton and benthos populations in the vicinity of the J.H. Campbell Power Plant, eastern Lake Michigan, 1977. Spec. Rep. No. 65. Great Lakes Res. Div., Univ. Mich., Ann Arbor, Mich. 639 pp.

Jude, D.J., G.R. Heufelder, H.T. Tin, N.A. Auer, S.A. KIinger, P.J. Schneeberger, T.L. Rutecki, C.P. Madenjian, and P.J. Rago. 1979. Adult and juvenile fish and ichthyoplankton in the vicinity of the J.H. Campbell Power Plant, eastern Lake Michigan, 1978. Spec. Rep. No. 73. Great Lakes Res. Div., Univ. Mich., Ann Arbor, Mich. 607 pp. 
Jude, D.J., G.R. Heufelder, N.A. Auer, H.T. Tin, S.A. Klinger, P.J. Schneeberger, C.P. Madenjian, T.L. Rutecki, and G.G. Godun. 1980. Adult and juvenile fish and ichthyoplankton in the vicinity of the J.H. Campbell Power Plant, eastern Lake Michigan, 1.979. Spec. Rep. 79 of the Great Lakes Res. Div., Univ. Mich., Ann Arbor, Mich. (in press).

Kirk, R.E. 1968. Experimental Design: Procedures for the Behavioral Sciences. Brooks/Cole, Belmont, Cal. 577 pp.

Krumbein, W.C. 1938. Size frequency distribution of sediments and the normal phi curve. J. Sediment. Petrol. 8: 84-90.

Lenz, F. 1954. Die Metamorphose der Tendipedinae (13c. B.). In E. Lindner, ed., Die Fliegen der palaearktischen Region, Vo1. 3, pp. 139-169.

Marzolf, G.R. 1965. Substrate relations of the burrowing amphipod Pontoporeia affinis in Lake Michigan. Ecology 46:579-592.

Mozley, S.C. 1974. Preoperational distribution of benthic macroinvertebrates in Lake Michigan near the Cook Nuclear Power Plant. In Seibel, E. and J.C. Ayers, eds. The biological, chemical, and physical character of Lake Michigan in the vicinity of the Donald C. Cook Nuclear P1ant, pp. 5-138. Spec. Rep. No. 51, Great Lakes Res. Div., Univ. Mich., Ann Arbor, Mich. - 1975. Preoperational investigations of zoobenthos in southeastern Lake Michigan near the Cook Nuclear Plant. Spec. Rep. No. 56. Great Lakes Res. Div., Univ. Mich., Ann Arbor, Mich. 132 pp. and W.P. Alley. 1973. Distribution of benthic invertebrates in the south end of Lake Michigan. In Proc. 16th Conf. Great Lakes Res., pp. 87-96. Internat. Assoc. Great Lakes Res. and 0. Chapelsky. 1973. A ponar grab modified to take three samples in one cast with notes on ponar construction. In Proc. 16th Conf. Great Lakes Res., pp. 97-99. Internat. Assoc. Great Lakes Res. 
and L.C. Garcia. 1972. Benthic macrofauna in the coastal zone of southeastern Lake Michigan. In Proc. 15th Conf. Great Lakes Res., pp. 102-116. Internat. Assoc. Great Lakes Res. and R.P. Howmiller. 1977. Environmental Status of the Lake Michigan Region, Vol. 6, Benthos of Lake Michigan. Argonne Nat. Lab. ANL/ES-40. Argonne, IIl. 48 pp. and M.H. Winnell. 1975. Macrozoobenthic species assemblages of southeastern Lake Michigan, U.S.A. Verh. Internat. Verein Limnol. $19: 922-931$.

Powers, C.F. and A. Robertson. 1965. Some quantitative aspects of the macrobenthos of Lake Michigan. In Proceedings Eighth Conference on Great Lakes Research, pp. 153-157. Great Lakes Res. Div. Publ. 13. Univ. Mich., Ann Arbor, Mich.

Roback, S.S. 1957. The immature tendipedids of the Philadelphia area (Diptera: Tendipedidae). Monogr. Acad. Nat. Sci. Philadelphia 9. 152 pp. Robertson, A. and W.P. Alley. 1966. A comparative study of Lake Michigan macrobenthos. Limnol. Oceanogr. 11: 576-583.

Saether, 0.A. 1969. Some nearctic Podonominae, Diamesinae, and Orthocladiniinae (Diptera: Chironomidae). Bull. Fish. Res. Board Can. 170. $154 \mathrm{pp}$.

- 1971. Nomenclature and phylogeny of the genus Harnischia (Diptera: Chironomidae). Can. Ent. 103: 347-362. - 1973. Taxonomy and ecology of three new species of Monodiamesa Kieffer, with keys to nearctic and palaearctic species of the genus (Diptera: Chironomidae). J. Fish. Res. Board Can. 30: 665-679. - 1975. Nearctic and palaearctic Heterotrissocladius (Diptera: Chironomidae). Bull. Fish. Res. Board Can. 193. 67 pp. 
- 1976. Revision of Hydrobaenus, Trissocladius, Zalutschia,

Paratrissocladius, and some related genera (Diptera: Chironomidae). Bull. Fish. Res. Board Can. 195. 287 pp.

- 1977. Taxonomic studies on Chironomidae: Nanocladius,

Pseudochironomus, and the Harnischia complex. Bull. Fish. Res. Board Can. 196. $143 \mathrm{pp}$.

Seibel, E., R. Jensen and C. Carlson. 1974. Surficial sediment distribution of the nearshore waters in southeastern Lake Michigan. In Seibel, E. and J.C. Ayers, eds. The biological, chemical, and physical character of Lake Michigan in the vicinity of the Donald C. Cook Nuclear Plant, pp. 369-432. Spec. Rep. No. 51, Great Lakes Res. Div., Univ. Mich., Ann Arbor, Mich. Sokal, R.R. and F.J. Rohlf. 1969. Biometry. The principles and practice of statistics in biological research. W.H. Freeman and Company, San Francisco, Calif. 776 pp.

Soponis, A.R. 1977. A revision of the nearctic species of Orthocladius (Orthocladius) van der Wulp (Diptera: Chironomidae). Ent. Soc. of Canada, Ottawa. $187 \mathrm{pp}$.

Truchan, J.G. 1970. Biological survey of Lake Michigan in the vicinity of the Consumers Power Company's thermal discharge, August 11-13, 1970. (Unpub. ms.) Rep. of Mich. Dept. of Nat. Res., Lansing, Mich. 16 pp. Upchurch, S.B. 1969. Computer program for: sediment textural analysis. U.S. Lake Survey Misc. Paper 69-3, Dept. Army, Lake Survey District, Corps of Engineers. 27 pp.

Winnell, M.H. and D.J. Jude. 1979. Spatial and temporal distribution of benthic macroinvertebrates and sediments collected in the vicinity of the J.H. Campbell Plant, eastern Lake Michigan, 1978. Spec. Rep. No. 75. Great Lakes Res. Div., Univ. Mich., Ann Arbor, Mich. 199 pp. 

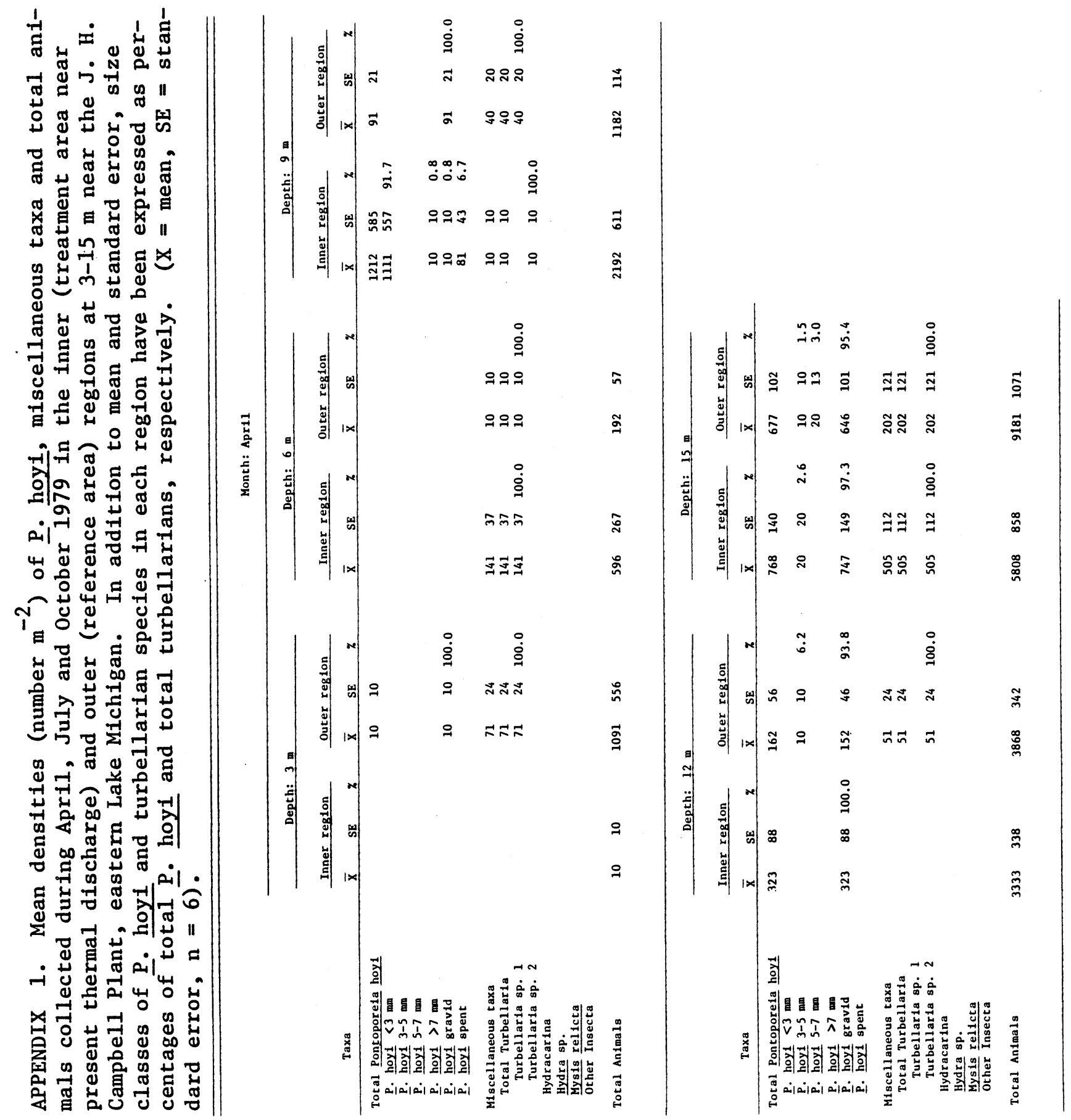


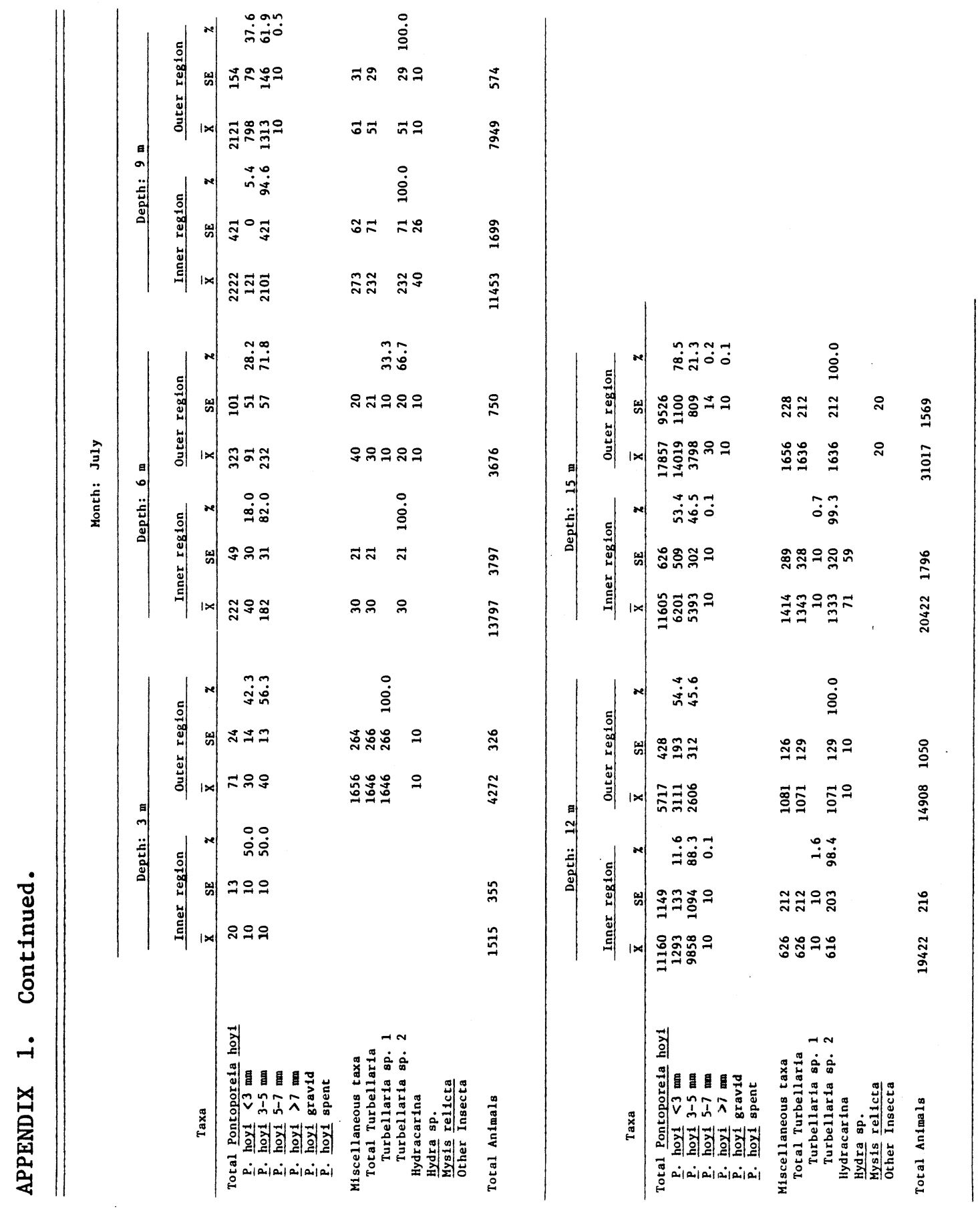




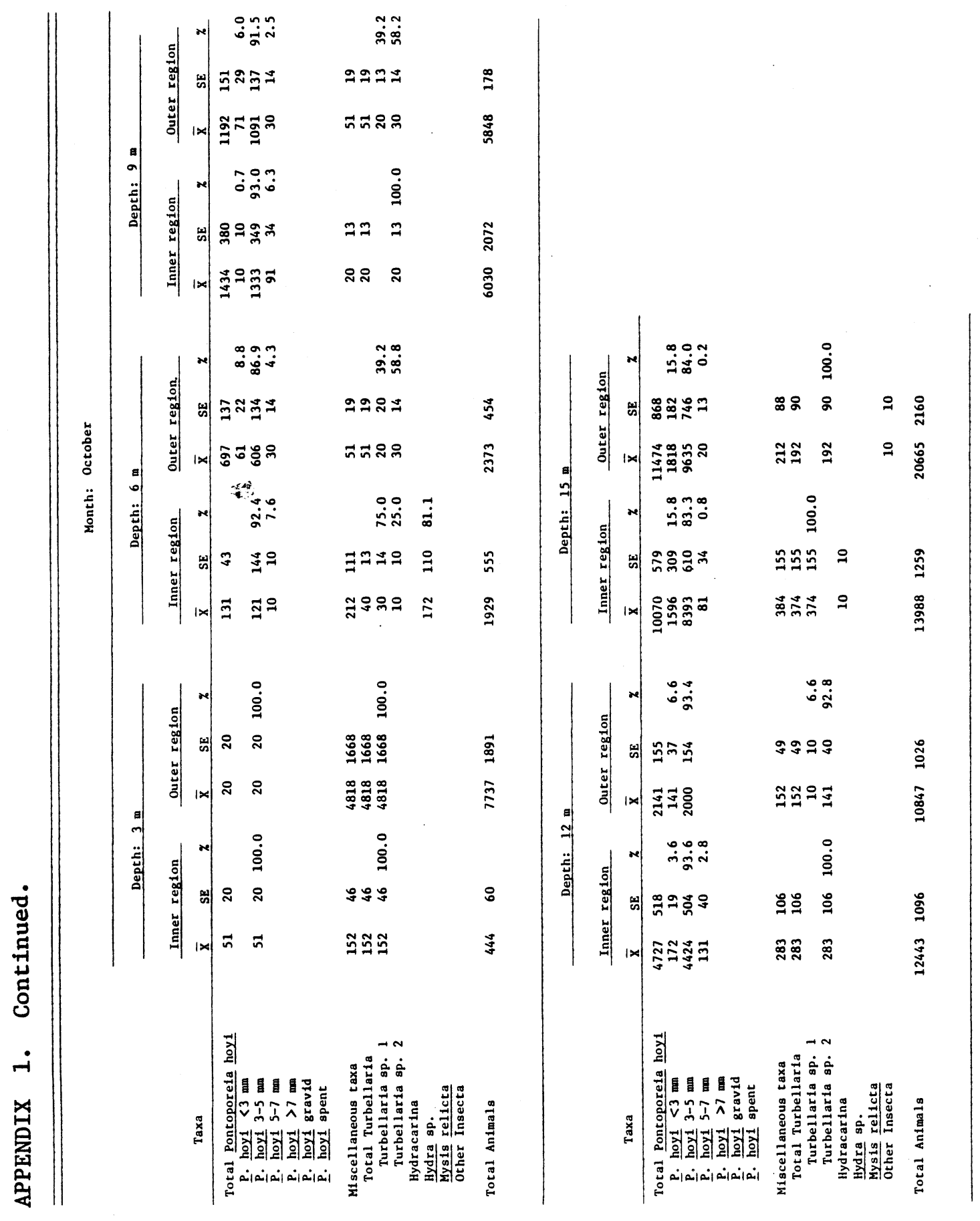




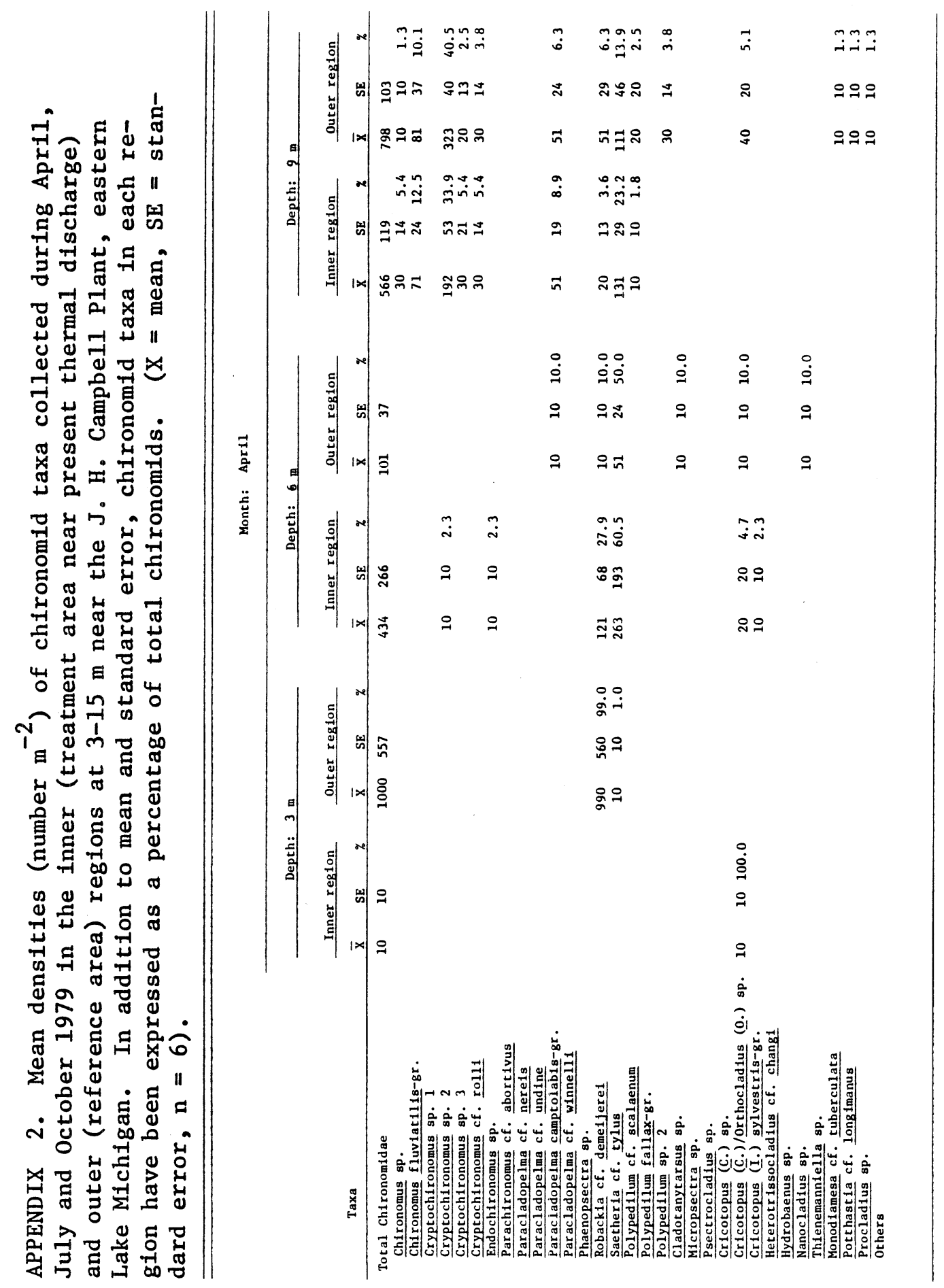




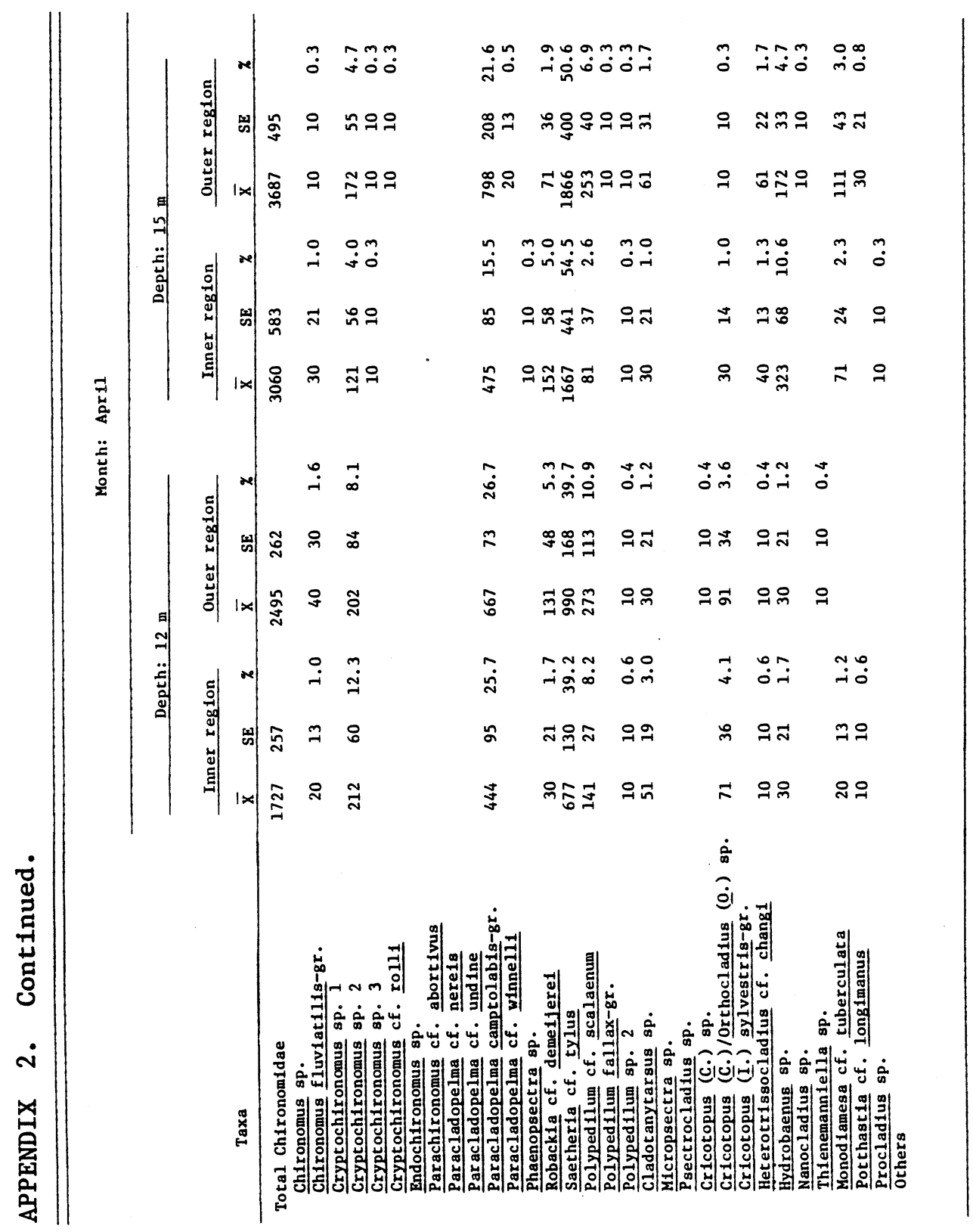




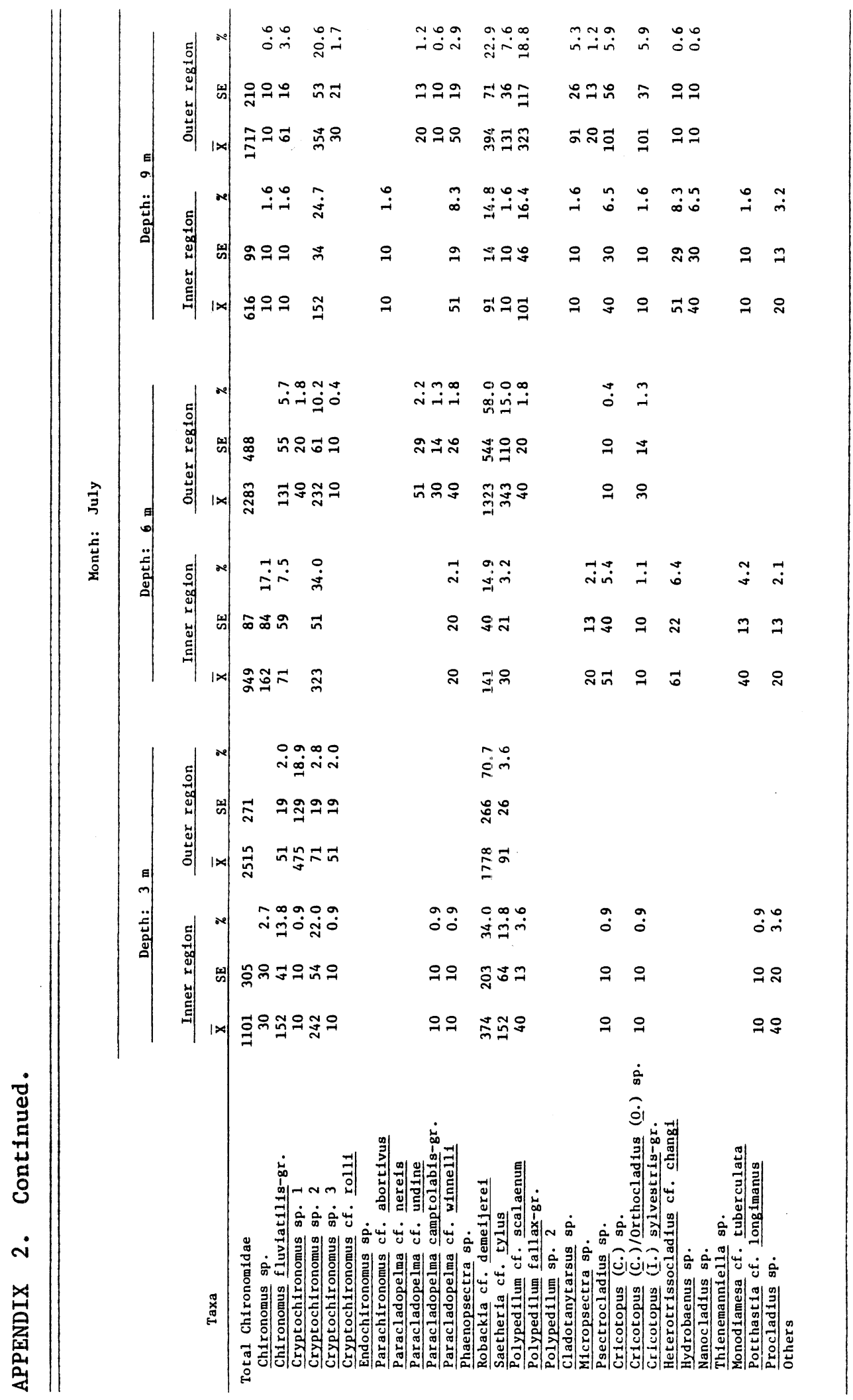




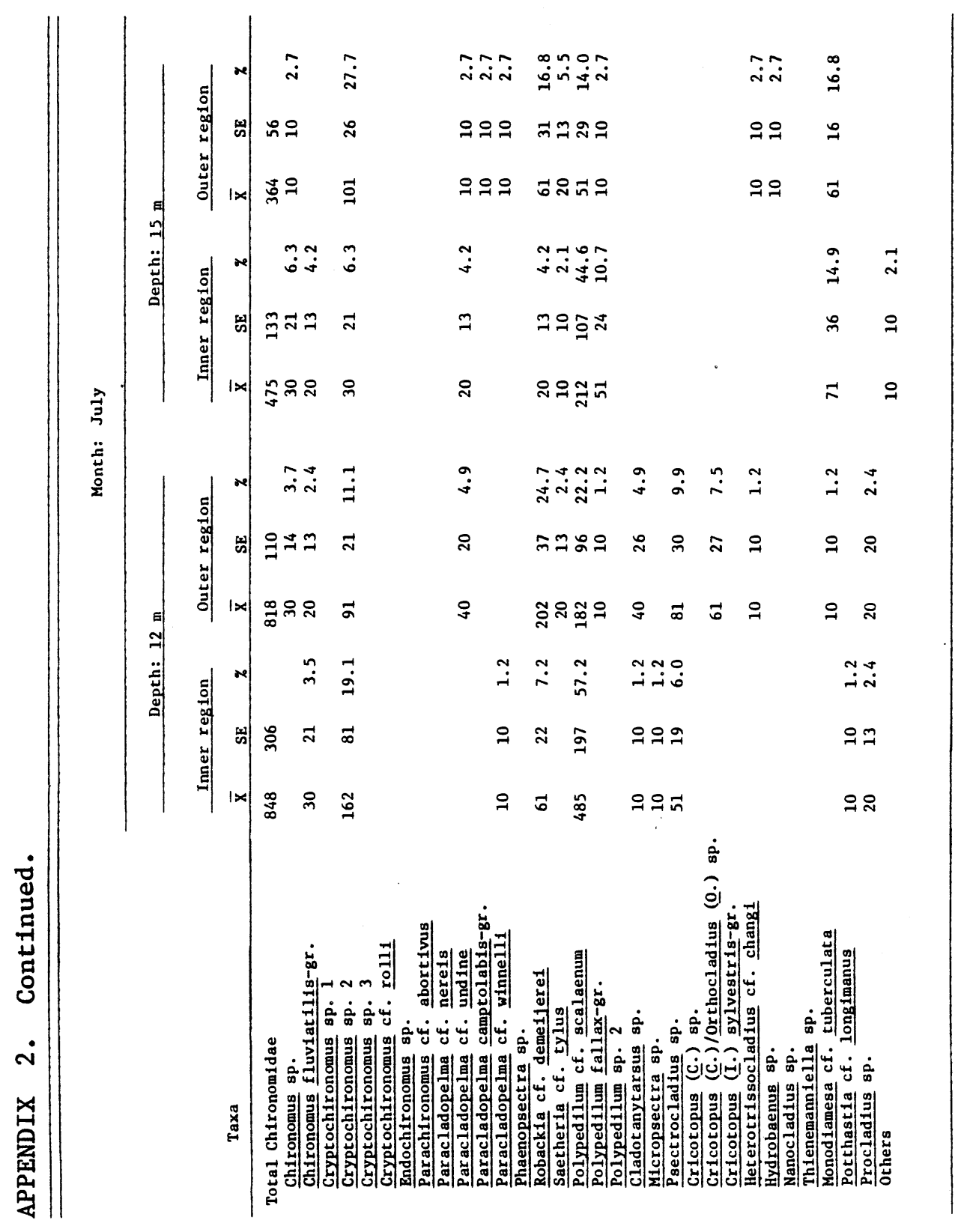




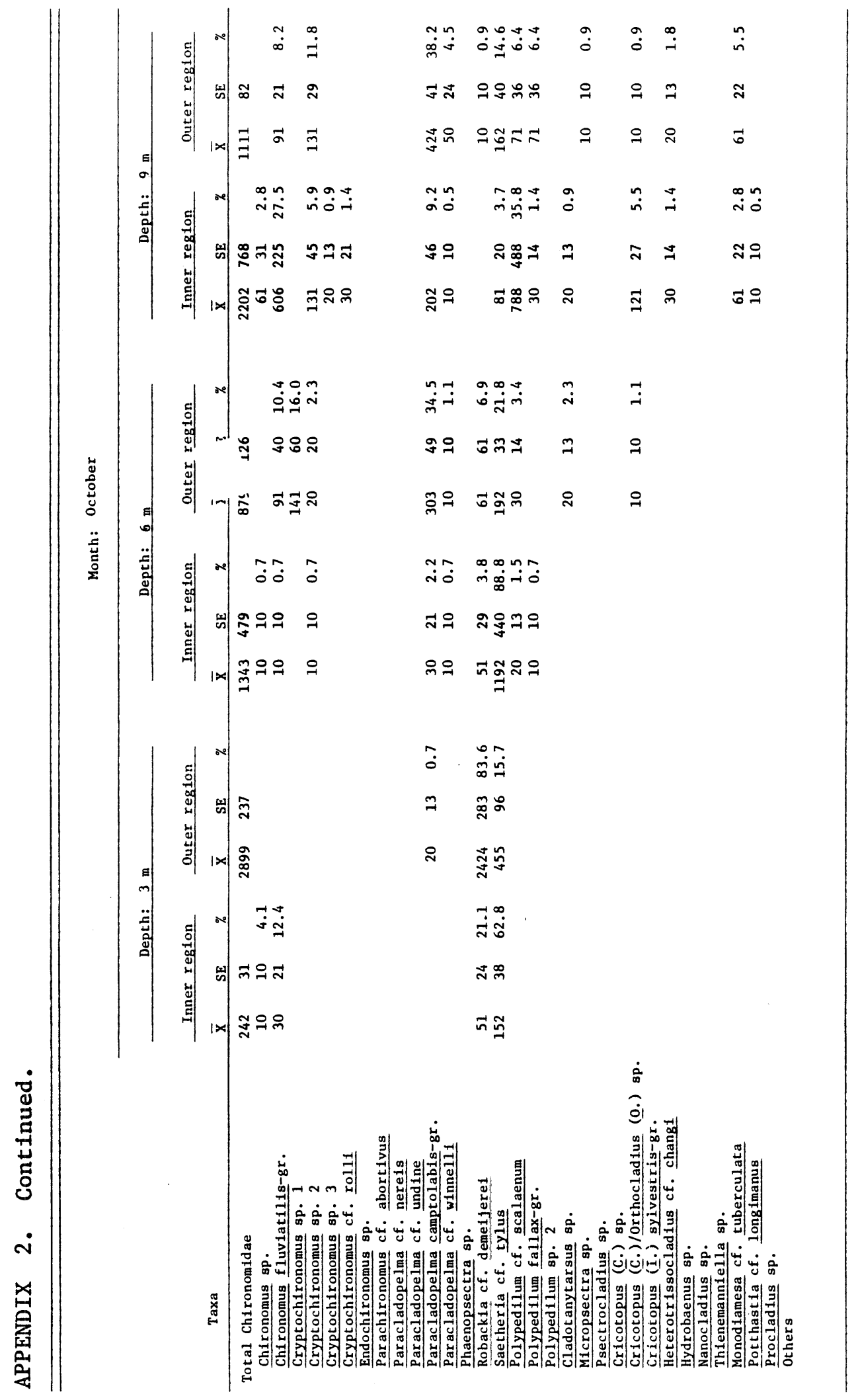




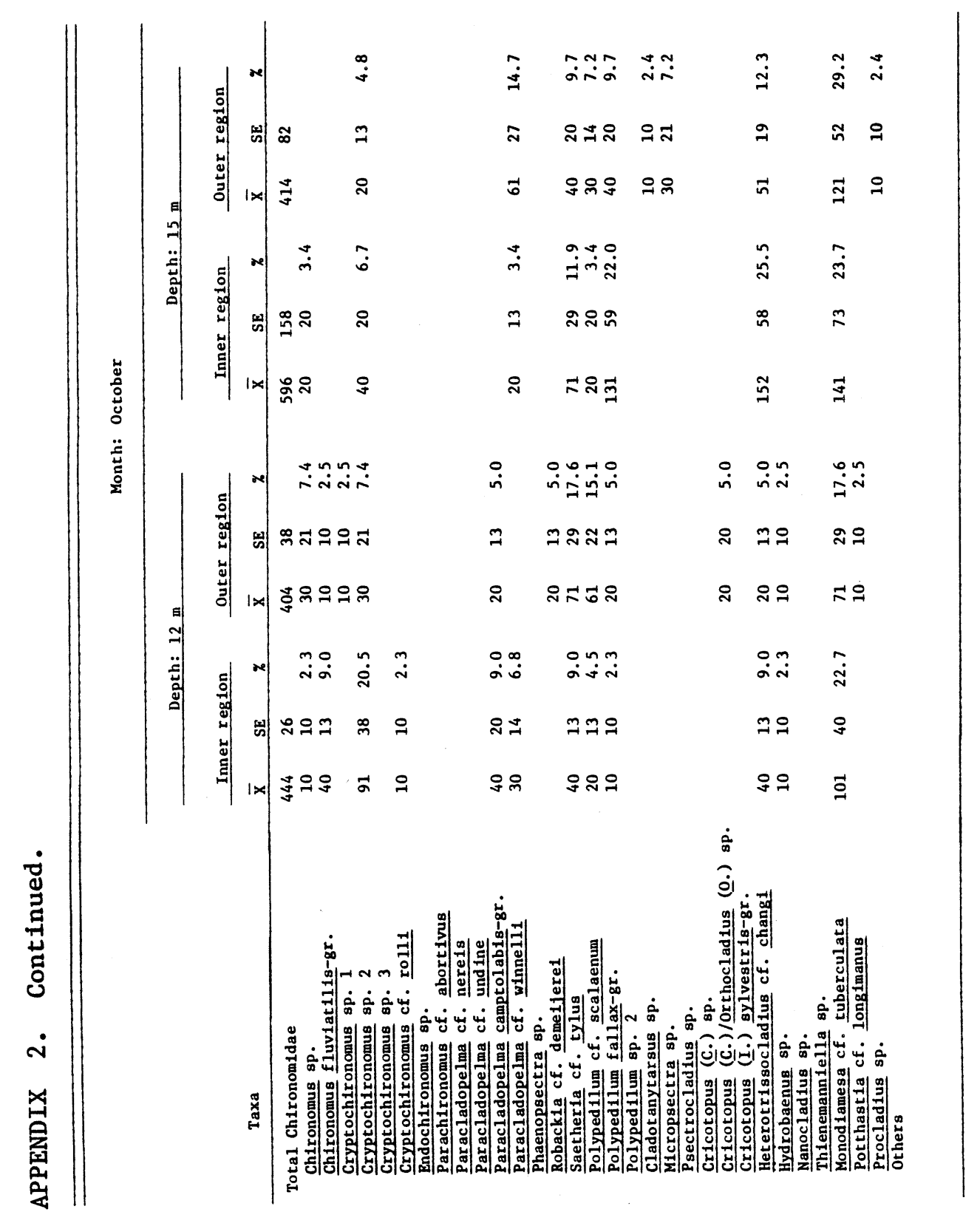




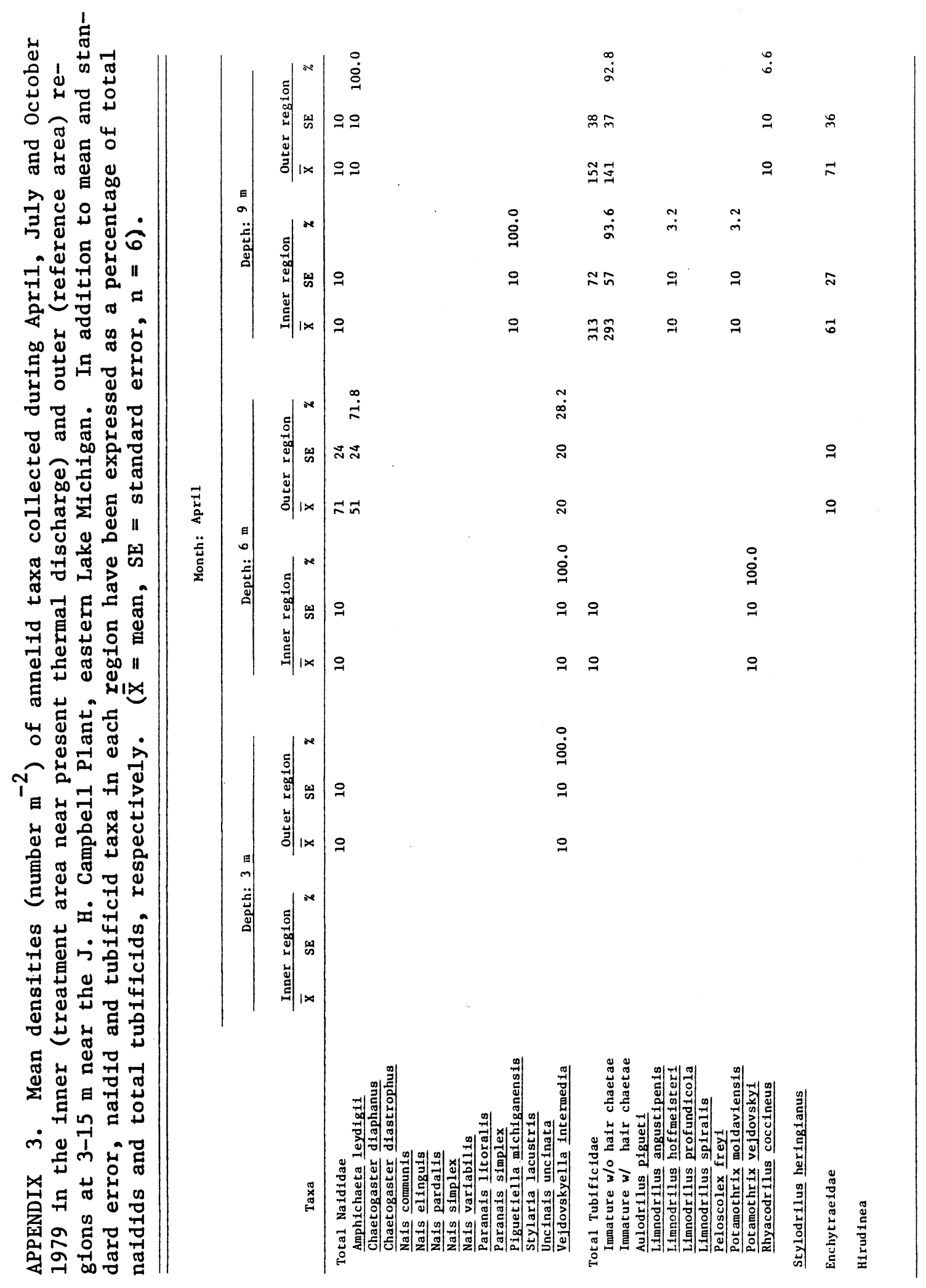




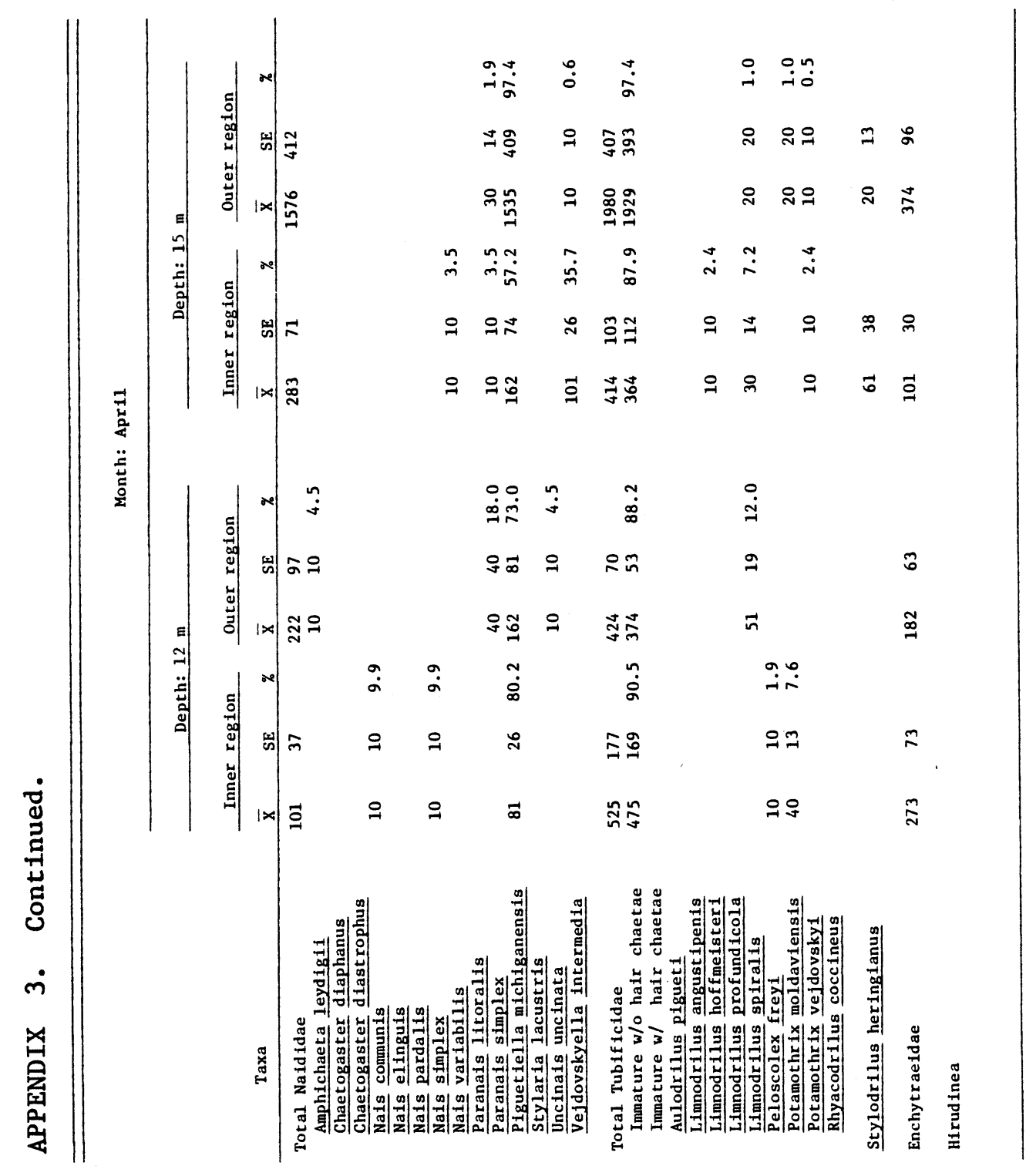




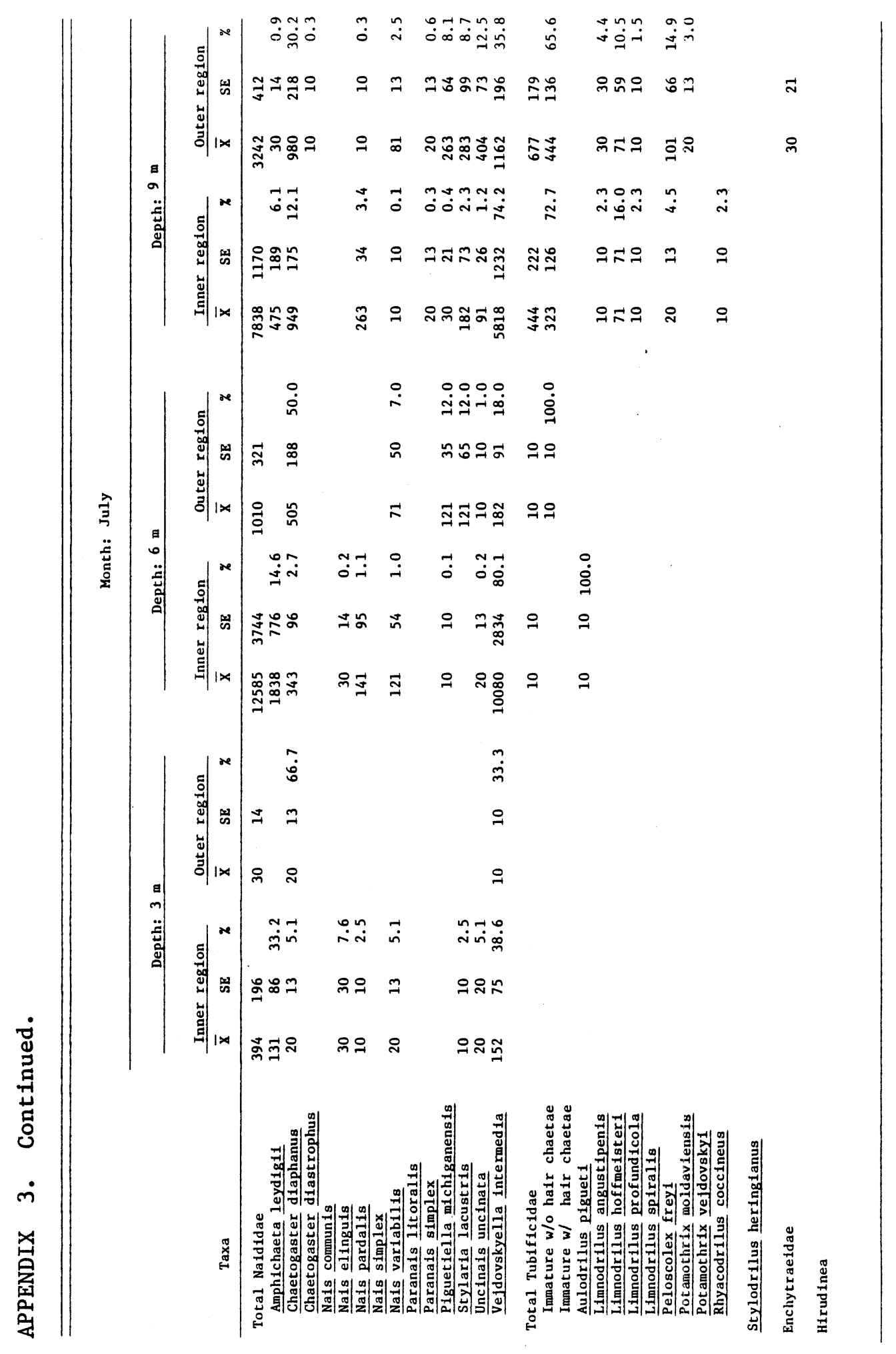




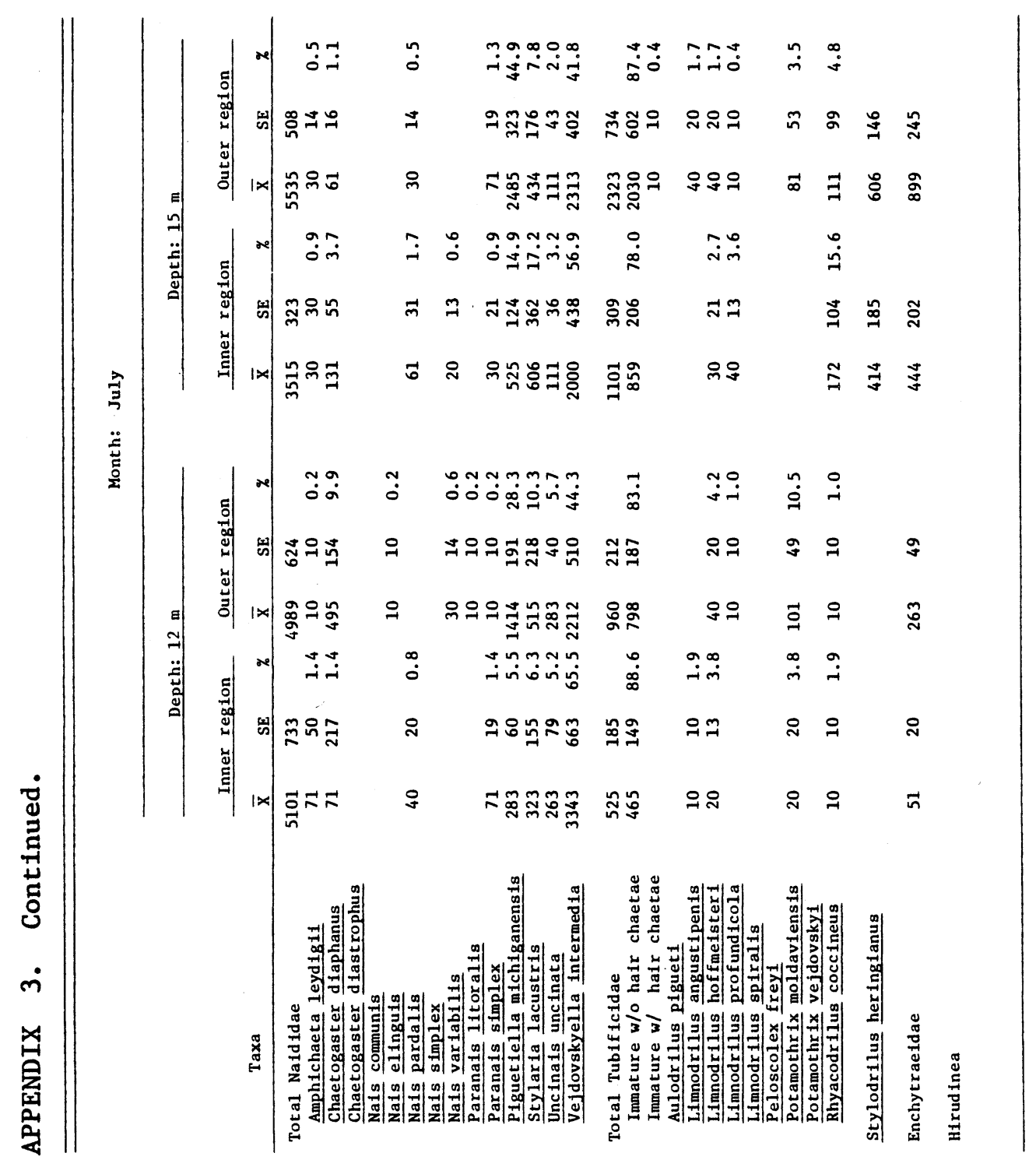




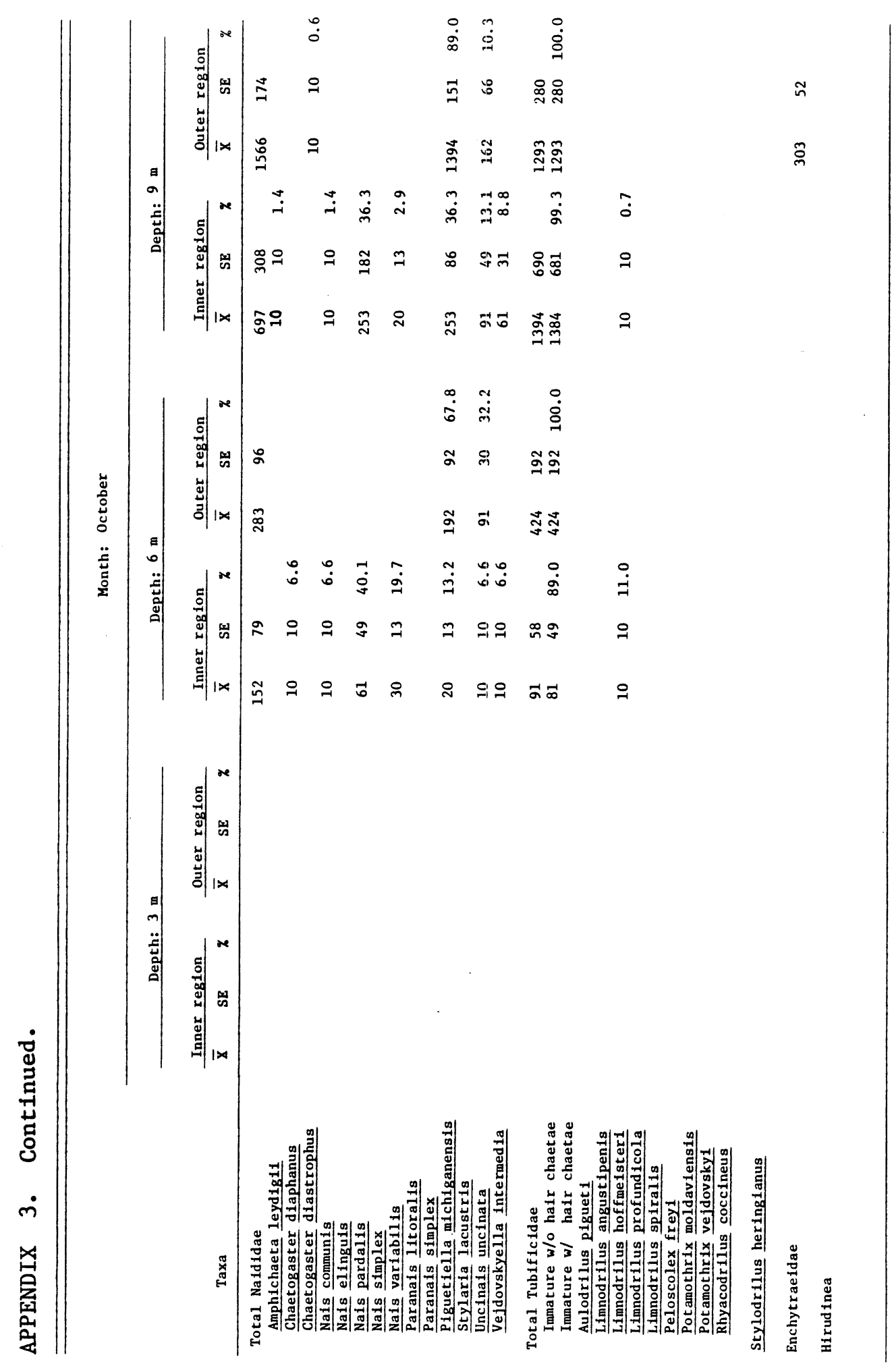




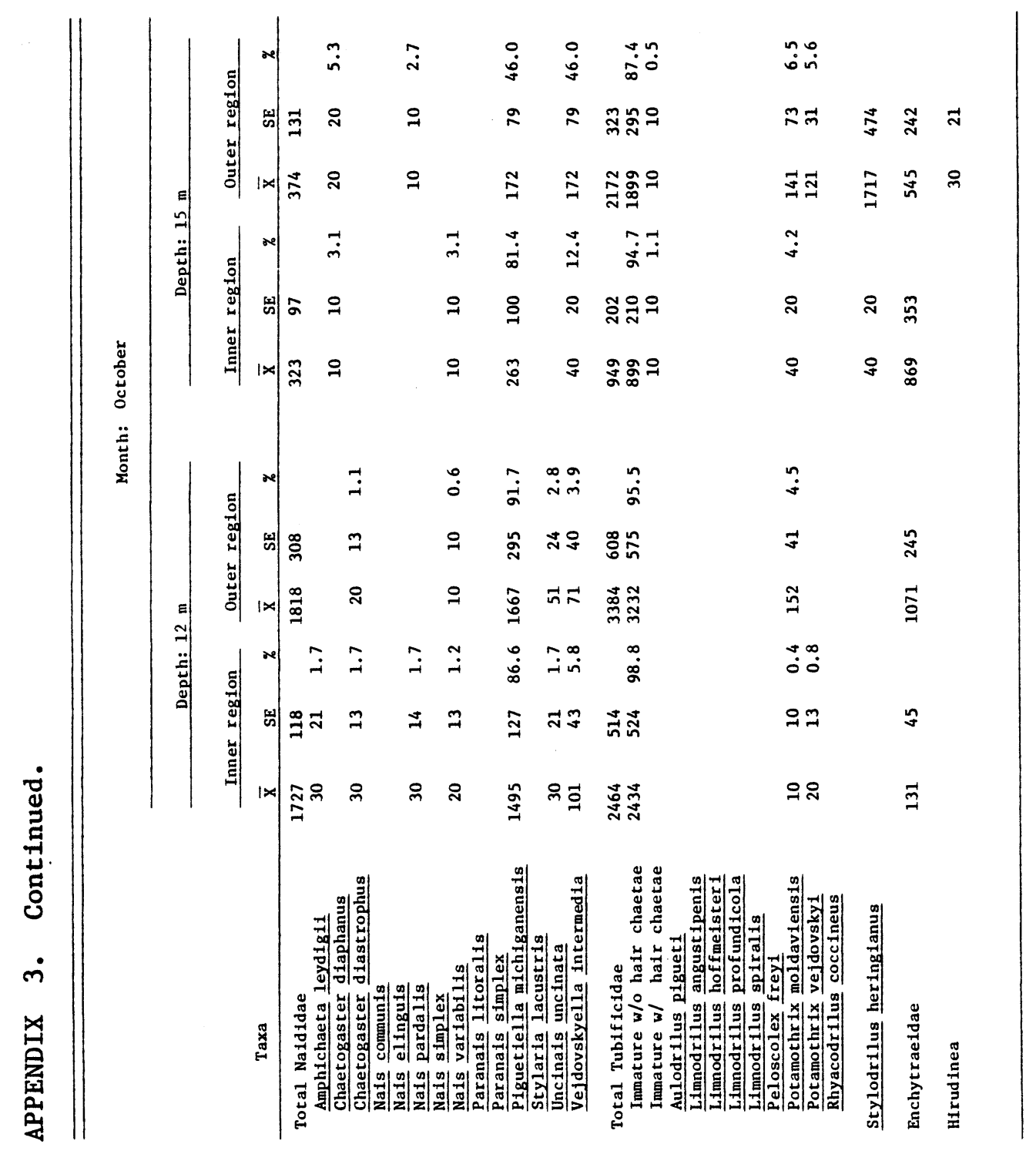




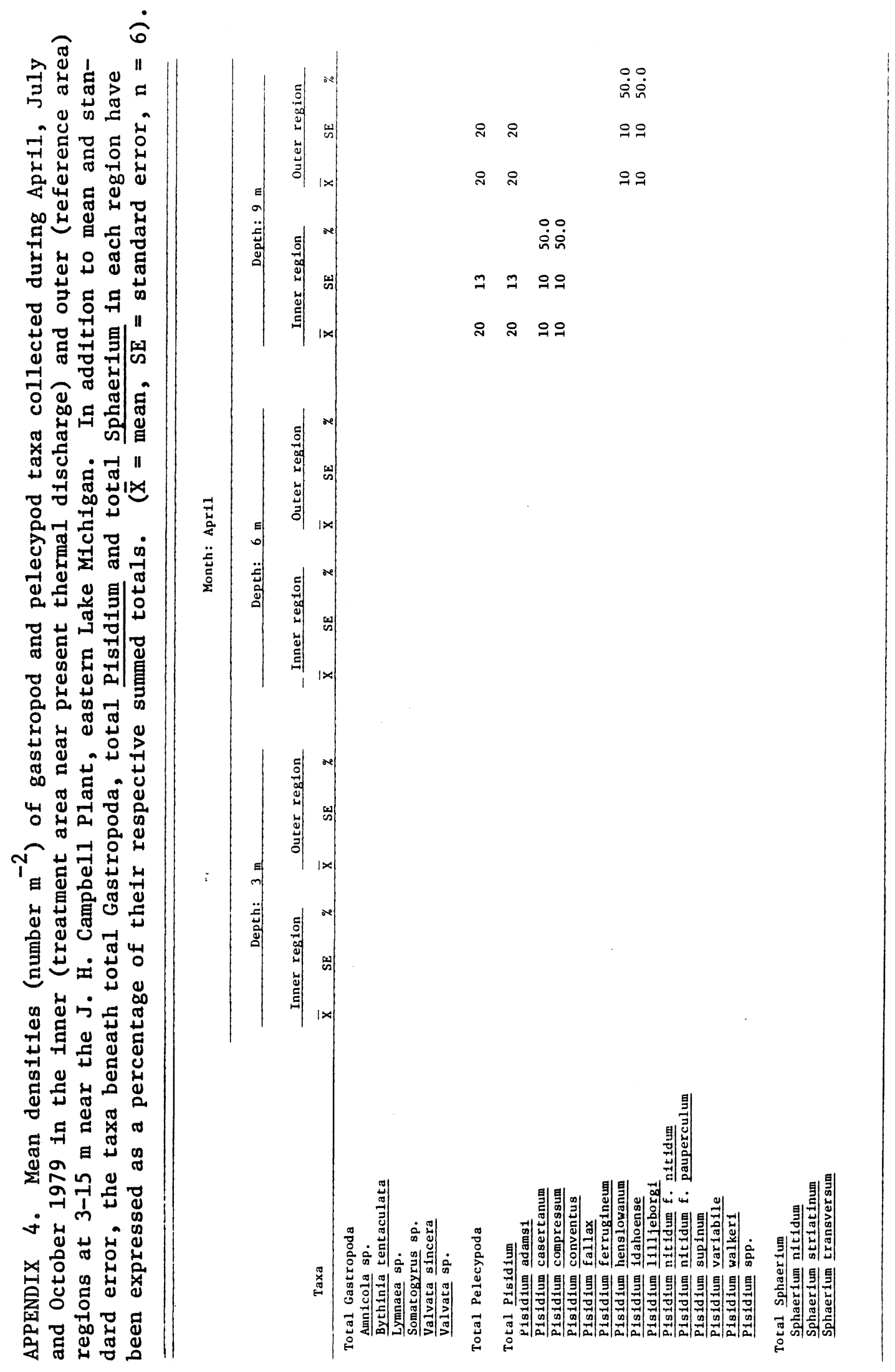




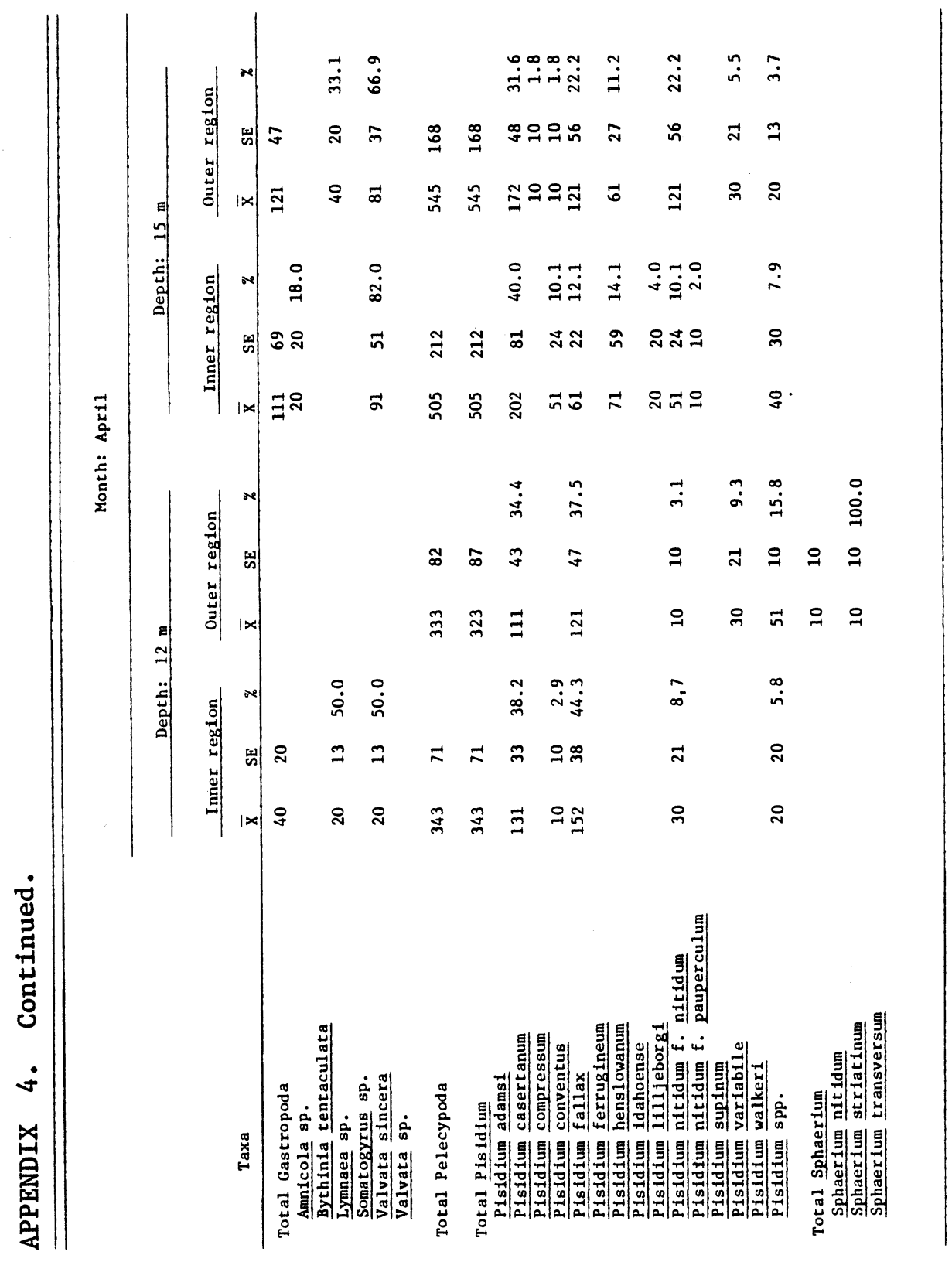




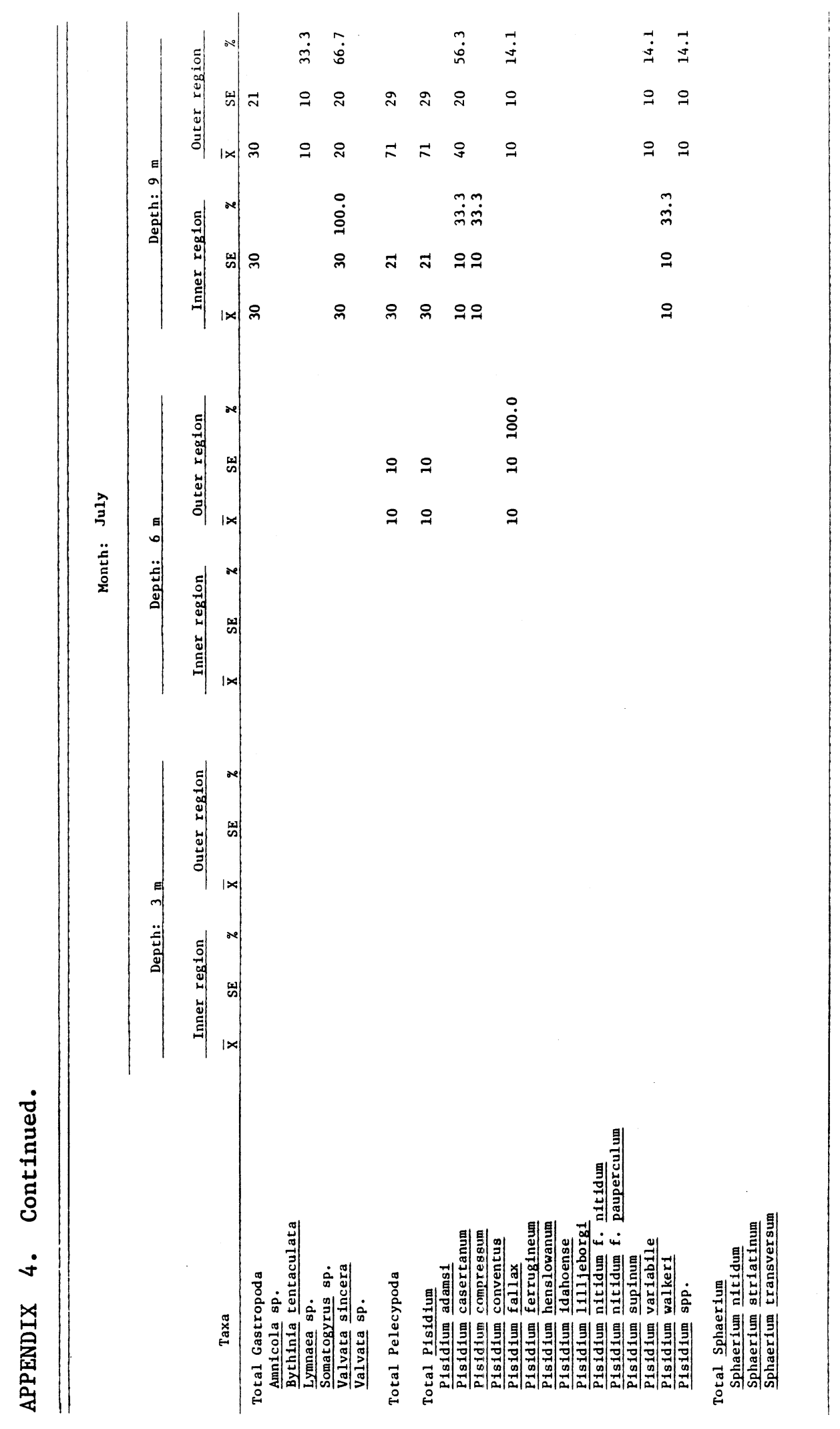




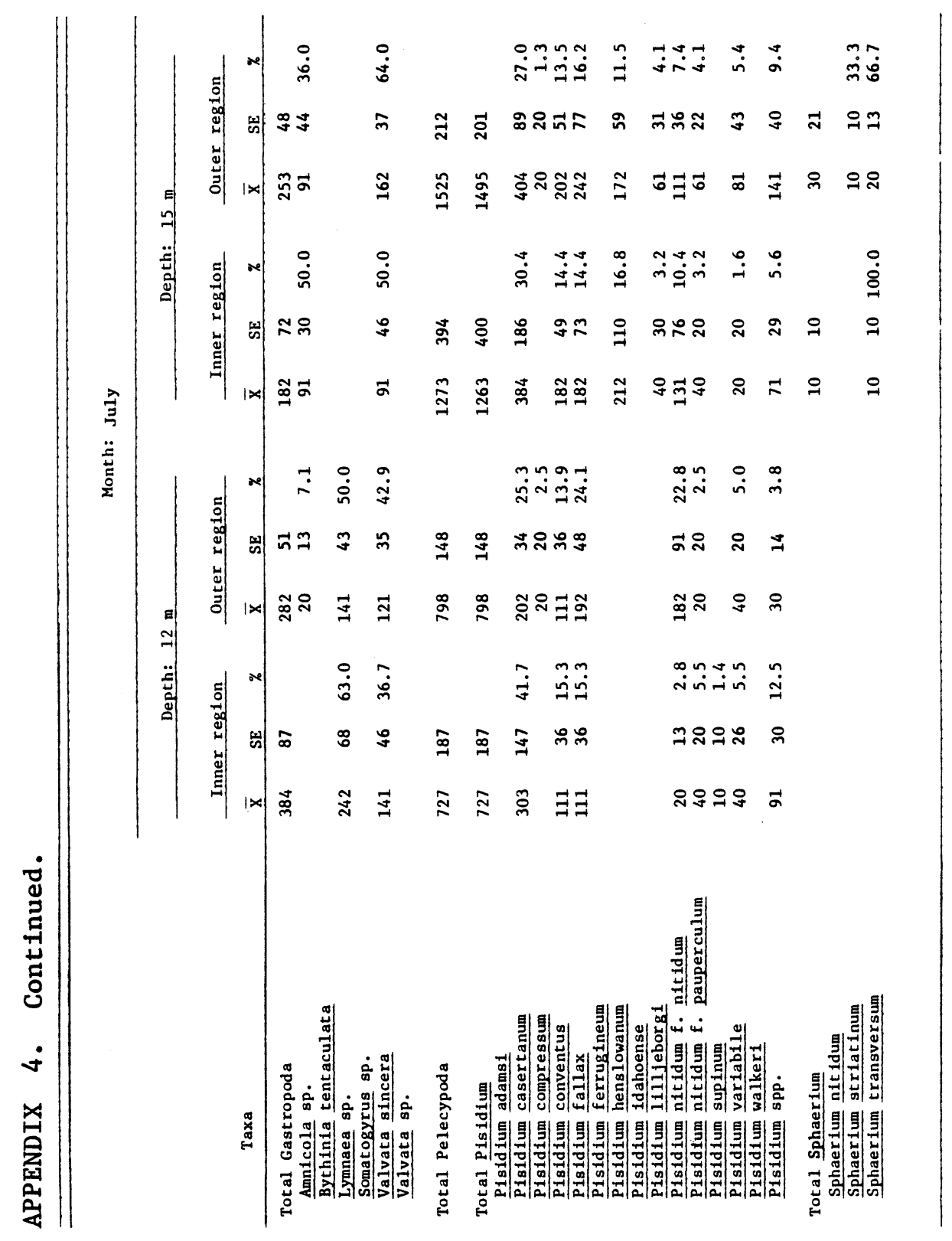




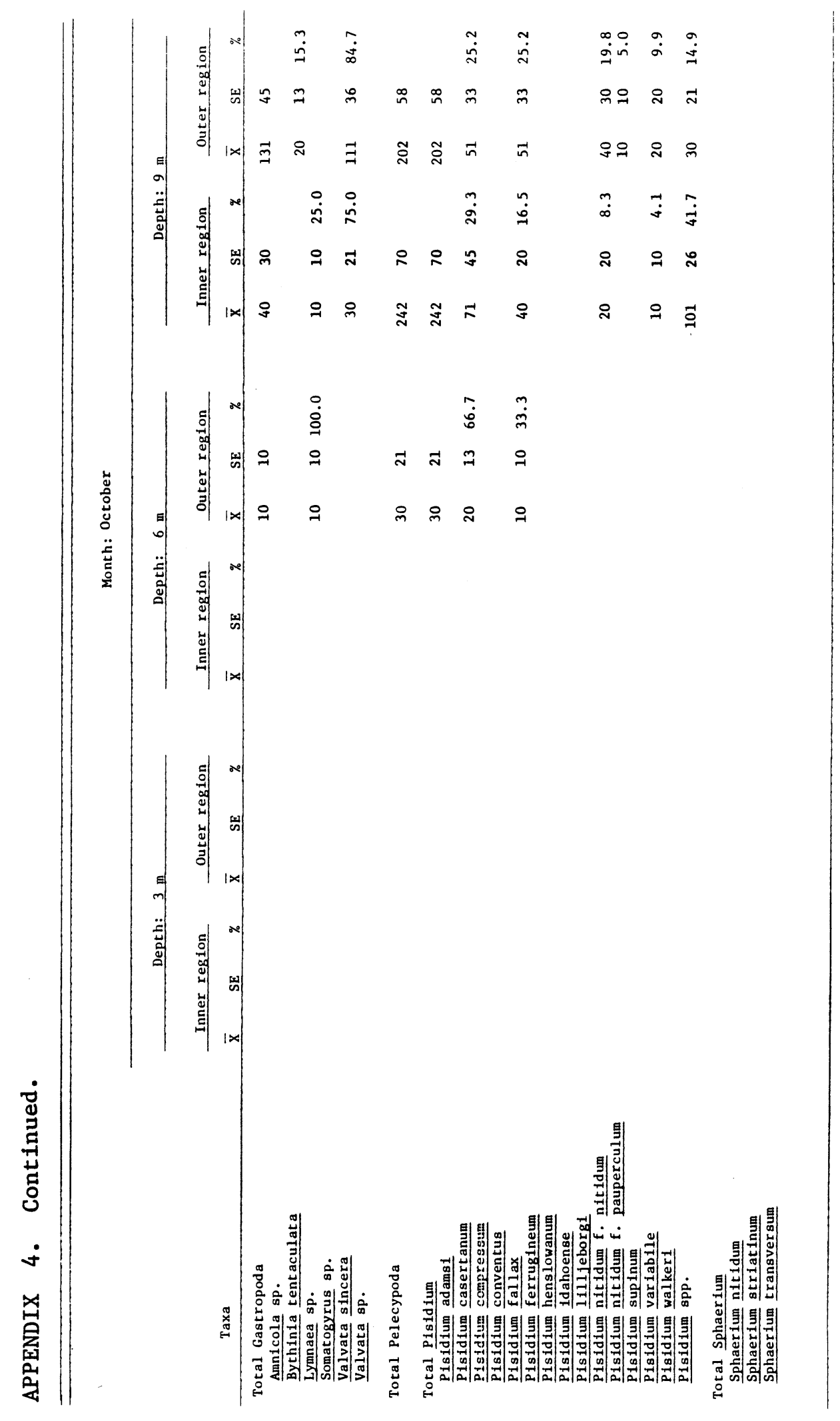




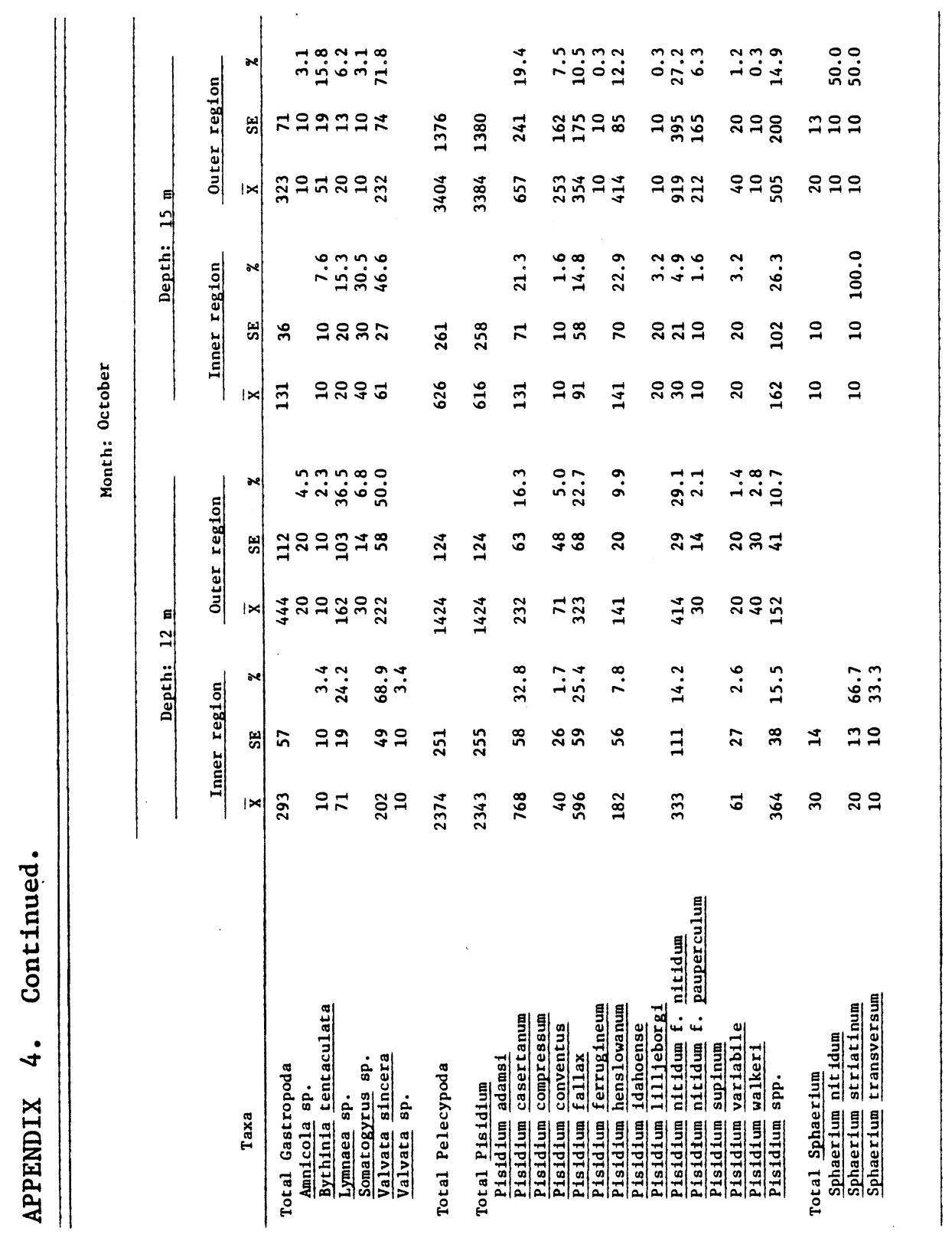

